\title{
Fennel (Foeniculum vulgare) Rests on the Holy Maria-Magdalena's Hairs, Studied by Scanning Electron Microscopy and Elemental Analysis
}

\author{
Gérard Lucotte ${ }^{1 *}$, Thierry Thomasset ${ }^{2}$, Alain Salmon ${ }^{3}$ \\ ${ }^{1}$ Institut d'Anthropologie Moléculaire, Paris, France \\ ${ }^{2}$ Laboratoire d'Analyse Physico-Chimique, UTC de Compiègne, France \\ ${ }^{3}$ Plénan Le Grand, France \\ Email: *lucotte@hotmail.com
}

How to cite this paper: Lucotte, G., Thomasset, T., \& Salmon, A. (2018). Fennel (Foeniculum vulgare) Rests on the Holy Maria-Magdalena's Hairs, Studied by Scanning Electron Microscopy and Elemental Analysis. Archaeological Discovery, 6, 216270 .

https://doi.org/10.4236/ad.2018.63012

Received: April 2, 2018

Accepted: June 11, 2018

Published: June 14, 2018

Copyright $(9) 2018$ by authors and Scientific Research Publishing Inc. This work is licensed under the Creative Commons Attribution International License (CC BY 4.0).

http://creativecommons.org/licenses/by/4.0/

\begin{abstract}
As our new contribution to the scientific knowledge of Holy Maria-Magdalena remains, we have studied pollens and several vegetal tissues of fennel adhering to her hairs by optical microscopy and SEM-EDX. Pollen grains, foliar, pedicelar and stem debris found are characteristics of Foeniculum vulgare. Detailed examination of these tissue debris shows that the plant involved was carefully processed and cultivated. Fennel symbolism is an important attribute to the Marie-Madeleine worship concerning the French "Tradition des Saints de Provence".
\end{abstract}

\section{Keywords}

Maria-Magdalena's Hairs, Fennel, Pollens and Vegetal Tissues, Optical Microscopy, SEM-EDX, Elemental Analysis

\section{Introduction}

Holy Maria-Magdalena, named here Ste Marie-Madeleine (3?-63?), is the most abundantly cited (at least twelve citations, without taking account some repeats) women of the four Gospels. According to the French "tradition des Saints de Provence", she landed to the French (the Gaule at this era) Mediterranean shores, in a region corresponding to the current part of Les Saintes-Marie-de-laMer. She (and her companions) attained further the towns of Marseilles and Aix-en-Provence, where they evangelized the Provence region. Thereafter, she withdrew for thirty years to the cave of La-Sainte-Baume, where she died (in 63); she was buried in the currently named village of Saint-Maximin-la-Sainte- 
Baume.

Her body was exhumed on 19 December 1279 (according to Chronicles of Pope and Emperors, 1320). Bernard Gui, who was an auricular witness of the facts, wrote: "In the year of grace of Jesus-Christ in 1279, the nineteenth day of December, the Prince Charles, son of Charles King of Sicily, Count of Provence and then King of Sicily, had looked for the body of Ste Marie-Madeleine with so much solicitude and as much a devotion in this holy oratory in which St Maximin, one of the seventy disciples of the Seigneur Jésus-Christ, venerated in the (diocese of) Aix formerly, had given (to her) one burial place...”

The precision concerning the fennel is also given by Bernard Gui, who furnished (Franzoni, 2016) some details observed during the exhumation: "It produces then an extraordinary fragrance, as if one had opened a flavoured container... from her holy tongue, even attached to the head and the throat, left a root with a (green) fennel twig (which) extended". Figure 1 shows a later representation of the scene.

Some relics (cranium, bones and hairs) of Marie-Madeleine were kept in the Saint-Maximin basilica, where a large lock of Marie-Madeleine hair is arranged in a dedicated reliquary. We have obtained some hairs from this lock, for scientific purposes (microscopic examination and chemical analyses). We have published recently (Lucotte, 2016; Lucotte \& Thomasset, 2017) the mitochondrial DNA haplogroup found by extracting genomic DNA from the bulb of hair number 10, and also the brown-red observed colour of the hairs by scanning electron microscopic characterization of its melanosomes.

During hair observation studies, we have found some rests (pollens, leaf and stem debris) of fennel (Foeniculum vulgare), on or at the vicinity of some hair parts. The present study describes in details these rests, and gives an interpretation of their presences in the frame of the French "Tradition des Saints de Provence".

\section{Material and Methods}

The material is seven of the about ten of a large lock of Marie-Madeleine's hairs that is kept in a dedicated reliquary in the Saint-Maximin basilica. These hairs, numbered 4 to 10, were loaded on a sticky-paper (Figure 2), for SEM examination and EDX analyses. A special characteristic of these hairs is their extreme dryness (Lucotte \& Thomasset, 2017); so, when they were loaded (in folding back its) on the sticky-paper, most of the rests (pollen grains, vegetable debris, mineral and metallic particles...) adhering to hairs were dropped on the sticky-paper in their immediate neighbouring respective hair environments. The circled areas of the sticky-paper examined here are areas P1 (in the vicinity of some part of hair number 6) and P2 (at the basis of hair number 4), which contain pollen grains; areas A (in the vicinity of some part of hair number 9), B (located up to some part of hair number 10) and C (in the vicinity of another part of hair number 6), contains vegetable rests. 


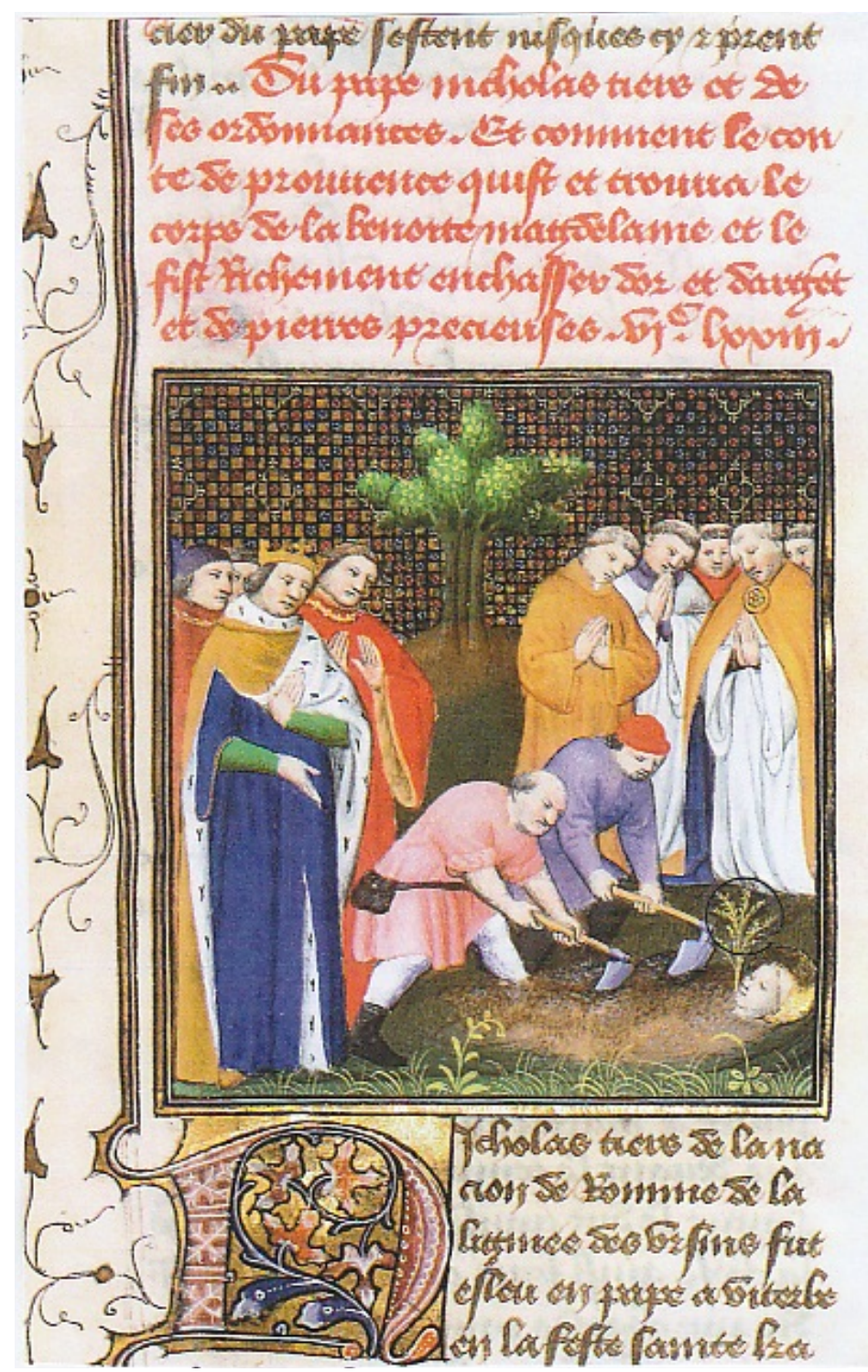

Figure 1. A 1415 representation of the discovery of the Marie-Madeleine body (by Maître Boucicaut, who was active in Paris between 1408 and 1418). In that illumination one can see at the left part the Prince surrounded by his counsellors and a clerk's group at the right part; Marie-Madeleine's face (with a fennel plant-circled-emerging from the right part of her face) is cleared by two labour workers.

Optical microscopy studies were realized using a confocal stereoscopic microscope.

The SEM (Scanning Electron Microscopy) apparatus used is a FEI model Quanta FEG. Elemental analysis was achieved by using EDX (Energy Dispersive $\mathrm{X}$-Ray spectroscopy), this SEM microscope being equipped with the probe model X-flash 6/30. Both LFD (Large Field Detector) and CBS (Circular Back Scattering) were used, the last one to detect heavy elements.

Each elemental analysis is given in the form of a spectrum, with kiloelectrons/Volts $(\mathrm{ke} / \mathrm{V})$ on the abscissa and elemental peaks heights $(\mathrm{cps} / \mathrm{eV})$ in 


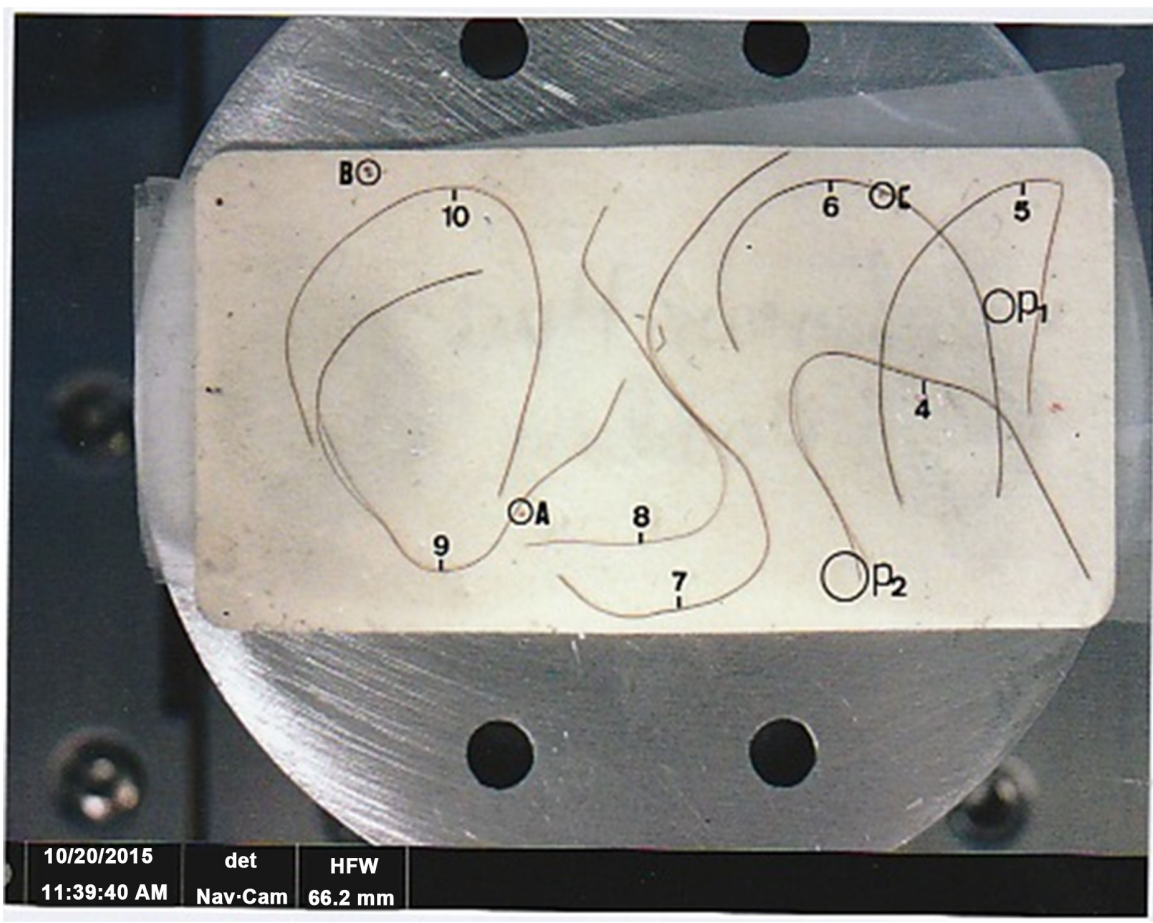

Figure 2. Optical view of seven (numbered 4 to 10) hair fragments of Marie-Madeleine, loaded on a sticky-paper. The P1 circle includes pollens located at the basis of hair number 4 . The A circle includes a structure located at the vicinity of hair number 10; The P2 circle includes pollens located at the basis of hair number 9; the $\mathrm{B}$ circle includes two structures located up to hair number 10; the $\mathrm{C}$ circle includes a structure located at the vicinity of hair number 6 .

ordinates. Estimating peak heights, it is possible to obtain some semi-quantitative results.

EDX-mapping was obtained (power: $20 \mathrm{kV}$; distance: $9.9 \mathrm{~mm}$; acquisition time: $15 \mathrm{~min}$.) for the elements $\mathrm{C}, \mathrm{O}, \mathrm{S}, \mathrm{K}, \mathrm{Cl}, \mathrm{Na}, \mathrm{Ca}, \mathrm{Si}, \mathrm{P}, \mathrm{Mg}$ and $\mathrm{Al}$.

\section{Results}

Results obtained correspond to pollen grains, located near number 6 and at the basis of hair number 4, leaf structures in A and B, and a stem structure in C.

\subsection{Pollen Grains}

There are about two hundred of pollen grains loaded on the sticky paper, all from the same species. Figure 3 shows at least twenty visible of them, located inside of the P1 circle. They are seen individually, or lumped together; their orientations differ.

Pollens numbered $\mathrm{p} 1$ and $\mathrm{p} 2$ are seen ( $\mathrm{p} 2$ especially) in equatorial views. The enlarged SEM photographs of Figure 4 shows their characteristics: they are pollen grains of the prolate (of elongated form) type; the $\mathrm{p} 1$ length is approximately of $40 \mu \mathrm{m}$ (its width is about $10 \mu \mathrm{m}$ ). Both p1 and p2 show two longitudinal sulcis, interrupted equatorially by one prominent pore. On the $\mathrm{p} 1$ photograph one 


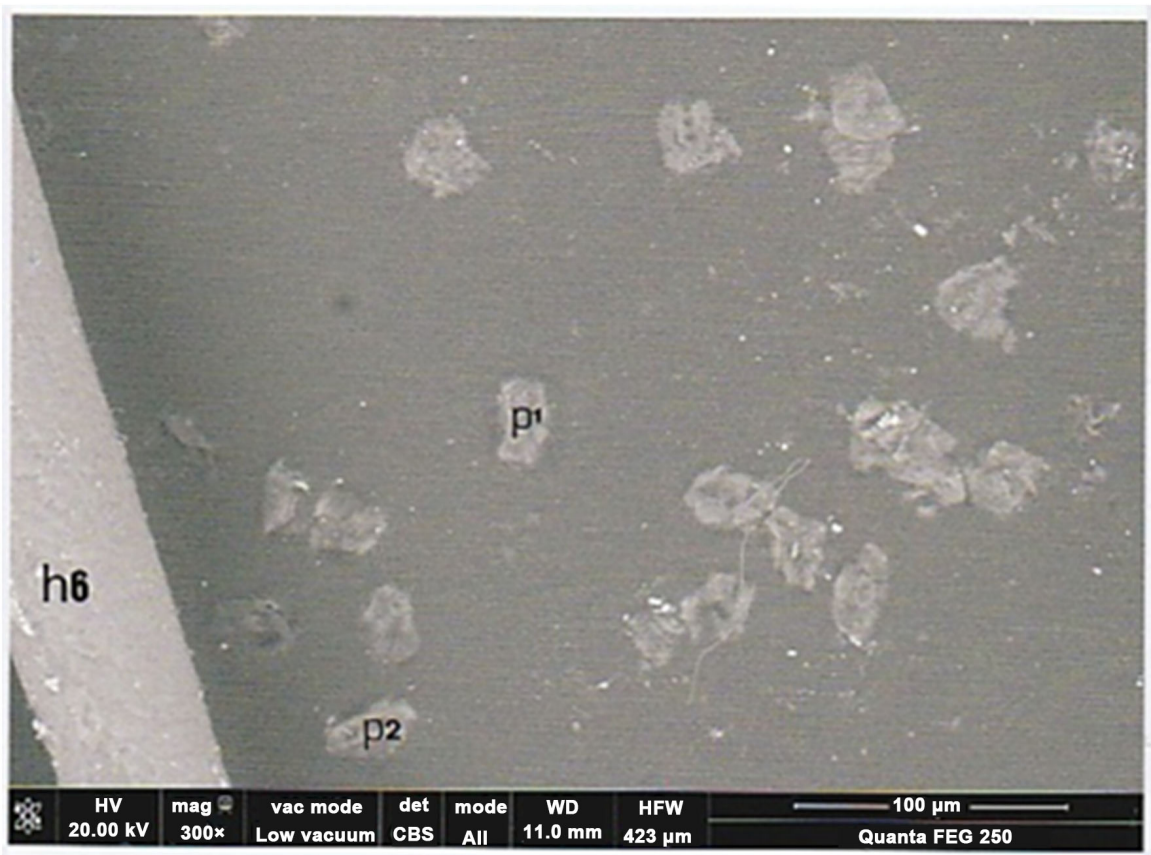

Figure 3. A SEM photograph (in CBS, 300x) of pollens (among them, pollen grains numbered $\mathrm{p} 1$ and $\mathrm{p} 2$ ) located at the vicinity of some part of hair number 6 (h6).

can distinguish the details of the wall surface, which corresponds to an ornamentation of the reticulate type.

Figure 5 photographs show pollen grains (that taken in optical microscopy is of red colour, which is that of the hair colour) located at the basis of hair number 4; that area corresponds to the most important density of pollen observed on the sticky-paper surface.

Six examples of these pollen grains, or pollen groups, are shown in Figure 6. In equatorial or longitudinal views their length vary from 29.1 to $42.4 \mu \mathrm{m}$, depending on orientation; in these views they show at least one longitudinal sulcus, interrupted equatorially by a pore. Some views (as that of photograph 6.2) show a reticulate type of ornamentation. The polar view (photograph 6.3) is triangular. When tightly lumped together, the pollen outline (notably that of the pollen grain in intermediate position of the group of three showed in photograph 6.5) is greatly altered.

What is more of the normal diversity, the variation in shapes and dimensions of these pollen grains is due to their dryness; this dryness intervenes mainly as seen in polar views (where outline is not rounded but triangular, because of extrusion of volumes located between sulcis), but also on width and general outline of these pollens.

A detailed study of the fennel pollens (Foeniculum vulgare) was recently published (D'Avila et al., 2016). In the present study, examination of more than fifty pollen grains (seen in equatorial or longitudinal views) confirms this diagnosis. Table 1 summarizes, in accordance to the pollen terminology nomenclature adopted in SEM studies (Hesse et al., 2009), our own characterization. 

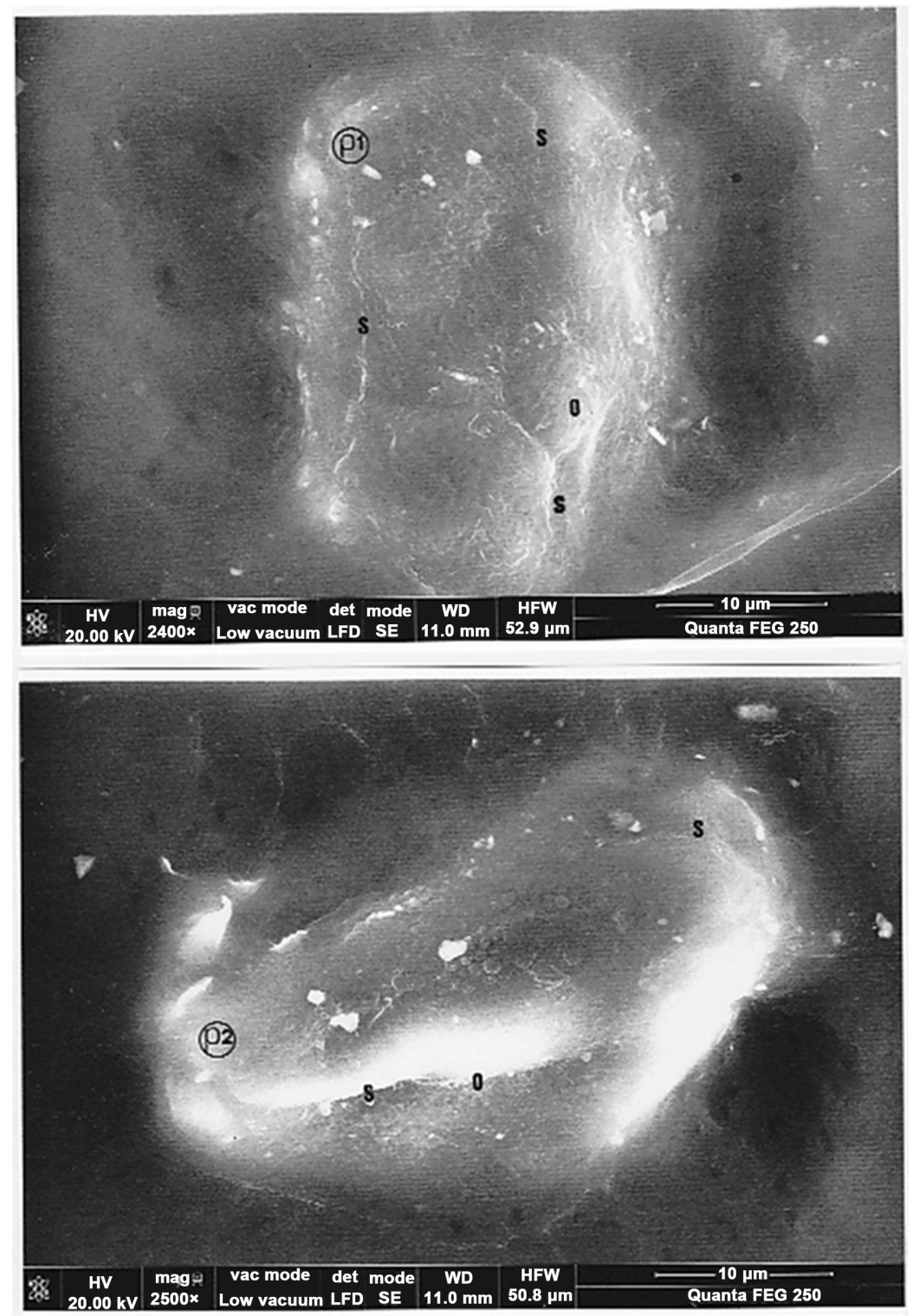

Figure 4. Enlarged views of pollens $\mathrm{p} 1$ and $\mathrm{p} 2$. Above: SEM photograph (in LFD, $2500 \times$ ) of p1. Below: SEM photograph (in LFD, 2500×) of p2. S: sulcis; O: pores.

The mean measurement of lengths-which seems independent of dryness is of about $35 \mu \mathrm{m}$; the mean measurement of widths, which is clearly dependent of dryness (and of compression effect) is of about $15 \mu \mathrm{m}$. In general, we can say that the observed pollen grains are characterized as follow; prolate, isopolar, triheteroapertured (an additional criterion is the ornamentation, which is of the reticulate type). But these three first characters are valid for all the pollen grains belonging to plants of the Apiacea family (Jones \& Jones, 2001), even if you retain additional dimensions criteria.

Supplementary Figure 1 gives some examples of photographs (in optical microscopy and in SEM) of fennel pollens of reference; among them, the SEM photograph was particularly useful for our own study. 

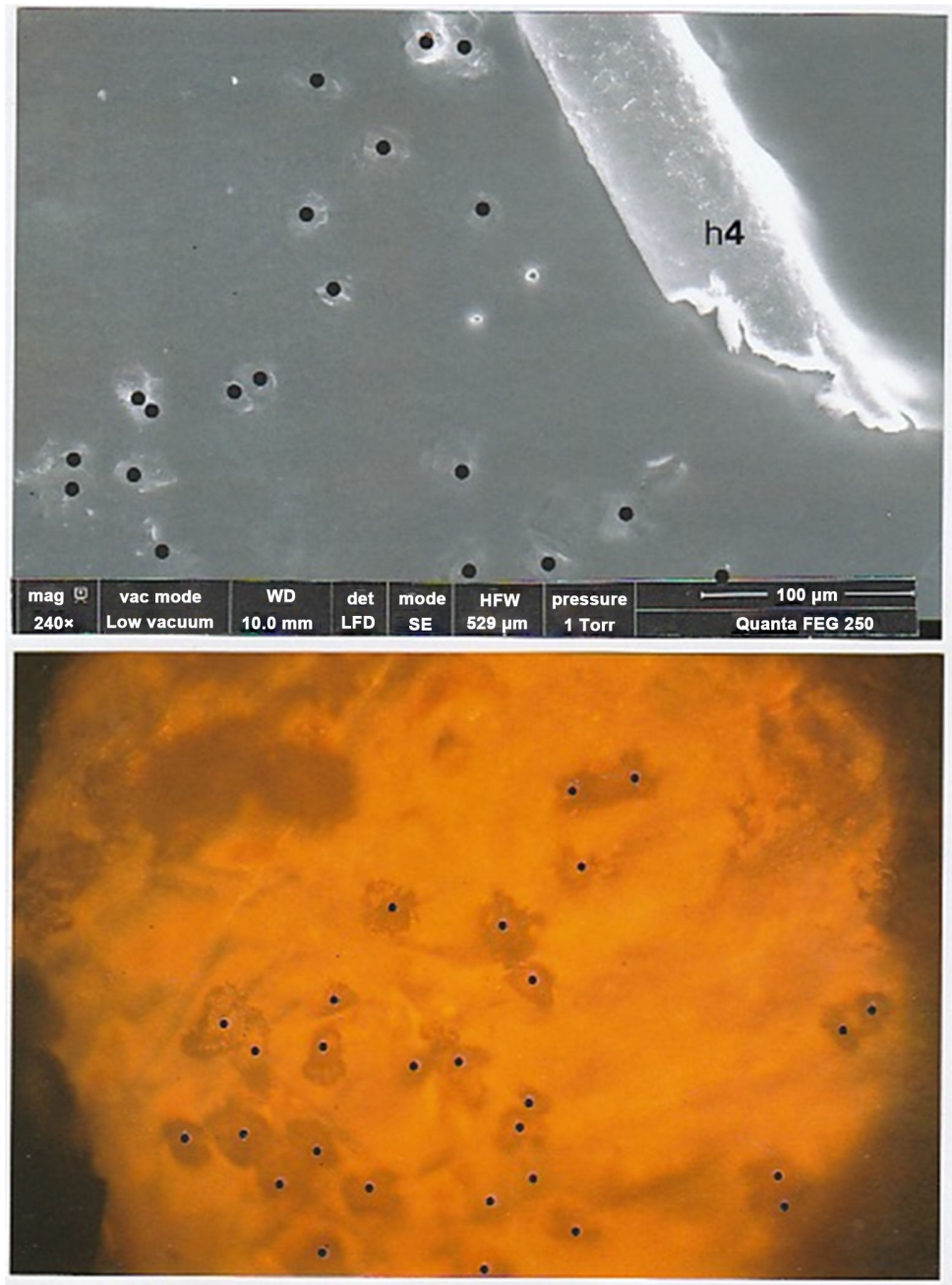

Figure 5. SEM and optical microscopy photographs of pollens located at the basis of hair number 4 (h4). Above: SEM photograph (in LFD, 240×) of the pollens. Below: some of these pollens seen (in red colour) in optical microscopy $(250 \times)$; each polllen grains are indicated by a black point.

To be noted is that it is impossible to distinguish (D'Avila et al., 2006) between the pollens of the three aromatic species of fennel (Foeniculum vulgare), dill (Anethum graveolens) and coriander (Coriandrum sativum).

\subsection{The Fennel Plant}

\subsubsection{Background}

The fennel, named Foeniculum vulgare (taxonomically F. vulgare Mill), is a medicinal plant belonging to the Apiaceae (previously Umbelliferae) family, known and used by humans since the Antiquity (Badgujar et al., 2014).

Foeniculum vulgare is an upright, branching perennial herb (Supplementary Figure 2) with soft, feathery, and almost hair-like foliage growing up to two metres tall. It is typically grown in vegetable and herb gardens for its aniseflavoured foliage and seeds, both of which are commonly harvested for use in cooking. 

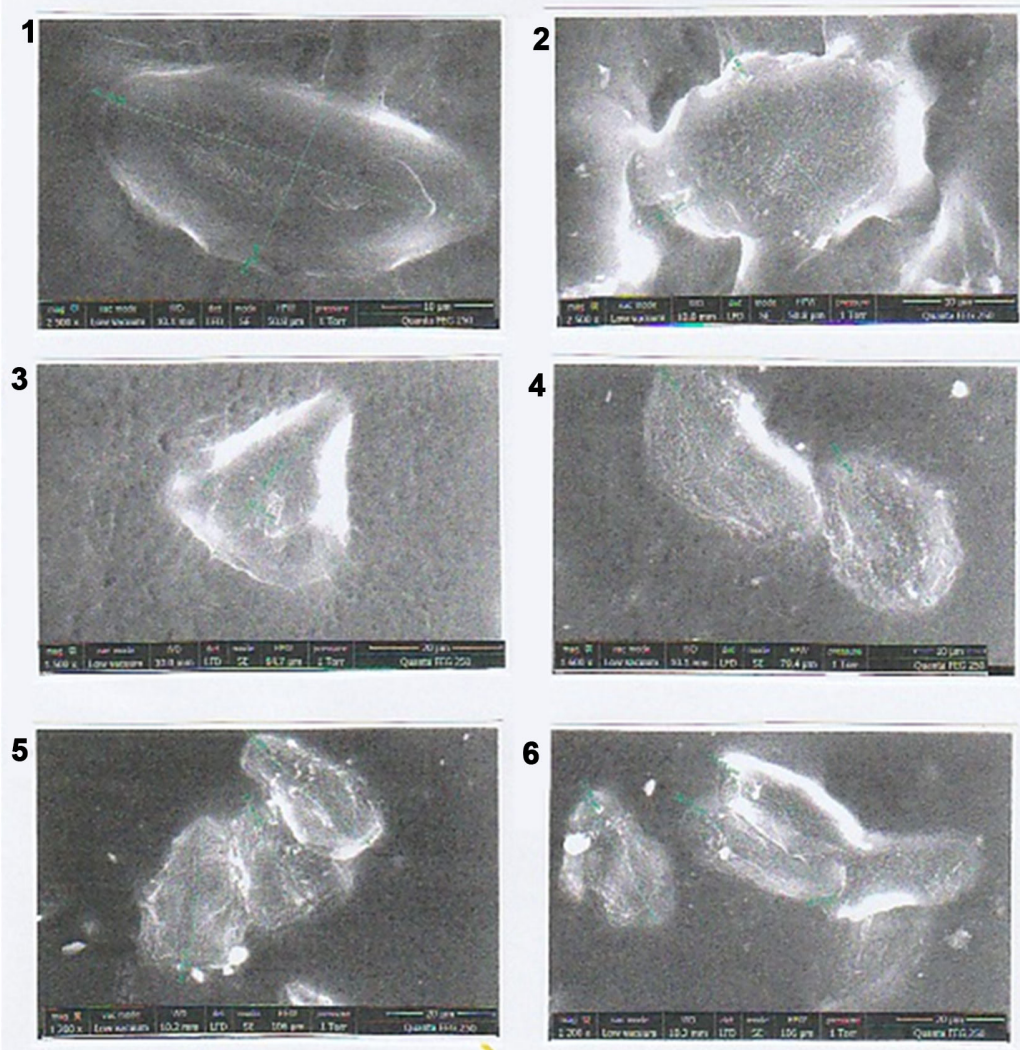

Figure 6. SEM photographs of some examples of these pollen grains. 1: SEM photograph (in LFD, $2500 \times)$ of a pollen grain $(42.4 \times 19.3 \mu \mathrm{m})$ seen in equatorial view. 2: a pollen grain $(29.1 \times 20.5 \mu \mathrm{m})$ seen (in LFD, $2500 \times)$ in longitudinal view. 3: a pollen grain $(39.2 \times 33.3 \mathrm{um})$ seen (in LFD, $1500 \times)$ in polar view. 4 : two pollen grains (35.3 and 28.6 um of lengths, respectively) seen (in LFD, $1600 \times)$ in longitudinal views. 5: three pollen grains (34.3, 27.7 and $35 \mu \mathrm{m}$ of lengths, respectively) seen (in LFD, $1200 \times$ ) in longitudinal views. 6: a group of five pollen grains $(32.3,39,36.6$ and $36.2 \mu \mathrm{m}$ of length, respectively for the four firsts) seen (in LFD, 1200×) in longitudinal views.

It is erect and cylindrical, bright green, and smooth as to seem polished, with multiple branched leaves cut into the finest of segments. The leaves grow up to $40 \mathrm{~cm}$ long; they are finely dissected, with the ultimate segments filiforms (threadlike) of about $0.5 \mathrm{~mm}$ wide. The bright golden flowers are produced in large and flat terminal umbels (with thirteen to twenty rays) bloom in July to August.

Stem is striated; leaves are 3 - 4 pinnated, with base-segments filiforms (of up to $4 \mathrm{~cm}$ long). Leaf basis is sheeted; it has a green, sleek and slippery stem with upright stiff branches and much divided leaves in linear segments.

Foeniculum vulgare is a very polymorphic species (Badoc et al., 1995). The vulgare variety ( $F$. vulgare vulgare) corresponds to wild, or cultivated, plants. Foeniculum vulgare "Purpureum", or "Nigra", or "bronze-leaved" fennel, is widely available as a decorative garden plant. The Florence fennel variety (Foeniculum vulgare var. azoricum) is a cultivar group with inflated leaf bases which 
Table 1. Ten nomenclature criterias for pollens used in our characterization.

\begin{tabular}{|c|c|c|}
\hline Criterias & Nomenclature & Commentaries \\
\hline 1 & monad & $\begin{array}{l}\text { when they are tightly lumped together, it is mainly due to their } \\
\text { proximities on the stick paper }\end{array}$ \\
\hline 2 & form: prolate & elongated in form; the main measured length is about $35 \mu \mathrm{m}$ \\
\hline 3 & isopolar & $\begin{array}{l}\text { anisopolarity, when it exists, is an artefact due to differential } \\
\text { dryness or compression effect }\end{array}$ \\
\hline 4 & medium & their lengths are between 26 and $50 \mu \mathrm{m}$ \\
\hline 5 & perprolate & $\begin{array}{l}\text { the mean measured width is of about } 15 \mu \mathrm{m} \text {, but this } \\
\text { measurement is greatly dependent on dryness. The ratio between } \\
\text { polar }(\mathrm{DP}) \text { and equatorial }(\mathrm{DE}) \text { diameters }=2.3\end{array}$ \\
\hline 6 & sulcus: sulcate & $\begin{array}{l}\text { at least one long longitudinal sulcus is observed in equatorial } \\
\text { views }\end{array}$ \\
\hline 7 & trisulcated & three sulcis, for observations in combination \\
\hline 8 & porus: pore & $\begin{array}{l}\text { one voluminous pore in equatorial position, located on the } \\
\text { corresponding sulcus }\end{array}$ \\
\hline 9 & tripored & one such pore, for each sulcus \\
\hline 10 & heteroapertured & because it is trisulcated and tripored \\
\hline
\end{tabular}

form a bulb-like structure. It is of cultivated origin and has a mild anise-like flavour, but is sweeter and more aromatic; Florence fennel plants are very much smaller than the wild type. The inflated leaf bases are eaten as a vegetable, both raw or cooked. Several cultivars of the Florence fennel are also known by several other names, notably the Italian name "finocchio".

\subsubsection{Foeniculum vulgare azoricum Is Used for Comparative Purposes in Our Study}

It is a today fennel plant of the variety azoricum, the bulbous form (Figure 7), that was used for comparisons. This figure shows macroscopic and microscopic aspects of some pedicels and leafs of the sample. The SEM photograph summarizes the distinctive arrangements of stomates on the epidermis surface: typically they are aligned for the pedicel and in a staggered arrangement for foliar 'leaf.

Longitudinal cuts of stems were also practised, to compare vessel structures and arrangements.

The SEM photograph of Figure 8 shows that, for the today fennel specimen studied, leaves have both foliar and pedicelar (at the basis) parts. The below spectrum shown is a typical one of both of these parts, EDX analyses being realized at several leaf points. This spectrum shows carbon and oxygen peaks (that constitute the organic part majority) and little peaks of minerals; among them the potassium peak predominates, an essential characteristic of most vegetables in general, and of the fennel plant specially.

\subsection{A Foliar Structure in A}

Figure 9 shows the structure located inside circle A. It is round in form, with a maximal diameter of about $350 \mu \mathrm{m}$; its spectrum is that of a vegetable. 


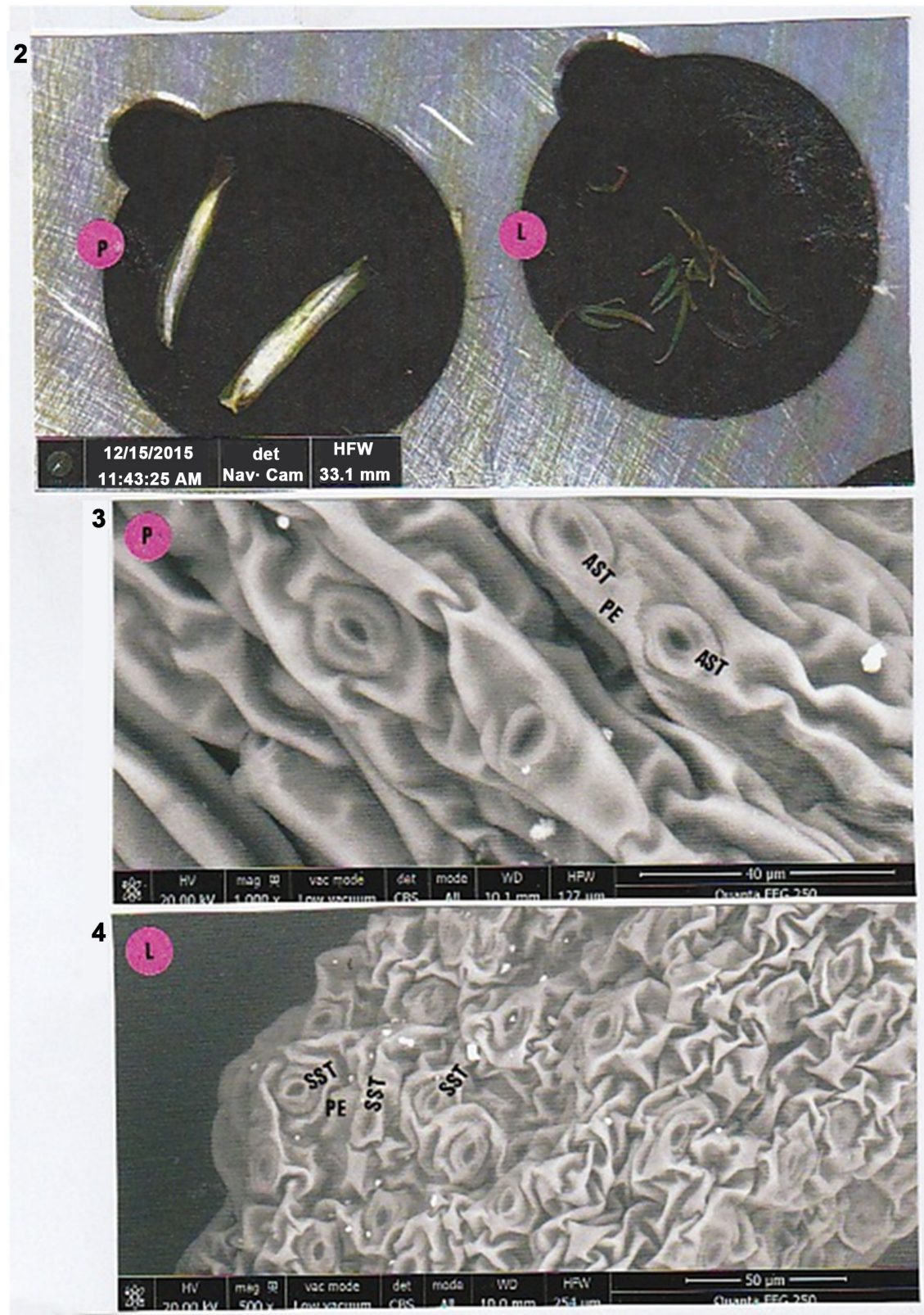

Figure 7. A today plant of fennel. 1: the fennel sample (L: leaf; P: pedicel; S: stem; B: bulb). 2: Optical microscopic view of P and L. 3: SEM photograph (in CBS, 1000×) of some part of the pedicelar (P) epidermis. AST: two aligned stomates; PE: folded epidermis. 4: SEM photograph (in CBS, 500×) of some part of the foliar leaf (L) epidermis. SST: three adjacent stomates, in a straggered arrangement.

There are numerous stomates on its surface, mainly located at the rounded periphery. As these adjacent stomates are staggered (like to those shown on photograph 4 of Figure 7) and the epidermis between them is highly folded, that establishes that the vegetable structure observed is a fragment of a fennel leaf.

Figure 10 compares stomate dimensions of two of them to those of a today fennel leaf stomata. Although their partial dimensions differ, their proportional sizes (as well for ostiol measurements) for total stomate length (including or not 


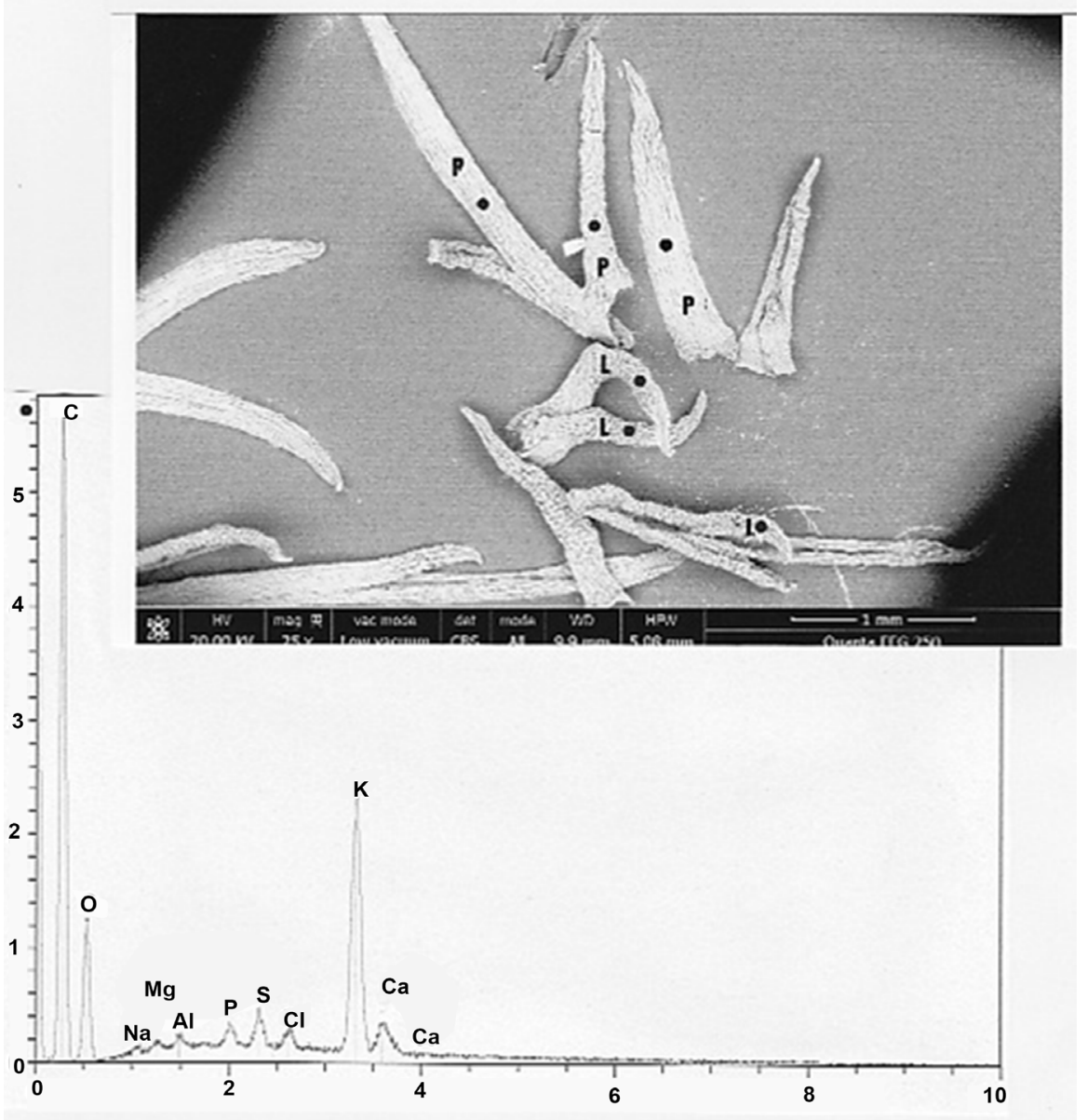

Figure 8. Elementary analyses of pedicelar and foliar parts of leafs of the today sample of the fennel plant. Above: SEM photograph (in CBS, $25 \times$ ) of pedicelar (P) and foliar $(\mathrm{L})$ parts of leafs (black dots indicate the locations where EDX analyses are realized). Below: a representative EDX spectrum at the black dots. C: carbon; O: oxygen; Na: sodium; Mg: magnesium; Al: aluminium; P: phosphorous; S: sulphur; $\mathrm{Cl}$ : chlorine; K: potassium; Ca (two peaks): calcium.

guard cells) and height (including sentinel or annex cells) are the same for the today fennel leaf and for the structure studied. In general similarity is very great between stomates of this type, said as "low-triangular" (Ellis, 1979).

Figure 11 gives elemental compositions of two sorts of particles (1 and 2) deposited on the surface of the structure examined (see Figure 9). Particle 1 is a calcium carbonate that, because of its high calcium content, is a lime; numerous other particles of similar aspect are deposited on the leaf surface. Particle 2 is rich in rare earths (cerium and lanthane).

The calcium carbonate is a very common deposit, that of this of rare earth micro-marble is very unusual. It is in fact an artefact due to the use of one such product (we have documented proofs of that) for the cleaning

(http://www.ampere.com/polissage-terres-rares) of the posterior face of the reliquary glass. Supplementary Figure 3 shows another example of this sort of rare earth micro-marble, found at the proximity of hair number 3. 


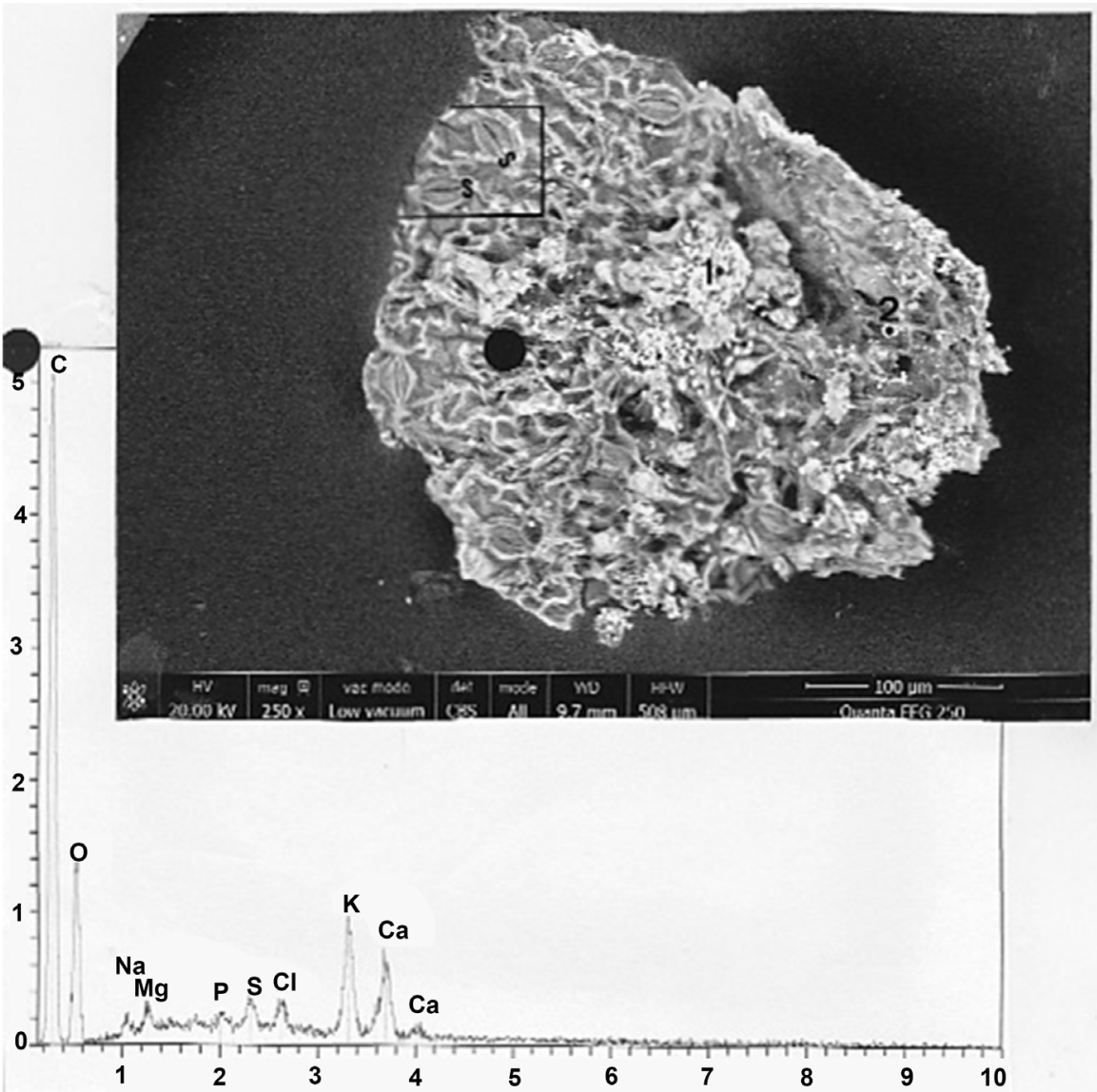

Figure 9. Morphology and composition of structure A. Above: SEM photograph (in CBS, $250 \times$ ) of this structure. The rectangular area containing two stomates (S) is enlarged in the following photograph (1: particles number 1; 2: particle number 2); the big black spot indicates the location where EDX analysis is realized. Below: spectrum at the black spot.

\subsection{Foliar and Pedicelar Structures in B}

Figure 12 shows the two structures (piece 1 above, piece 2 below) located inside of circle B. They are elongated in forms, with a greatest dimension of about 330 $\mu \mathrm{m}$. Its spectras are that of vegetables.

The stomates of piece 1 (Figure 13) are struggered; so it appears as a foliar part of a fennel leaf. On the three studied particles (1, 2 and 3) deposited on the surface of this piece (Figure 14), the two firsts are mineral particles of silica (with a very elevated peak of silicium).

The third particle is a potassium sulphate, in fact a sulphate double of potassium and of calcium). We have found such a product several times on Marie-Madeleine hairs; for example, Supplementary Figure 4 and, Supplementary Figure 5 show particles (both of micro-needles and micro-plaques) of sulphate double of potassium and calcium located on the surface of some part of hair number 1 .

Because that stomates of piece 2 (Figure 15) are mainly aligned (like to those shown on photograph 3 of Figure 7), it appears as a pedicelar part of a fennel 

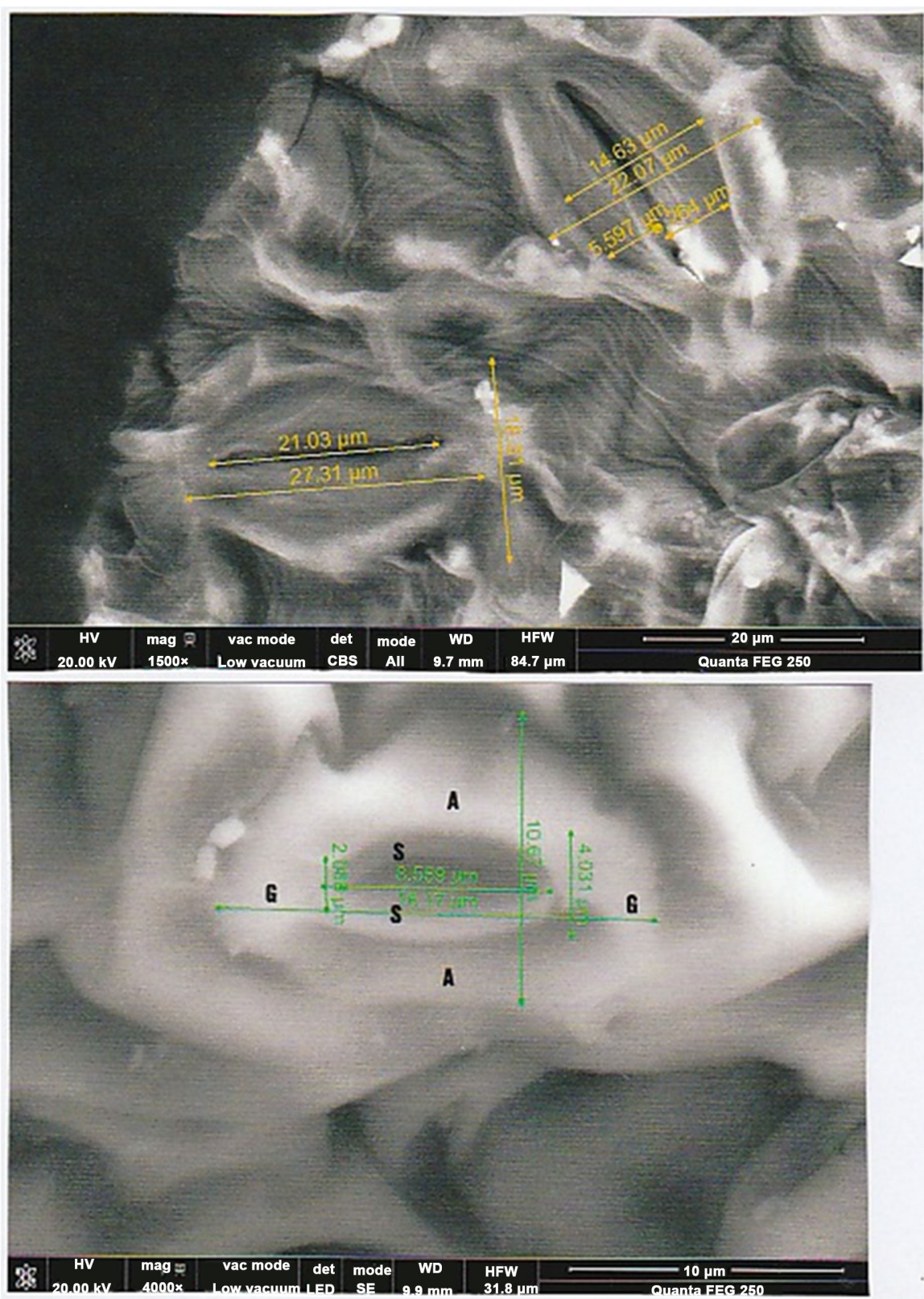

Figure 10. Comparison between stomates of structure A to those of the fennel leaf. Above: SEM photograph (in CBS, 1500x) of two adjacent stragered stomates of A. Below: SEM photograph (in LFD, 4000x) of one stomate of the today fennel leaf. Dimensions (in $\mu \mathrm{m})$ are, horizontally, those of the ostiols and of the sentinel cells (S); vertically, those of the stomate cells (S) and those of annex cells (A); G are the guard cells.

leaf. On the two studied particles ( 1 and 2 ) deposited on the surface of this piece (Figure 16), the second is another sulphate double of potassium and calcium.

The first one is a clay mineral particle of an alumino-silicate of the montmorillonite/illite type, relatively iron-rich; because of its elevated content in iron oxide, it must appear as red in optical microscopy.

Supplementary Figure 6 shows another example of montmorillonite/illite mineral particles deposited on some part of the hair number 2 surface. As we 

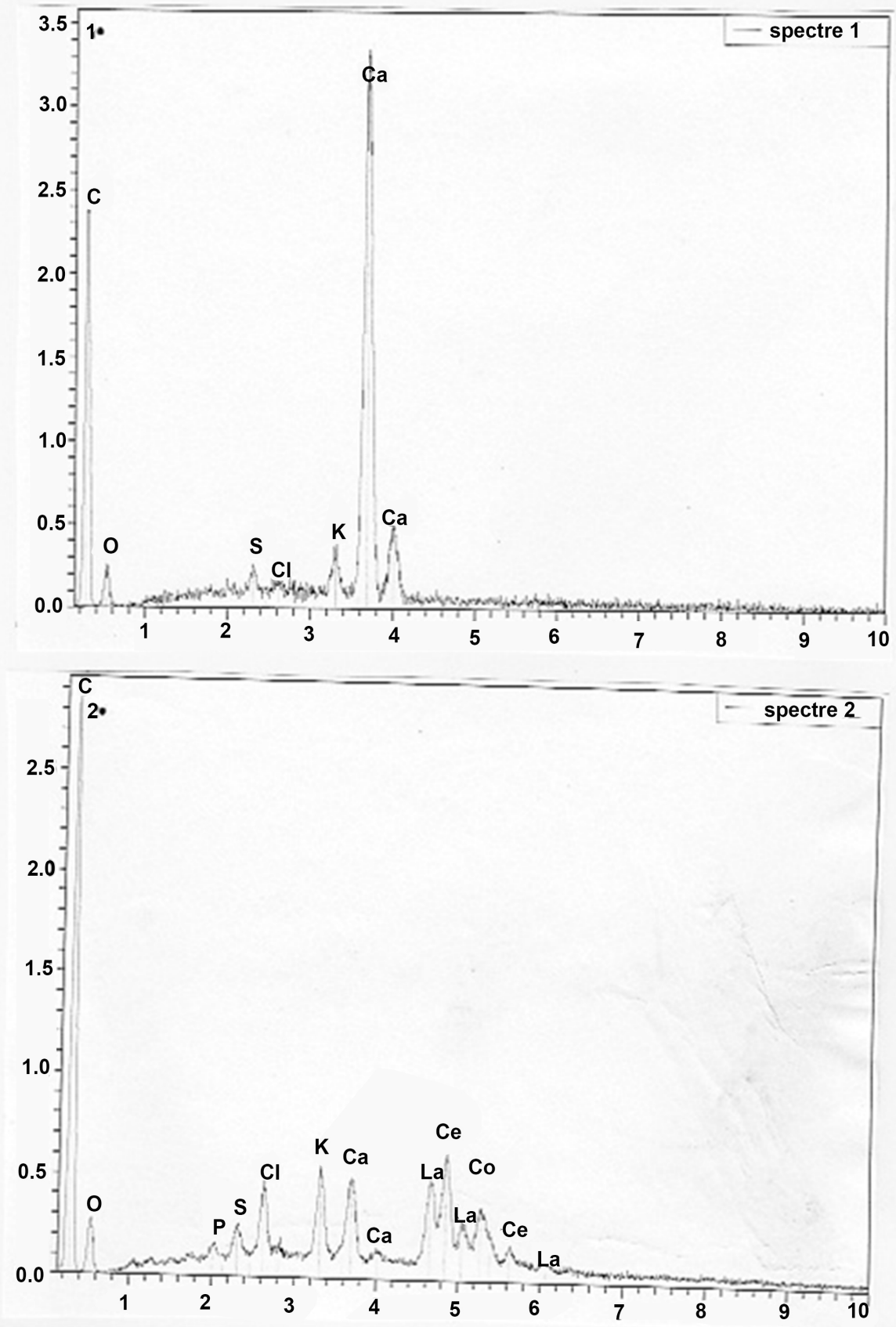

Figure 11. Spectras of particles 1 (spectre 1) and of particle 2 (spectre 2), as indicated on the Figure 1 photograph. Above: spectrum of particles 1. Below: spectrum of particle 2; La (three peaks): lanthane; Ce (three peaks): cerium.

found previously there is a mean of about $5 / 6$ of such particles (of relatively great sizes) only per hair, so these clay-mineral particles cannot be responsible for the red hair colour observed (Lucotte \& Thomasset, 2017).

\subsection{A Stem Structure in C}

Figure 17 shows the structure located inside of circle C. It is a piece of triangular form (height of about $360 \mu \mathrm{m}$ ); its spectrum is that of a vegetable. 


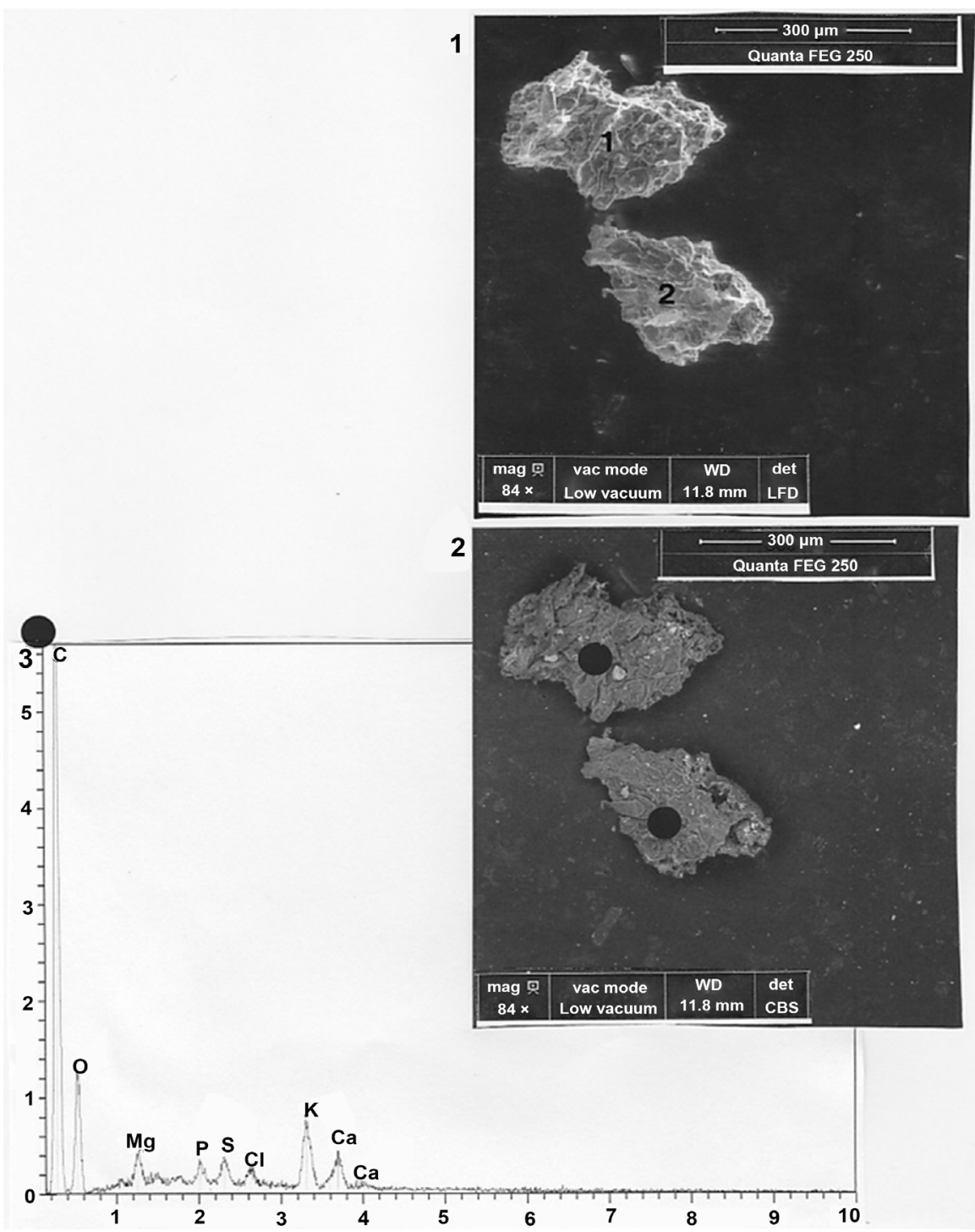

Figure 12. Morphology and composition of pieces one (1) and two (2) of the structure B. 1: SEM photograph (in LFD, $84 \times$ ) of pieces 1 and 2. 2: SEM photograph (in CBS, $84 \times$ ) of pieces 1 and 2 (black spot indicate the locations where EDX analyses are realized). 3: spectrum at the black spots.

Angular outlines observed at the piece periphery (Figure 18) corresponds to flutes of the stem. Careful examination shows that the piece had some complexity; so, several peculiar aspects of it are further explored: the pores (circles 1 and 2); some peculiarities of the epidermis surface (circles 3 and 4); a cribled tube (circle 5) and (circle 7) aspect of a scalariform vessel. The greatest degree of complexity is observed inside the rectangular area indicated as 6 , that was studied in details.

\subsubsection{Pores}

There are no stomates on the piece surface, but circular pores. Figure 19 shows enlarged views of two of them ( $\mathrm{p} 1$ and $\mathrm{p} 2) ; \mathrm{p} 2$ is a well delimitated circular pore, of an internal diameter of about $4 \mu \mathrm{m}$. 


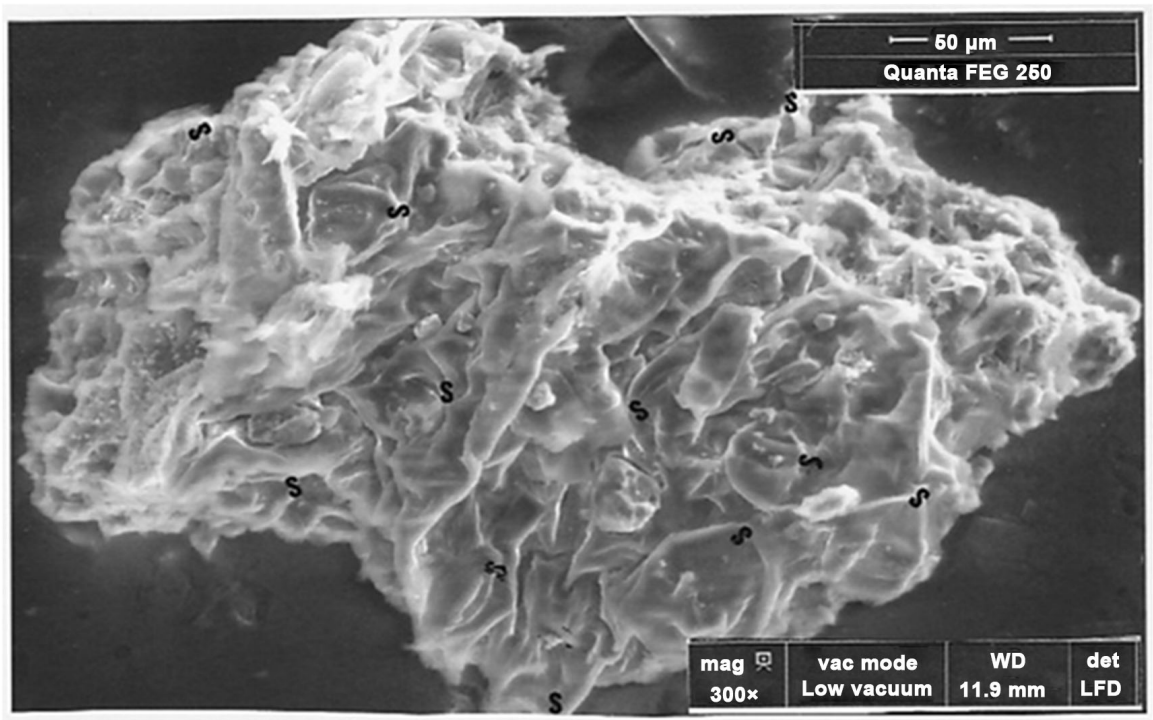

Figure 13. SEM photograph (in LFD) of piece 1. S (orientated among ostiol cracks) indicate twelve stomates.

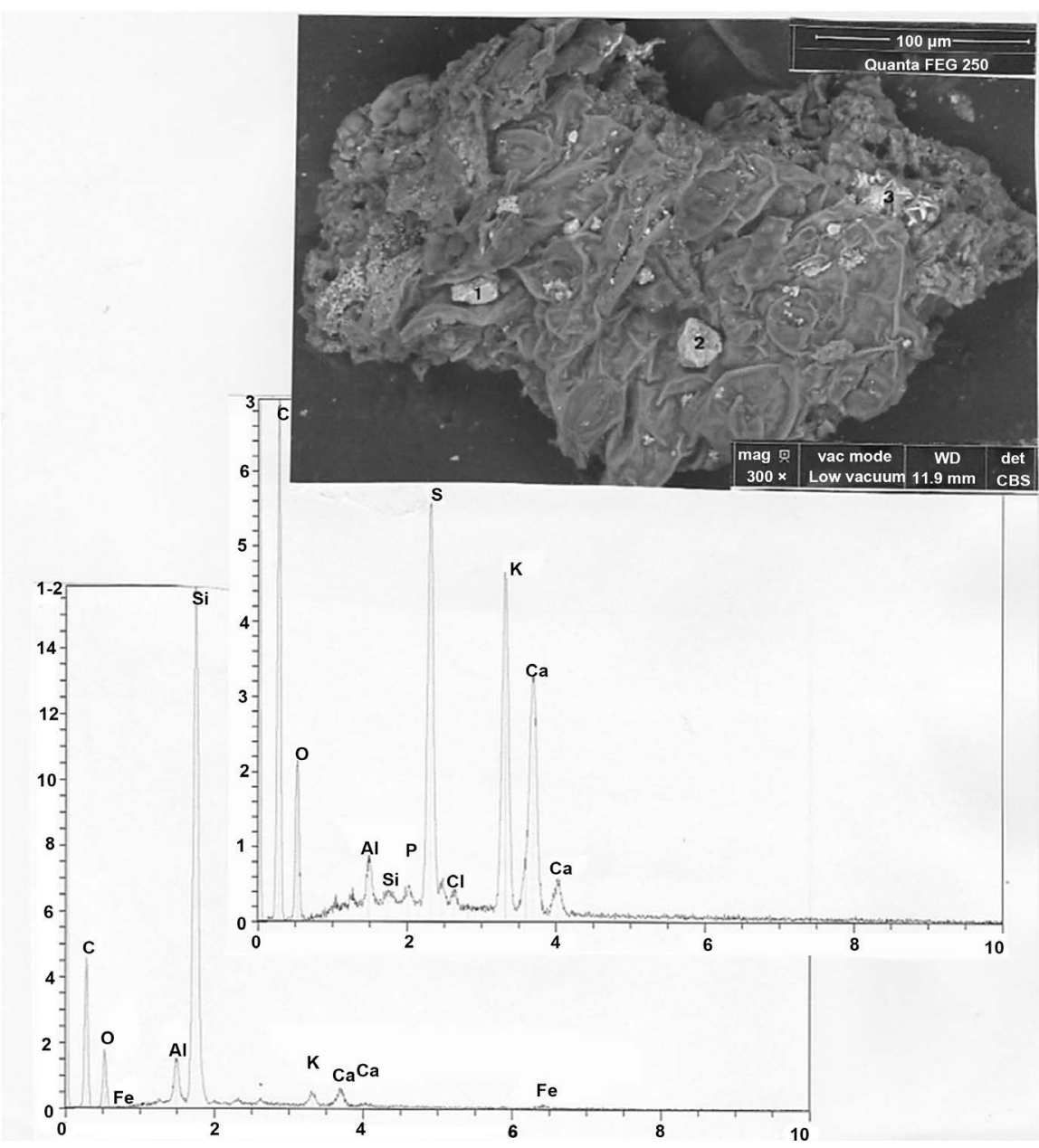

Figure 14. Above: SEM photograph (in CBS, 300×) of piece 1 (1, 2 and 3 indicate three mineral particles). Below: upper, spectrum of particles number 3; lower: spectras of particles numbers 1 and 2 (there are traces of iron: Fe). 


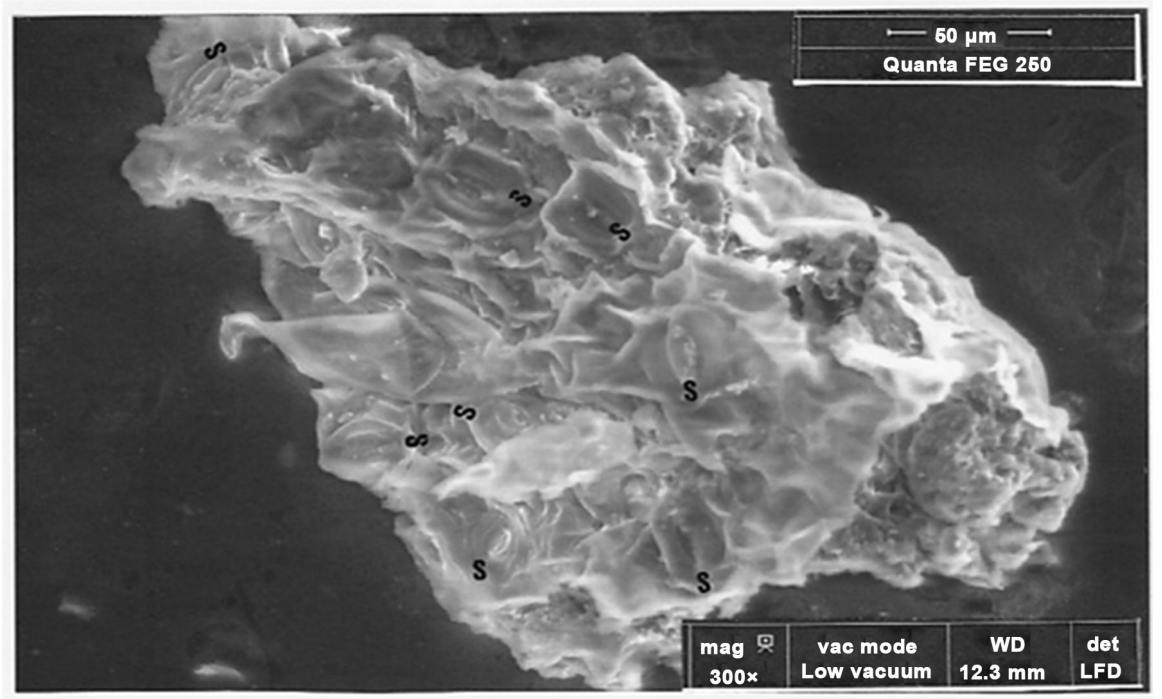

Figure 15. SEM photograph (in LFD, 300×) of piece 2 (S: eight stomates).

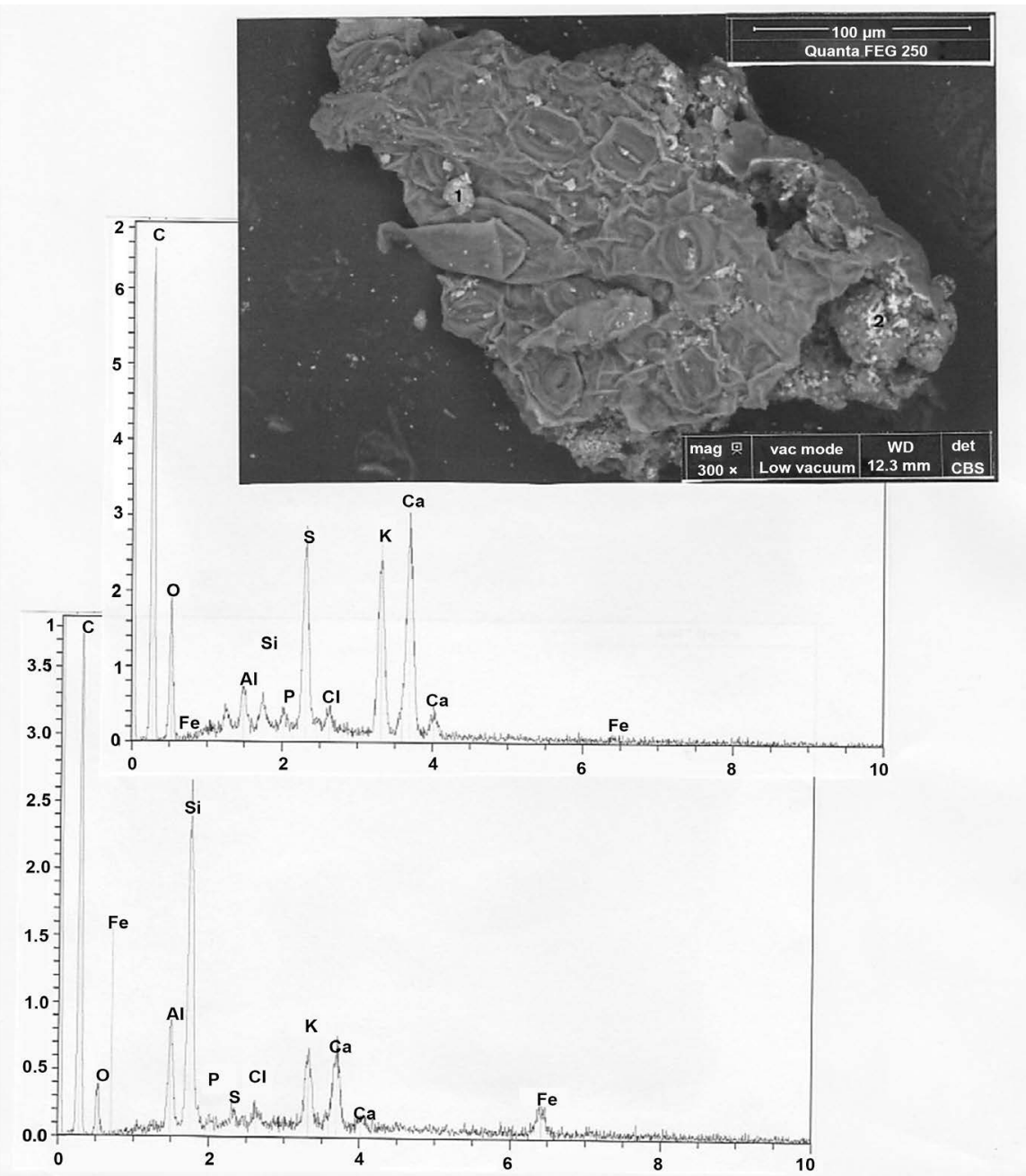

Figure 16. Above: SEM photograph (in CBS, 300×) of piece 2 (1 and 2 indicate two mineral particles). Below: upper, spectrum of particles number 2; lower; spectrum of particle number 1 (where the main iron peak appears). 


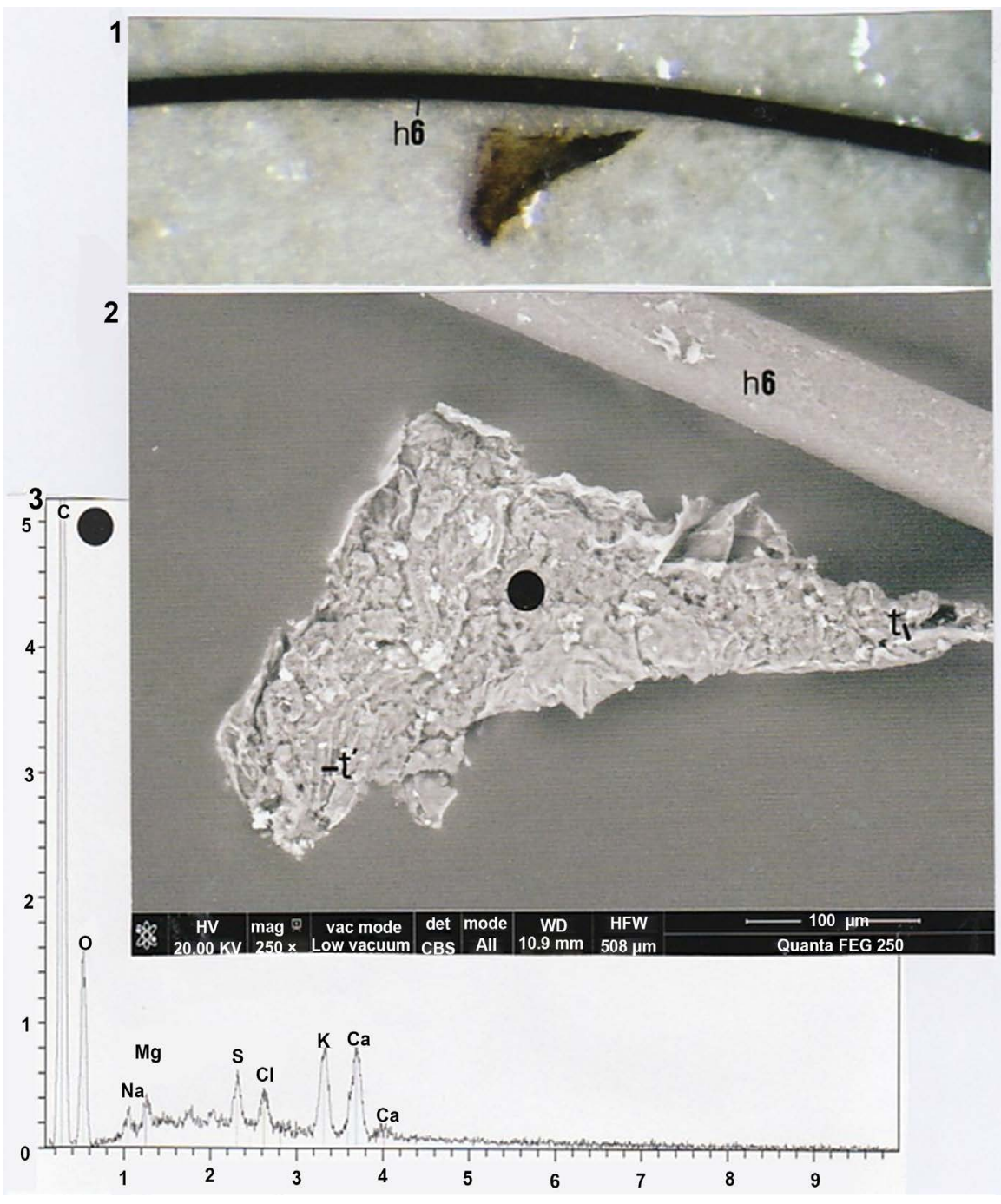

Figure 17. Morphology and Composition of C. 1: their structure, in optical microscopy (20x); h6 is some part of hair number 6. 2: SEM photograph (in CBS, 250x) of the structure (black spot indicates the location where EDX analysis is realized). 3: spectrum at the black spot.

These pores are similar to classically described "wood holes" (Speranza \& Galzoni, 1996). That indicates some degree of xylemation of the epidermis studied.

\subsubsection{Epidermis}

Figure 20 photographs show some aspects of this sclerified epidermis in some places. Its aspect inside of circle 3 shows that the epidermis plaque limits are orientated transversally (or in diagonally) in comparison to the stem longitudinal axis. The exfoliated aspect of some plaques (shown inside of circle 4) located at the exterior limit of the piece testifies that they overcome in fact strates of previous epidermis layers.

Both these peculiarities are compatible to the stem epidermis aspect of a perennial plant. 

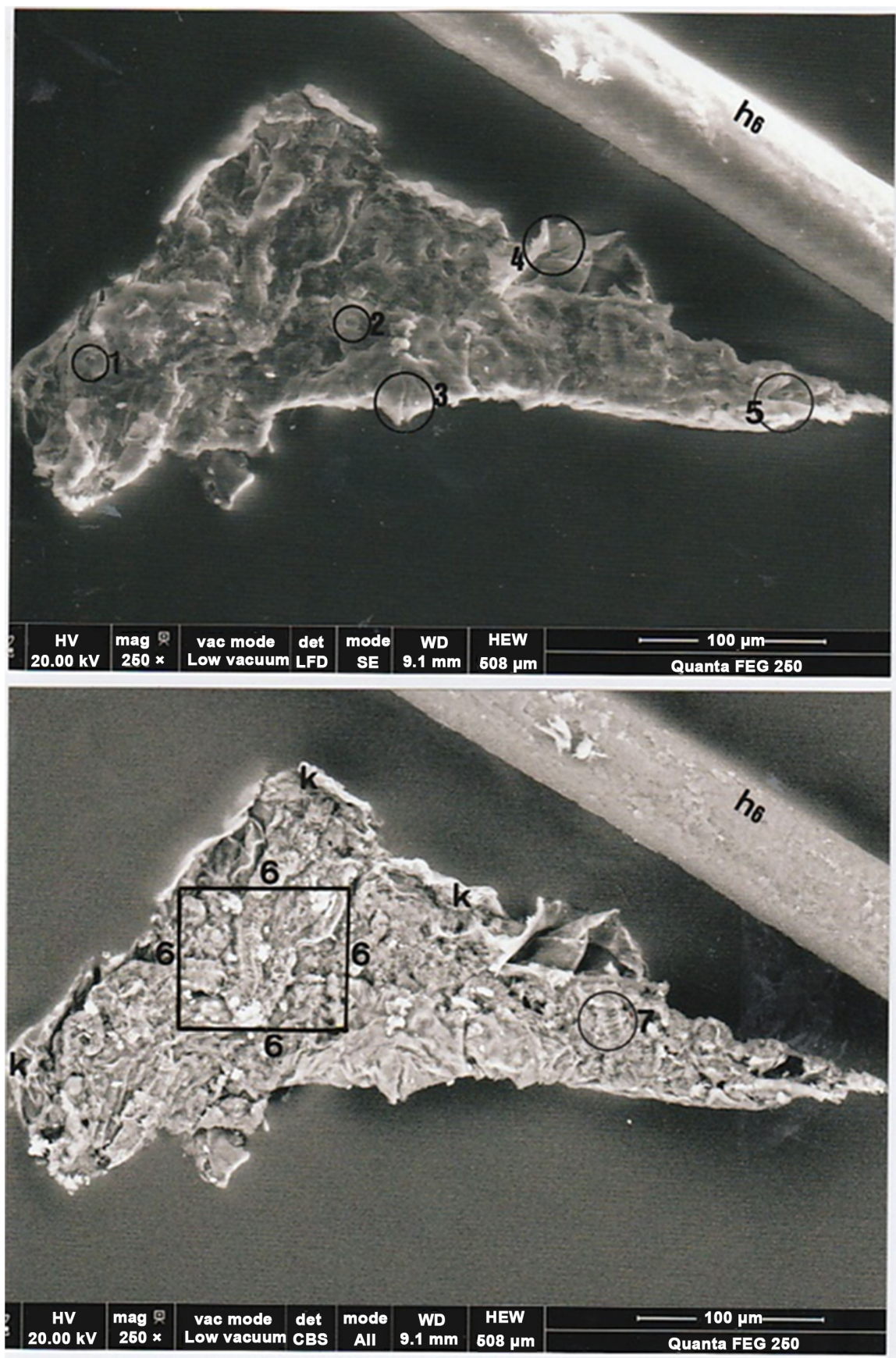

Figure 18. Above: SEM photograph (in LFD, 250×) of structure C (circles 1 and 2 indicate holes; circles 3 and 4 indicate regions of exfoliation of the epidermis; circle 5 indicates a vessel. Below. SEM photograph (in CBS, 250×) of structure C (the rectangular area 6 shows inside numerous evidence of vascularisation; circle 7 indicates a scalariform vessel). K: two angles (indicating the fluting of the stem) and one abrupt border.

\subsubsection{A Cribled Tube}

Figure 21 shows inside of circle 5 the external aspect of a segment of a cribled tube. Its form is roughly cylindrical (length of about $42 \mu \mathrm{m}$, on about $5 \mu \mathrm{m}$ of thickness). Its right extremity is broken and a cribbled plaque is visible at its other extremity. It is orientated along the stem longitudinal axis (one can see on 

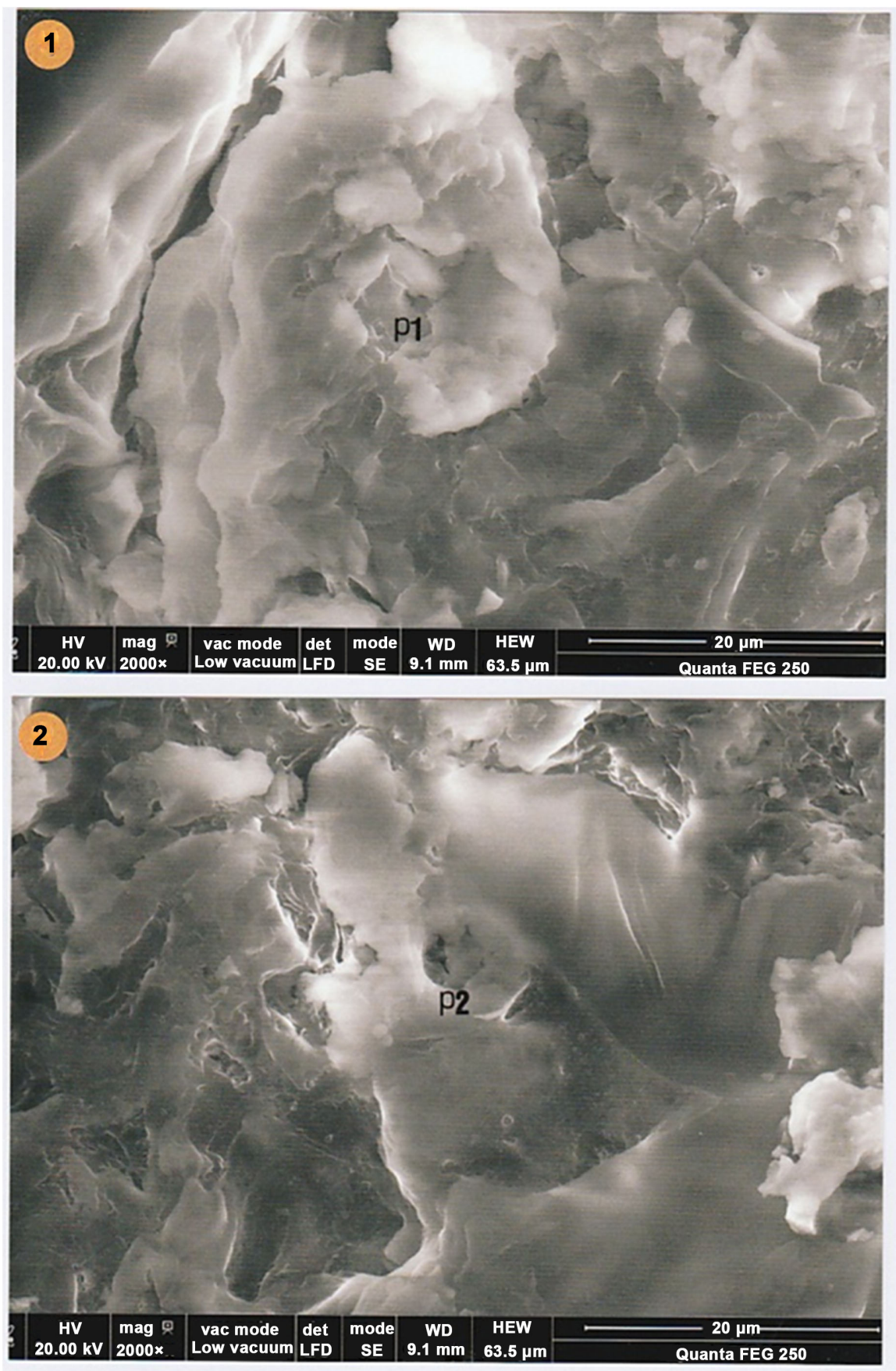

Figure 19. Above: SEM photograph (in LFD, 2000×) showing a first pore (p1) inside of circle 1. Below: SEM photograph (in LFD, 2000×) showing a second pore (p2) inside of circle 2 .

the SEM photograph of Figure 17 another segment of a cribbled tube $\left(t^{\prime}\right)$ that is in orthogonal orientation compared to that described here). Cribled tubes are peculiar vessels of the liber specialized in the transport of the elaborated seve (Speranza \& Galzoni, 1996).

Figure 22 photographs are enlarged views of the rectangular area shown on Figure 21 . One can see on it a relatively voluminous $(6.3 \mu \mathrm{m}$ of length) spore. 

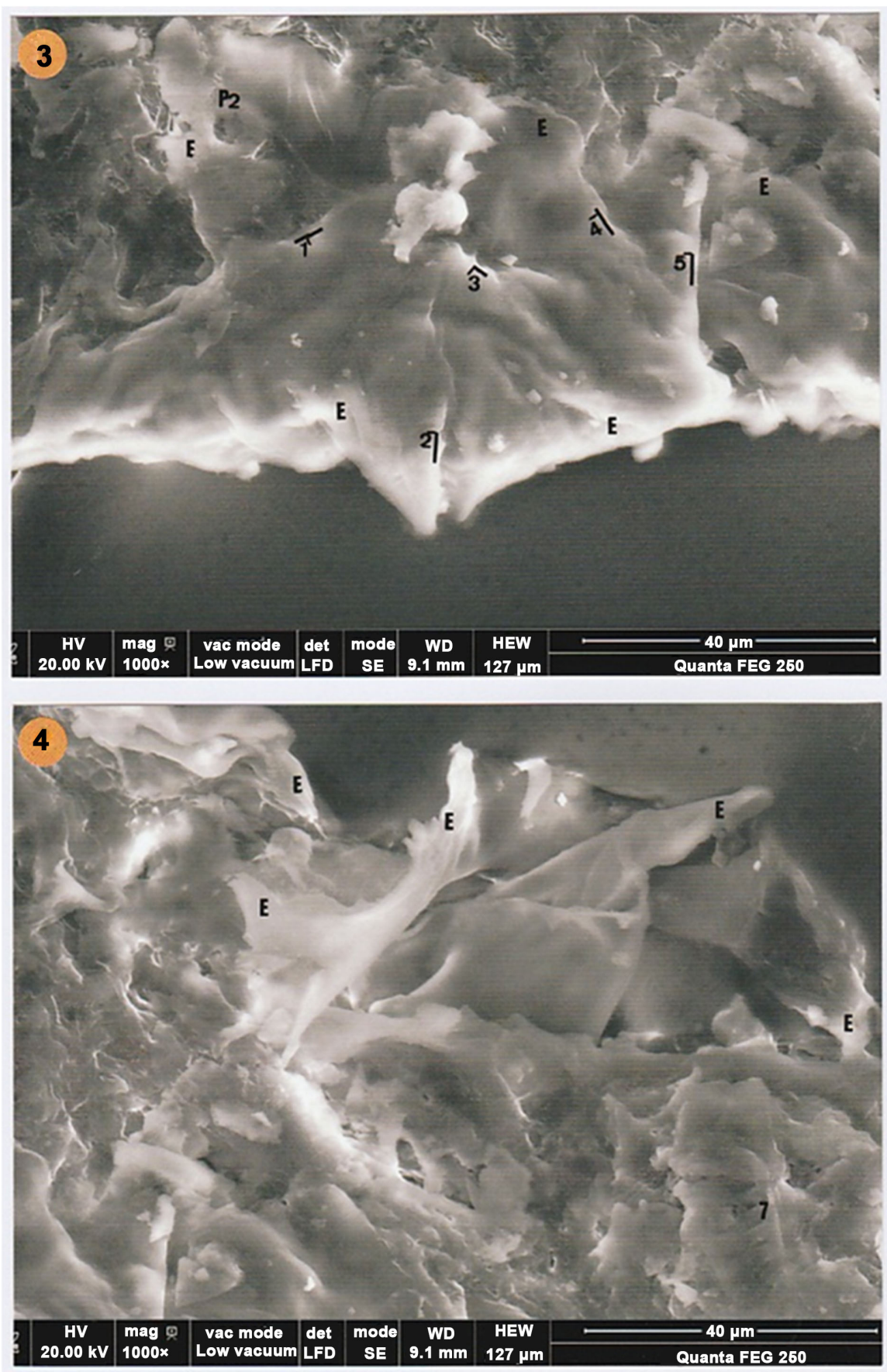

Figure 20. Above : SEM photograph (in LFD, 1000×) showing angular limits $(1,2,3,4$ and 5) of the epidermis plaques (E) inside of circle 3 (p2: the second pore). Below. SEM photograph (in LFD, 1000×) showing the exfoliated epidermis plaques inside of circle 4 (7: circle 7).

This spore, of ellipsoid form and organic composition, is an ascopore (Rodeva \& Gabler, 2011); it is associated to micro-filaments of a mycelium, visible at the step outline limit.

Three other more little (about $3 \mu \mathrm{m}$ of length) aligned ascopores, of another species, are seen inside of a stem micro-cavity. 


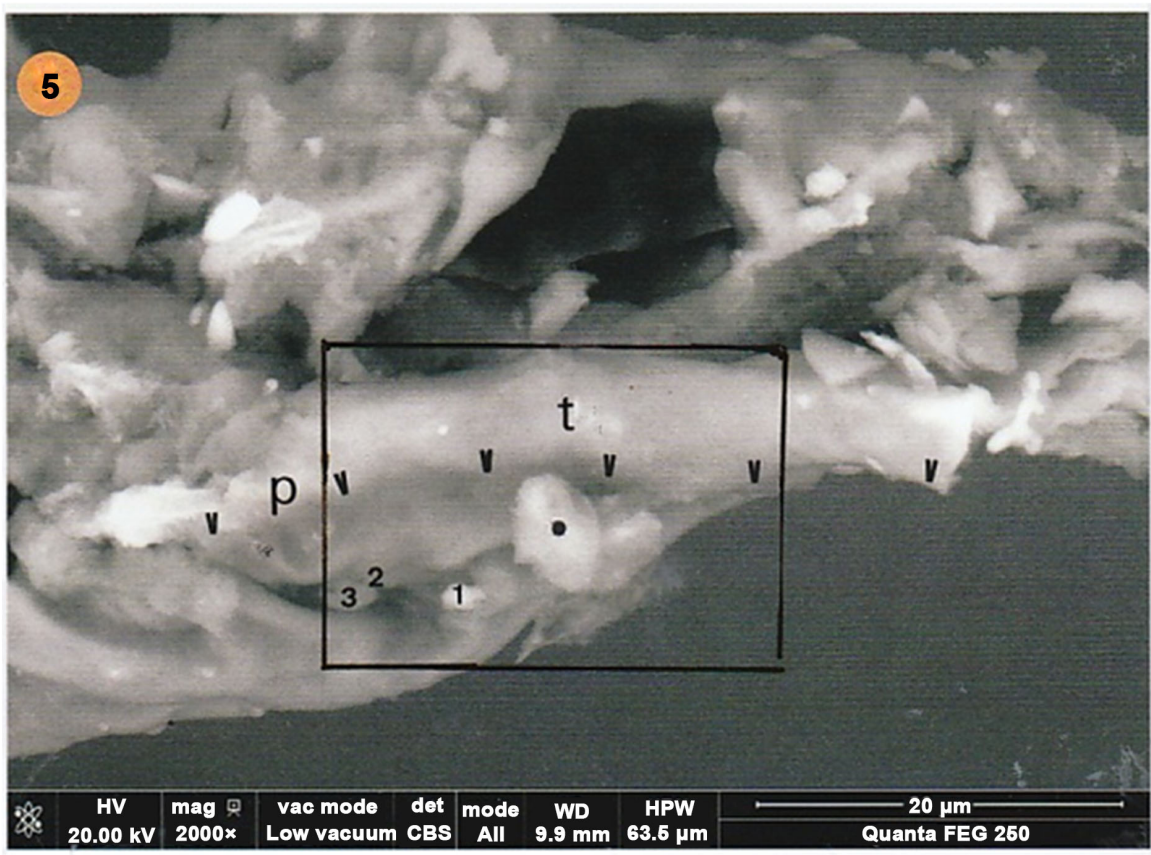

Figure 21. SEM photograph (in CBS, 2000x) showing the external wall of a cribbled tube $(t)$, its inferior limit being indicated by several arrow points (p: cribled plaque), inside of circle 5. The little black point indicates the biggest spore, and numbers 1, 2 and 3 three little spores. The showed rectangular area is enlarged in the following photograph.

All that proves that the stem studied were infected by at least two different sorts of mould species.

\subsubsection{Vessels}

Figure 23 shows vessels located inside of the rectangular area 6. The upper photograph of this figure shows a fragment of bilayer epidermis and three different sorts of vessel fragments (enlarged on the lower photograph): of a scalariform vessel, of a vessel with distant rings, and of areoled vessels; this photograph shows also double helix detached elements. All these vessels are grouped in one unit, orientated orthogonally from the stem axis.

Figure 24 shows, for comparison, two parts of a longitudinal (axial) cut of the stem of a today fennel. This comparison permits us to establish firstly fennel stem fragment under study and the today one are delimitated by the same sort of bilayer epidermis.

But it is above all the various vessel forms and their associations that are highly characteristic in plants (Sporanza and Galzoni, 1996). Comparison concerning now the vessel characteristics between the ancient and the today stems of fennel, shows that they have three characters in common:

The presence of scalariform vessels,

The simultaneous presence of the both forms of ringed (with distant, or bringed rings) and double helix vessels,

The presence of double helix detached elements.

In both cases also, areoled vessels are relatively rare. 

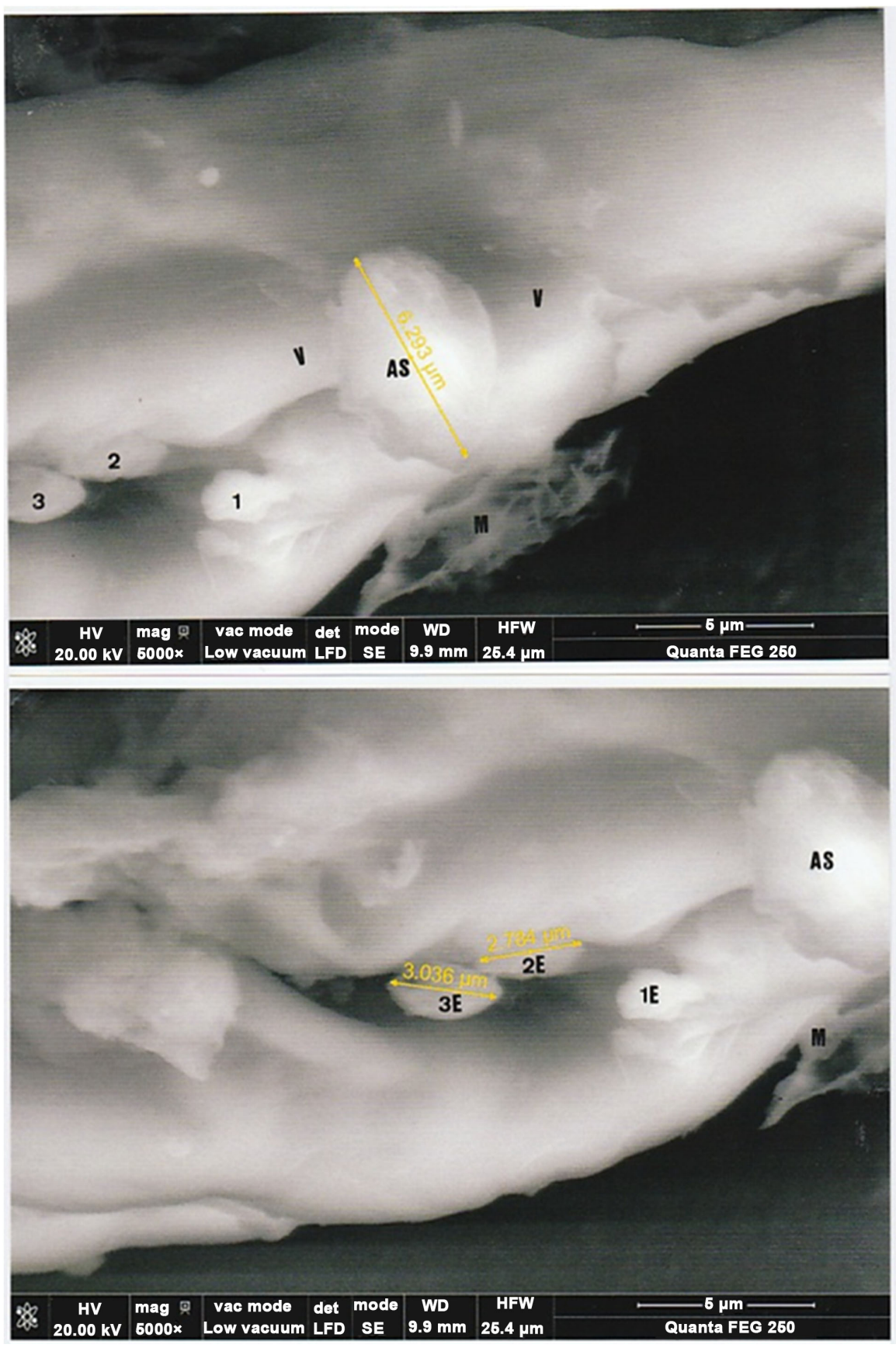

Figure 22. Above: SEM photograph (in LFD, 5000×) is an enlargement of the previous photograph (AS: ascopore; M: mycelium). Below: SEM photograph (in LFD, 5000×), shifted to the left from the previous one; $1^{\mathrm{E}}, 2^{\mathrm{E}}$ and $3^{\mathrm{E}}$ indicate three little spores (dimensions are in $\mu \mathrm{m})$.

\subsubsection{A Scalariform Vessel Fragment}

Figure 25 shows a fragment of scalarifrom vessel inside of circle 7. There is a quasi-identity (concerning scale' pattern and spacing, scale dimensions, width of the scalariform vessel and wall limits arrangement at each side of the vessel) between this observed vessel fragment and that of a scalariform vessel of the today fennel stem. 


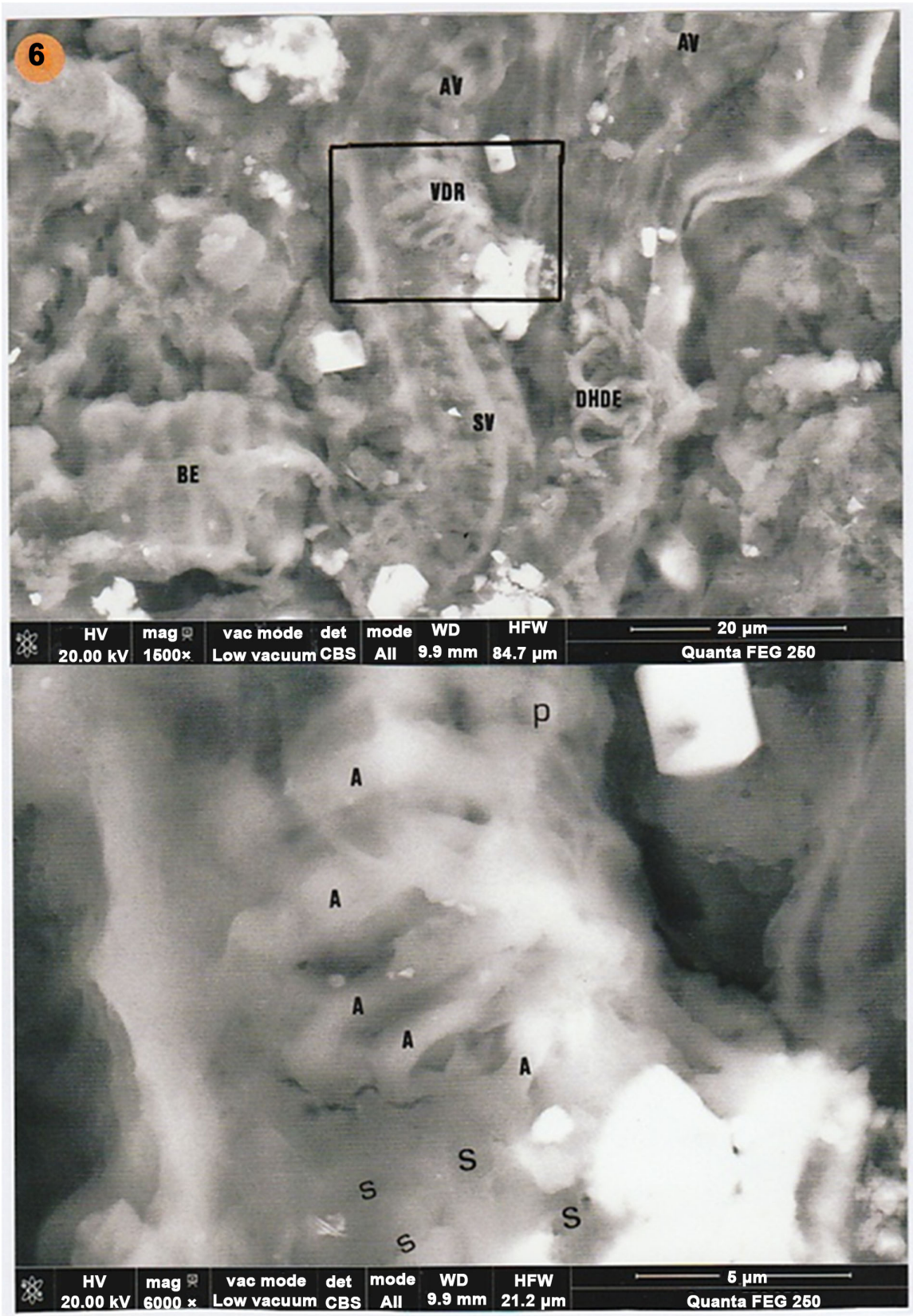

Figure 23. Vascular and epidermis structures inside of the rectangular area 6. Above: SEM photograph (in CBS, 1500x) of area. BE: bilayer epidermis; AV: areoled vessels; VDR: vessel with distant rings (the rectangle sub-area is enlarged in the below photograph); DHDE: double helix detached elements; SV: scalariform vessel. Below: SEM photograph (in CBS, $6000 \times$ ) of the enlarged above sub-area. A: rings of vessel with distant rings; p: areole of the areoled vessel; S: scales of the scalariform vessel.

\subsubsection{EDX Mapping of the Stem Fragment}

Map and EDX general spectrum of the stem fragment (structure C) are shown on Figure 26. Carbon and oxygen (main peaks) correspond to the organic matter, and the sulphur peak is relatively elevated; as expected, the potassium peak is the highest among the little peaks of minerals. Table 2 shows the normalized (carbon and oxygen excepted) composition of elements of C. 

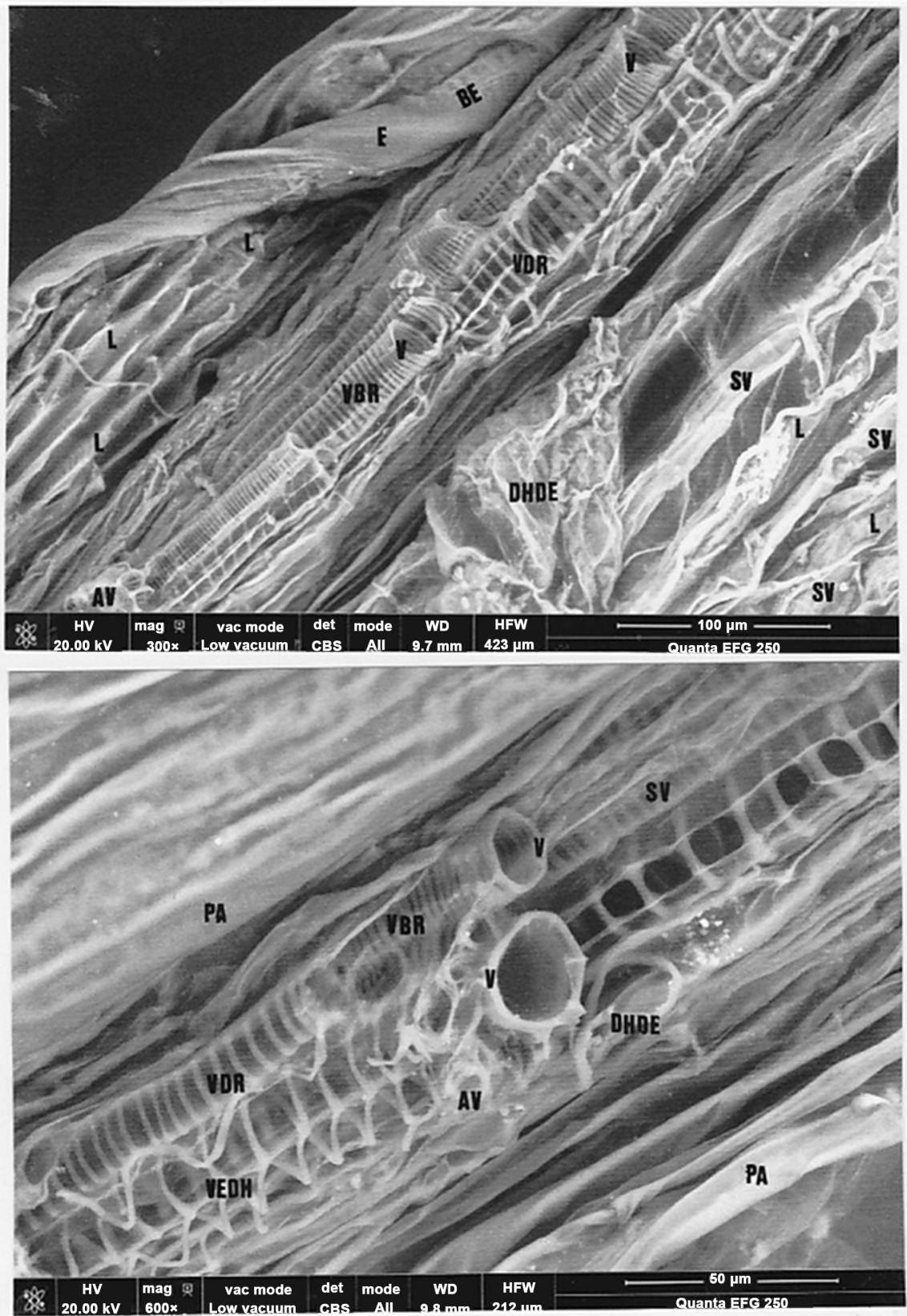

Figure 24. Vascular and epiderm structures in a longitudinal section of a today fennel stem. Above: SEM photograph (in CBS, 300×) of some part of the fennel stem cut. E: epidermis; BE: bilayer epiderm; V: two vessel apertures; AV: areoled vessel; VDR: vessel with distant rings; VBR: vessel with bringed rings; DHDE: double helix detached elements; SV: scalariform vessels; L: vessels of the liber. Below. SEM photograph (in CBS, 600×) of another part of the fennel stem cut. V: two vessel apertures; SV: a scalariform vessel; VBR: vessel with bringed rings; VDR: vessel with distant rings; VEDH: vessel elements with double helix; DHDE: double helix detached elements; AV: areoled vessel; PA: the two layers of the parenchyme, at each side of the vessels unit.

Figure 27 shows EDX mapping of elements of the stem fragment C. Carbon and oxygen are regularly present in piece $\mathrm{C}$; sulphur is more plentiful in the hair than in the piece. 

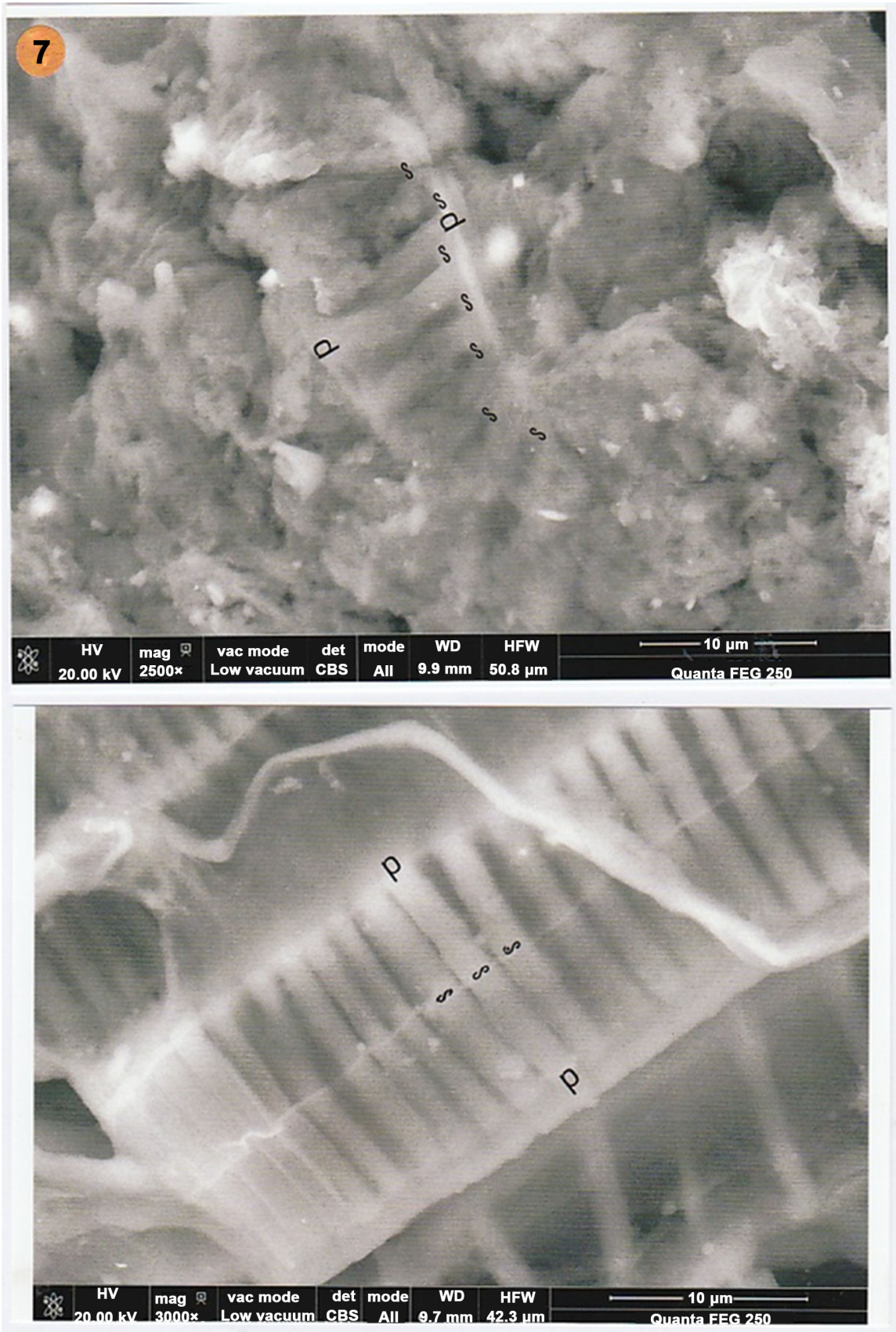

Figure 25. Comparison between a scalariform vessel of piece 7 to that of a today fennel stem. Above: SEM photograph (in CBS, 2500×) of the scalariform vessel of piece 7 (s: scales; p: the two walls of the vessel). Below: SEM photograph (in CBS, 3000x) of a scalariform vessel of a today fennel stem (s: scales; p: the two walls of the vessel).

Chlorine, sodium and aluminium are spread out regularly in the piece, but at low signal' level. Contrary to, calcium and silicium show packty distributions due to the presence of the corresponding mineral particles of calcium carbonate on the one hand and of silica and of amino-silicates on the other hand. Phosphorus and magnesium are particularly spread out in the central part of the piece. 

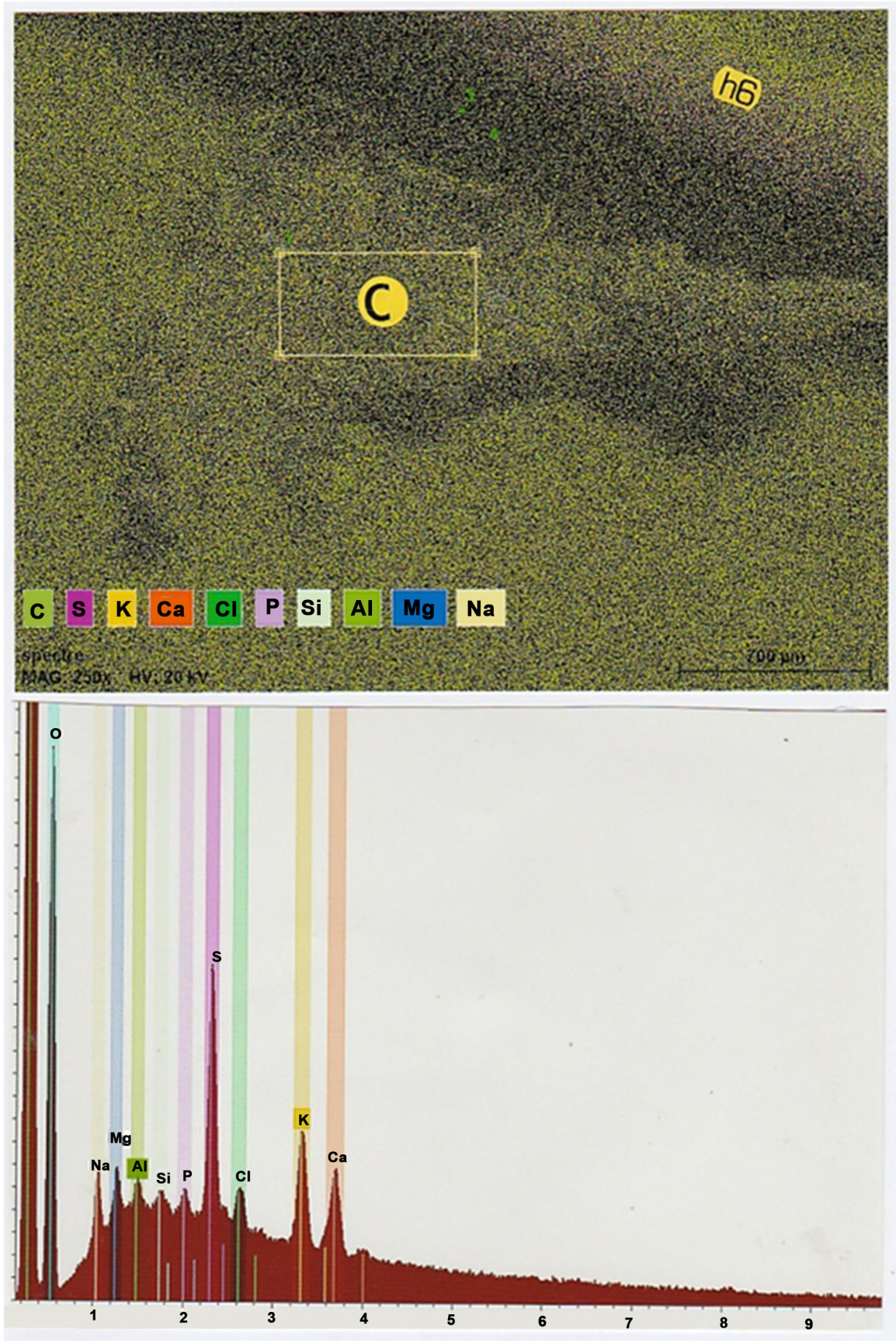

Figure 26. Map and general spectrum of structure C. Above: map of C (the general spectrum is taken in the rectangular area indicated); h6: the part of hair number 6. The coloured code of each element is indicated in the lower part of this map. Below: general spectrum of $\mathrm{C}$ (the upper limit of the lower red area indicates the background noise).

\subsubsection{Exploration of the Central Part of Piece C}

Figure 28 shows this central part of piece $\mathrm{C}$, enlarged on the below photograph. Twelve particles (numbered 1 to 12), of relatively great sizes, are shown in the enlarged photograph.

Figure 29 shows spectras of some of them. Particles numbered as 1, 3, 5 and 6 have a typical spectrum of vegetable; they are vegetable debris. 
Table 2. Normalized composition of elements in the general spectrum of Figure 26 (measured by rays of the K-serie).

\begin{tabular}{ccc}
\hline Elements & Atomic numbers & Normalized mass (\%) \\
\hline Sulphur & 16 & 24.33 \\
Potassium & 19 & 17.49 \\
Calcium & 20 & 16.51 \\
Sodium & 11 & 15.52 \\
Magnesium & 12 & 10.15 \\
Aluminium & 13 & 6.89 \\
Chlorine & 17 & 3.64 \\
Silicium & 14 & 3.19 \\
Phosphorus & 15 & 2.28 \\
\hline
\end{tabular}
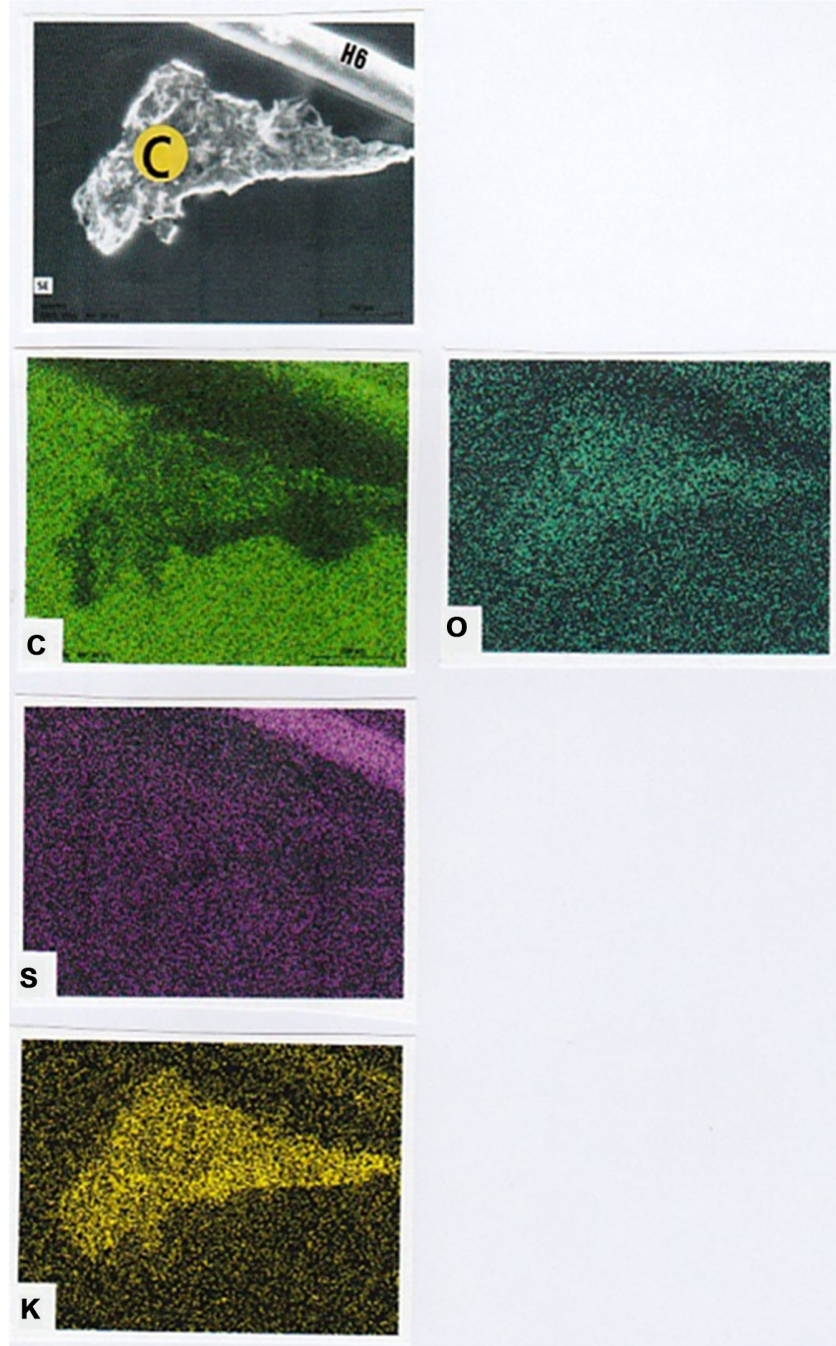

(a)
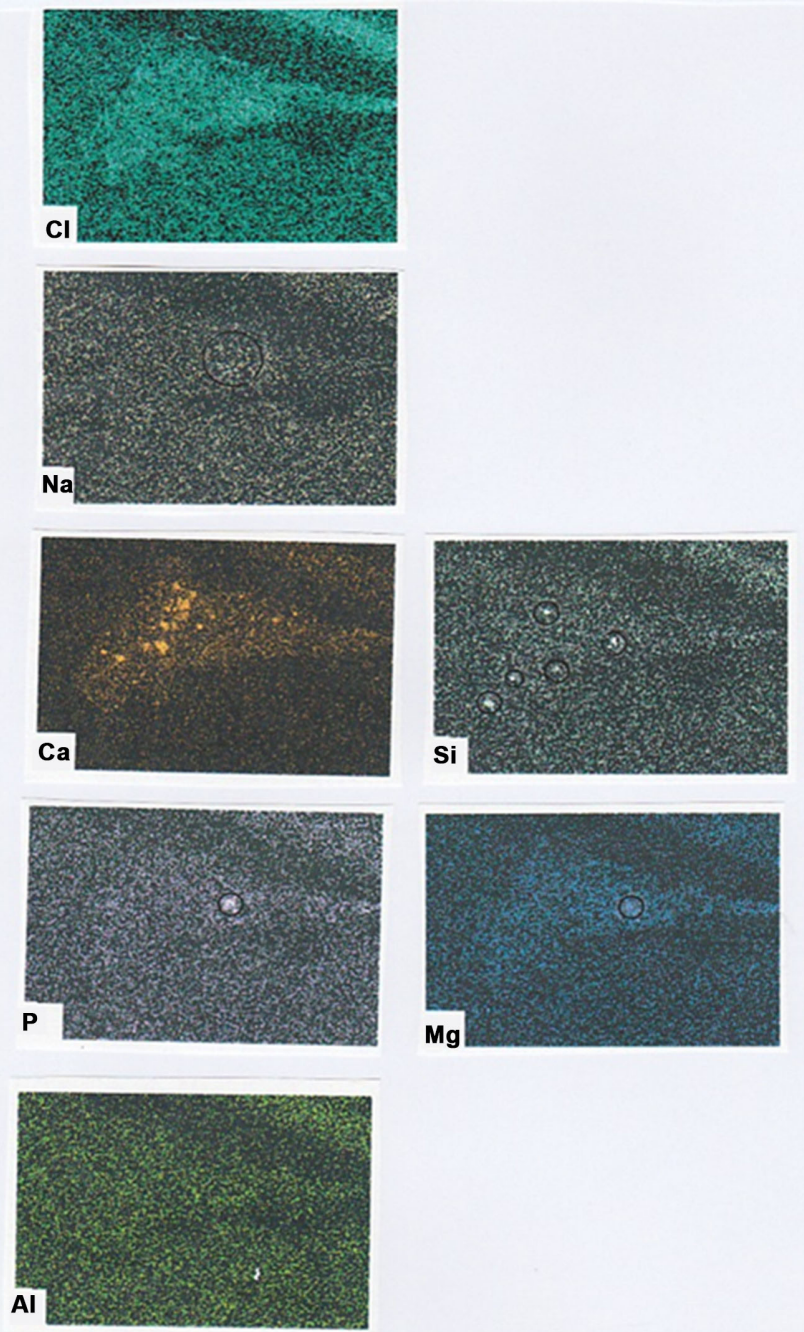

(b)

Figure 27. Mapping of structure C. First row: general map of structure C (h6: hair number 6). Second row: C, carbon mapping, O oxygen mapping. Third row: S, sulphur mapping. Fourth row: K, potassium mapping. Fifth row: $\mathrm{Cl}$, chlorine mapping. Sixth row: $\mathrm{Na}$, sodium mapping. Seventh row: Ca, calcium mapping. Eight row: $\mathrm{P}$, phosphorous mapping, Mg, magnesium mapping. Ninth row: Al, aluminium mapping. 

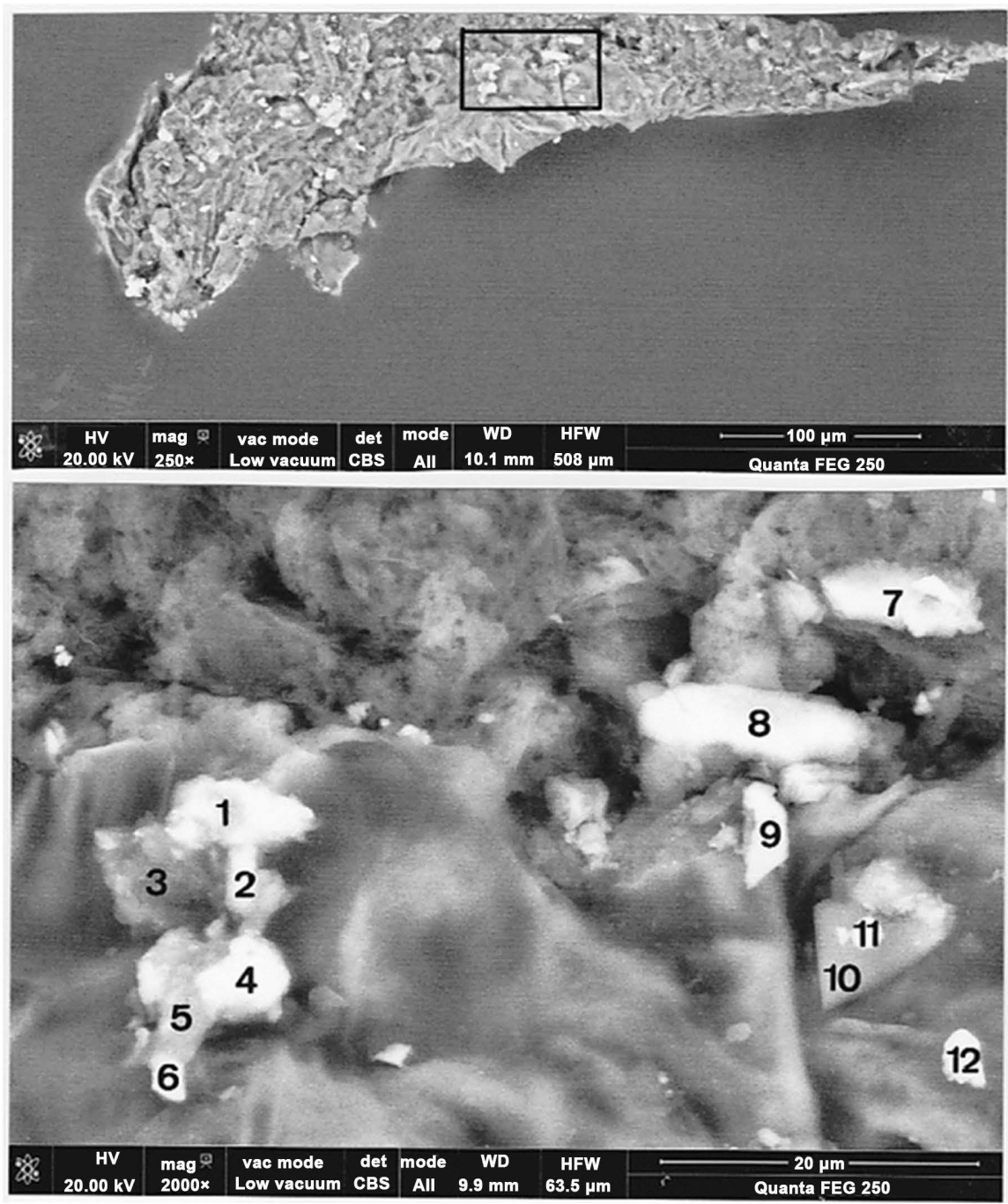

Figure 28. Photographs of the central part of structure C. Above: partial SEM photograph (in CBS, 250 $\times$ ) of $\mathrm{C}$ (the area in the rectangle is enlarged in the below photograph. Below: SEM photograph (in CBS, 2000x) of the enlarged rectangular area. Particles studied are numbered 1 to 12 .

Particles numbered as $7,8,9,10$ and 11 have a spectrum where the oxygen peak is relatively elevated. Among the smaller peaks, those of magnesium phosphate $\mathrm{Mg}\left(\mathrm{H}_{2} \mathrm{PO}_{4}\right)$ 2. All the particles numbered as 7, 8, 9 and 10 (Figure 30) are of magnesium phosphate; but the little particle number 11 is a calcite, stacked on the magnesium phosphate particle number 10.

Figure 31 concerns spectras of other particles shown in the below photograph of Figure 28. Particle number 2 is another silica; particle number 4 is another clay mineral of the montmorillonite/illite type, relatively iron-rich.

Particle number 12 is a potassium chloride (in fact a chloride double of potassium and magnesium): a marine salt $(\mathrm{KCl})$. Some other particles of such type are found elsewhere on the sticky-paper; for example, Supplementary Figure 7 shows two potassium chloride crystals located at the external border of some part of hair number 1 . 


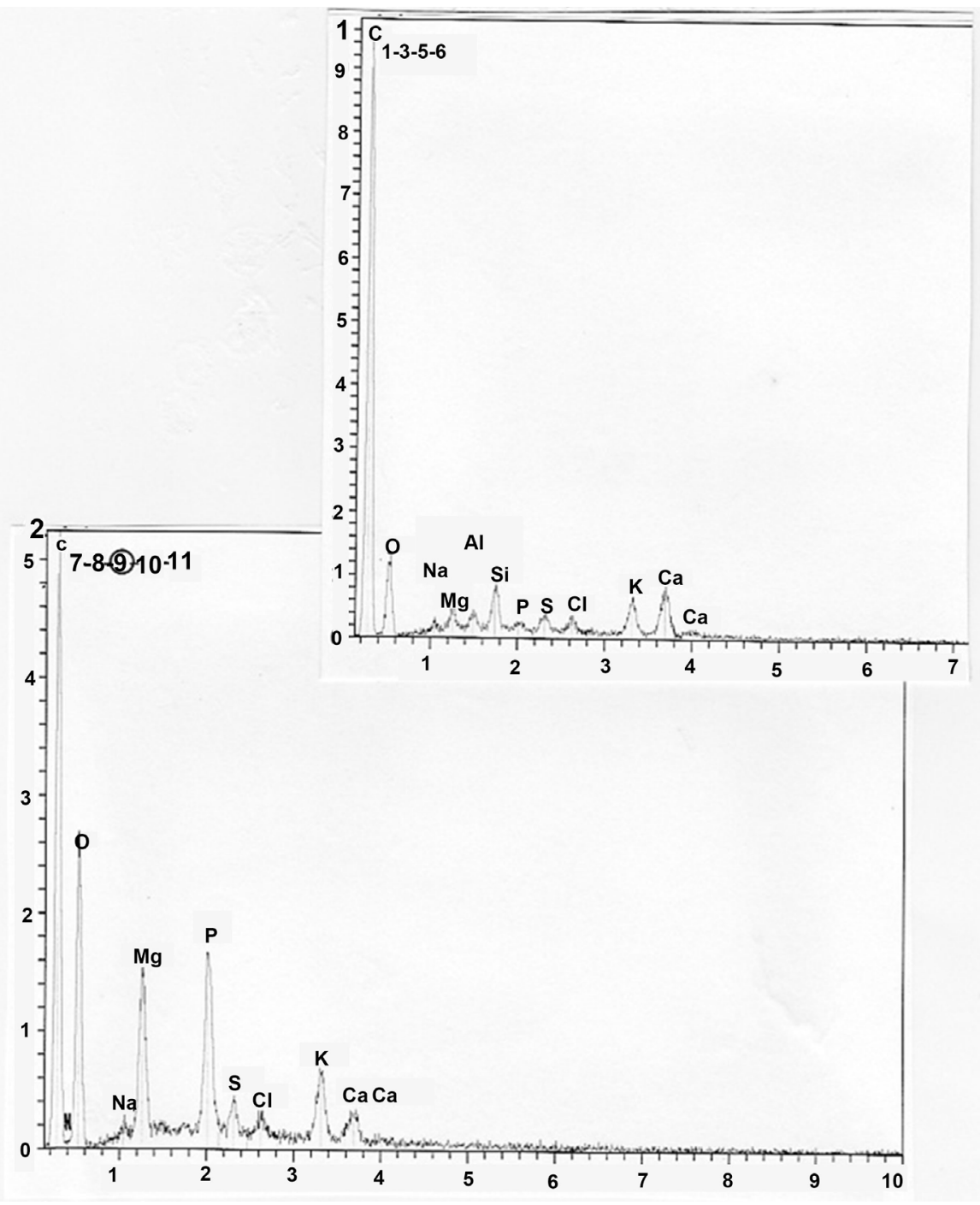

Figure 29. Spectras of some particles located inside of the rectangle of Figure 28. 1: spectrum in common to particle numbers 1, 3, 5 and 6.2: spectrum (in fact of particle number 9) in common to particle numbers $7,8,9,10$ and 11 . The position of the $\mathrm{N}$ (nitrogen) peak, located between those of carbon and oxygen, is given (in the below spectrum) as indicative.

Table 3 summarizes compositions of the twelve particles studied.

\section{Discussion}

We have found numerous fennel rests (pollen grains, leaf and stem debris) at the vicinity of some studied Marie-Madeleine's hairs. That confirms some wordings concerning the Ste Marie-Madeleine's discovery on 19 of December 1279.

But this "extraordinary fragrance" reported by Bernard Gui (that of the fennel smell) do not correspond to the usual notion of "odour of sanctity": the odour of sanctity (Yerby, 1969) - that appears to have emerged in the Middle Ages-according to the Catholic Church, is commonly understood to mean a specific 


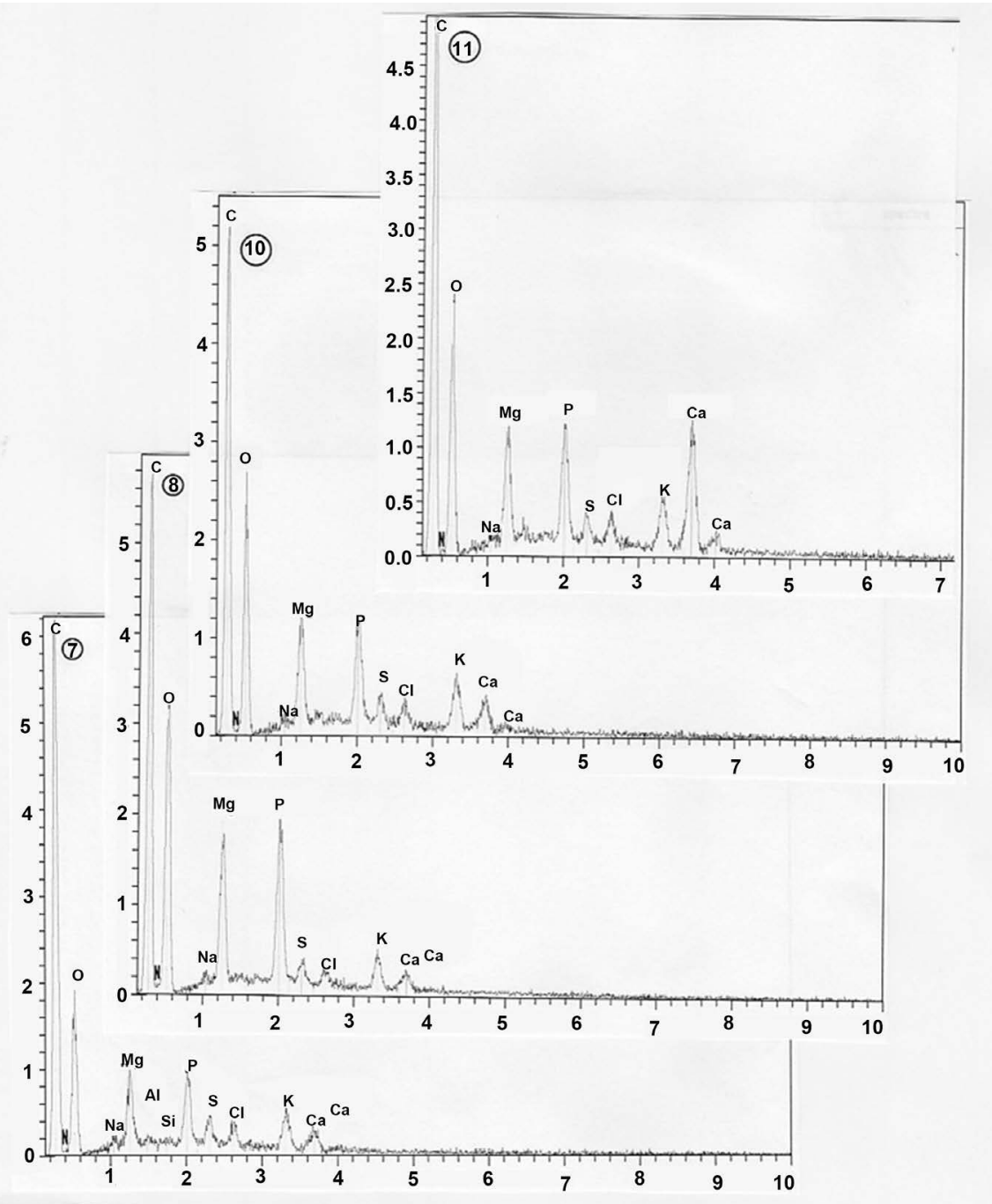

Figure 30. Spectras, from bottom to high, of particles numbers 7, 8, 10 and 11.

scent that emanates from the bodies of saints. This odour of sanctity (a religious term) is a concept occurring at the person's death that carried some weight in convincing the local ecclesiastic authority to "canonize" the saint (at that time, many saints were raised to that status by acclamation of faithful). There are many known examples of saintly men and women who have emitted agreeable fragrances having a strong odour of flowers during a very prayful time; but these flower odours were usually those of the rose and the violet, not of the fennel.

Another important point of the Bernard Gui story that must be taken in consideration is that the "green fennel twig" (ramusculo funiculi) come out of the mouth (the tongue being even attached to the osseous palate). Such a singularity must be simply explained if we admit that some fennel seeds (also sweet-smelling), that have grown further, have been implanted at the interior of the mouth of the corpse.

The different steps of the Marie-Madeleine's exhumation process are precisely described (Trouillet, 2016). In fact, if the date of the 19 of December 1279 is well 


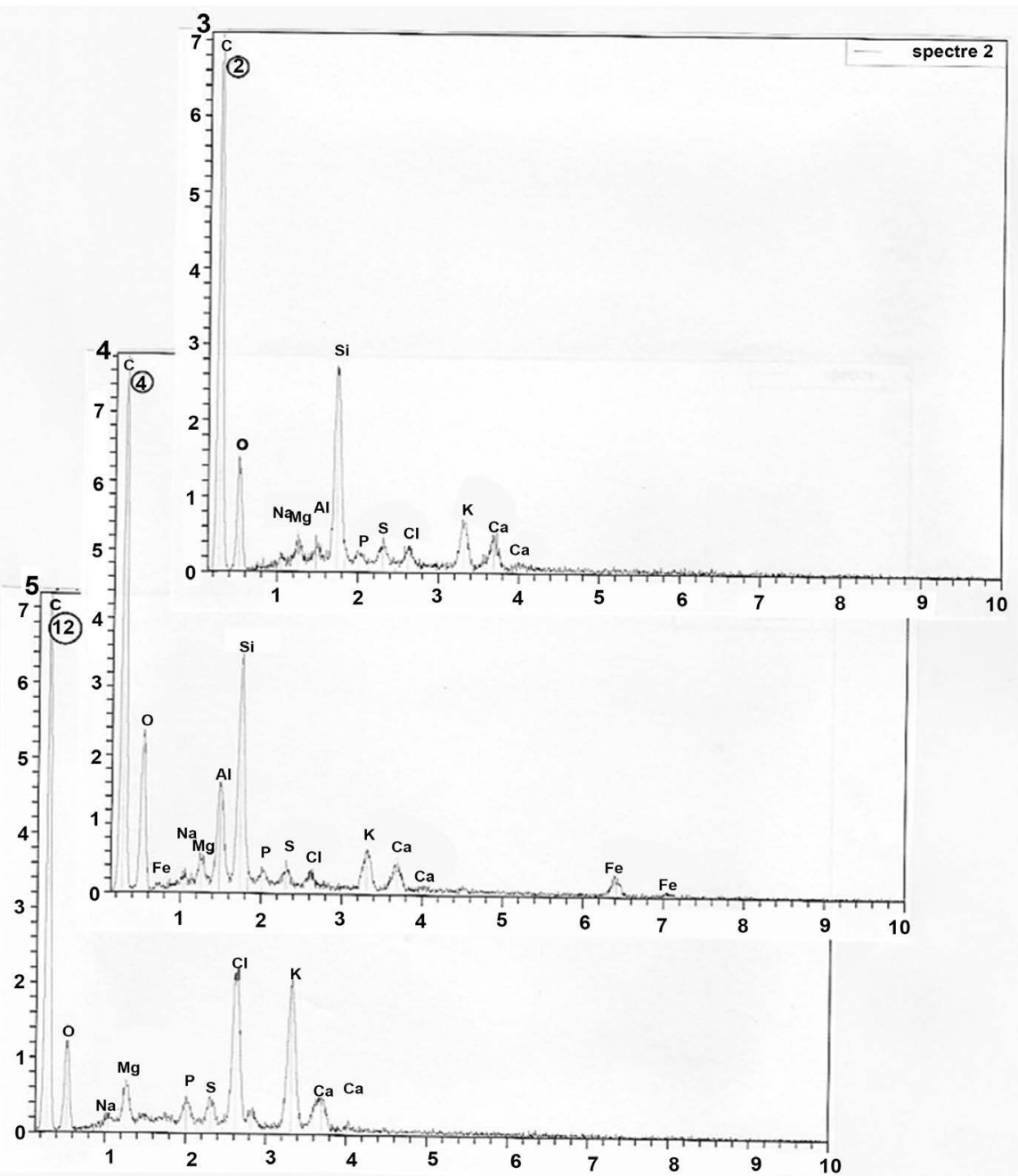

Figure 31. Other spectras of some particles located inside of the rectangle of Figure 28. 3: spectrum of particle number 2. 4: spectrum of particle number 4. 5: spectrum of particle number 12 .

Table 3. Compositions of the twelve particles found inside of the rectangular area of photographs of Figure 28.

\begin{tabular}{cc}
\hline Particle numbers & Compositions \\
\hline 1 & vegetal debris \\
2 & silica \\
3 & vegetal debris \\
4 & montmorillonite/illite \\
5 & vegetal debris \\
6 & vegetal debris \\
7 & magnesium phosphate \\
8 & magnesium phosphate \\
9 & magnesium phosphate \\
10 & magnesium phosphate \\
11 & calcite \\
12 & potassium chloride \\
\hline
\end{tabular}


that of the exhumation of the Marie-Madeleine's body, it was preceded by a first step(on 9 of December) of the "invention" (inventio): Charles-Prince of Salerneand his farm workers founded the Marie-Madeleine sarcophagus, opened her cover, and contemplated the Marie-Madeleine's rests (Franzoni, 2016); on the same day, Charles shut again the sarcophagus cover and appened seals on it. After that the second step (on 18 of December) was that of the "elevation" (elevatio): archbishops and bishops of Provence were convened by the Prince; the sarcophagus was open again, and they certified (it is the canonic verification of the contain) the rests: the entire body but the mandible and one leg; hairs surrounded the cranium.

The "ceremonial exhumation" (revelatio) of Marie-Madeleine's body was on the 5 of May 1280, at Saint-Maximin, in front of a considerable crowd (Franzoni, 2016). The ceremony was given around the little oratory of Saint Maximin, where the relics were found. To be noted is that-in his process-the Prince of Salerne scrupulously followed the successive steps of the previous relic inventions (Gronnier, 2015).

Who and what determines Charles of Salerne to search for Marie-Madeleine's body at that place (in this oratory)? By a sort of "divine inspiration" (inspiratione divina), or because that "in a dream, Marie-Madeleine herself had declared to him that her body was buried in a field, near the Villata church, where a green plant fennel indicated the place"? As reported by Trouillet, the prince was very much involved-both in time and money-(cum magnis laboribus et expensis) in the discovery of these relics: he went to Aix for consultation of historical books and annals, and questioned ancients about local traditions concerning that subject.

Charles's father, as the King Louis IX (Saint-Louis), married to Béatrice, one of the four daughters of the Count of Provence. She was probably influenced by her son Charles (who became Charles II of Anjou) in his engagement to the Provencal origin of Marie-Madeleine; at that time, it existed another possible location of Marie-Madeleine's body in Vézelay (in Burgundy). Among another source, it is King Louis IX himself, sometime after one of his pilgrimage to La-Sainte-Baume, that put in charge his nephew Charles to find Marie-Madeleine's relics in Provence.

We have already signalled the considerable importance taken by the olfactory fennel fragrance at the early stage of the inventio. Some confusion has been maintained later on this subject, between this particular fragrance and that of the previous perfume (the "nard") which Maria-Magdalena covered feet and/or Jésus' head (Matthew: 26, 6-13; Mark: 14, 3-9; Johan: 12, 1-8).

But the fennel plant itself intervenes in the inventio; we have already given the Bernard Gui 'description of the fennel green ramus that extruded from the mouth of the Marie-Madeleine rests. According to some sources (Franzoni, 2016), that have guided the prince in the relic discovery.

So, the fennel is very tightly associated to the Marie-Madeleine of the Provence tradition. Consequently symbolism of fennel 
(http://www.dictionnairedessymboles.fr/article-le-symbolisme-du-fenouil-53869 699.html) is a Ste Marie-Madeleine's attribute. Today in Marseilles, in the crypt of Saint-Victor (Notre-Dame-de-la-Confession), is again given the religion of "Notre-Dame-du-Fenouil", named at the origin as

"Notre-Dame-du-Feu-Nouveau" (that was contracted in provencal language as "feu mou", that means new fire).

Fennel (Foeniculum vulgare) is native to southern Europe and the Mediterranean area. The name comes from the Greek word for marathon, because of the famous battle at Marathon (490 B.C.) against the Persians was fought on a field of fennel. Foeniculum is a roman name, from the latin word foenum ("hay"), that was corrupted to fanculum in the Middle Ages.

Fennel was well known to the Ancients, and was cultivated by the ancient Romans for its aromatic fruits and succulent edible shoots. Pliny had much faith in its medicinal properties, according no less than twenty-two remedies to it.

Fennel perennial herb is a native to the Meditteranean region. It is now widely cultivated as an annual, biannual or perennial in various European countries (Muckensturm et al., 1997): in Bulgaria, Romania, Hungary, Greece, Italy and France.

What we know about the story of fennel in West Europe, and particularly in France, is a follows:

Wild fennel was a common aromatic herb in Provence, where it grows everywhere.

The growing of fennel became more common in West Europe after Charlemagne (capitulare of Willis, end of the VIIIth Century) enjoined its growing on imperial farms.

Fennel cultivation began to develop in the south of Italy in the XVIth Century. The Florence (the bulbous form) fennel variety was introduced in France by Catherine de Médicis (1519-1589), by seed exchanges between Italian and Provencal gardeners.

At the early times of the Middle Age in France, fennel was cultivated mainly because of its medicinal properties. It was (with other medicinal plants and herbs) cultivated in reserved gardens (named now "medieval gardens"), that were always in relationship to monasteries, abbeys and priories. We know that, since the beginning, these monastic gardens were cultivated by religious (mainly those monastic communities belonging to the order of Benedictines); their gardens supplied by herbs which were considered to be so precious for the treatment of various human ills. Fennel particularly, were credited with the power to soothe stomach problems, improve eyesight and cure rheumatism.

As shown in the present study, many fennel pollen grains were found: that proves that it was at least one cycle of annual reproduction for the corresponding plant. Observations about epiderm alterations of the studied stem fragment seems to indicate some perennial herb. Probably because of the time when it was dated, the fennel involved belonged to some wild ancient variety. 
But, more surprising, we have found that the tissue fennel debris we have studied correspond to those of plants that were cultivated and processed.

Table 4 gives the characterizations of the fourteen mineral and chemical particles we found on the tissue debris surface. Among the seven first lime and clay minerals could correspond to those of a fertile ground.

At the Middle Age period, farmers only had a rudimentary knowledge of fertilizers; but some farmers did have methods for fertilizing their soil (http://www.thefinertimes.com/Middle-Ages/farming-in-themiddle-ages.html). A common fertilization technique for farming at the times was called marling: for marling farmers spread clay containing lime carbonate onto their soil; this process restored the nutriments needed to grow crops.

Fennel, in its natural habitat, prefers sunny and clayey grounds. A special fennel demand that modern days fennel cultivation establishes (Polese, 2006) is it needs lime (that increases the $\mathrm{pH}$ of the soil) for its development; probably the lime particles observed testify of this empirical knowledge at this period.

More surprising is the discovery of two potassium sulphate (both in pieces 1 and 2 in B) and of five magnesium phosphate (all on the structure in C) particles on the fennel debris surface.

They look like, for the two first, to those of modern fertilizers named as potassium sulphate (obtained by the action of sulphuric acid $\mathrm{H}_{2} \mathrm{SO}_{4}$ on $\mathrm{KCl}$ ) and-to a lesser degree-as sulphate double of potassium and magnesium. In fact potassium sulphate is, although rare enough, a natural mineral product (arcanite). It is known since the Antiquity and before, and had received very numerous names. We are informed that it was produced commonly, at least since 1300 (alchemists used it for various purposes: in technical chemistry-in lapidary-therapy, dying, and even in symbolic astrology).

The relatively great size and irregular forms of the potassium sulphate deposits (in fact a mixture between potassium sulphate and calcium carbonate) on hair number 1 (see supplementary Figure 4 ) exclude that there were fine powder particles of such a today industrial product.

Table 4. Numbers of minerals and chemical formulaes of particles found on the fennel debris.

\begin{tabular}{ccc}
\hline Mineral products & Chemical formulaes & Numbers found \\
Lime & $\mathrm{CaO}$ & 1 \\
Calcite & $\mathrm{CaCO}_{3}$ & 1 \\
Clay minerals & montmorillonite & \\
Silica & illite ${ }^{(2)}:$ & 3 \\
Potassium sulfate & $\mathrm{SiO}_{2}$ & 2 \\
Magnesium phosphate & $\mathrm{K}_{2} \mathrm{SO}_{4}$ & 4 \\
Potassium chloride & $\mathrm{Mg}^{\left(\mathrm{H}_{2} \mathrm{PO}_{4}\right)_{2}}$ & 1 \\
\hline
\end{tabular}

${ }^{(1)}(\mathrm{Na}, \mathrm{Ca})_{0.3}(\mathrm{Al}, \mathrm{Mg}, \mathrm{Fe})_{2} \mathrm{Si}_{4} \mathrm{O}_{10}(\mathrm{OH})_{2} \cdot \mathrm{nH}_{2} \mathrm{O} ;{ }^{(2)}\left(\mathrm{K}, \mathrm{H}_{3} \mathrm{O}\right)(\mathrm{Al}, \mathrm{Mg}, \mathrm{Fe})_{2}(\mathrm{Si}, \mathrm{Al})_{4} \mathrm{O}_{10}\left[\left(\mathrm{OH}_{2}, \mathrm{H}_{2} \mathrm{O}\right)\right] \mathrm{SiO}_{2}$. 
Still more astonishing is the discovery of the four magnesium phosphate particles on the stem debris; it is only recently (Massey et al., 2009) that magnesium phosphate is produced as a fertilizer. Today, magnesium phosphate is an alimentary complement that is used for the treatment of low amounts of magnesium in the blood.

Magnesium phosphate is in fact a general term for salts of magnesium and phosphate; three forms exist: magnesium phosphate $\left(\mathrm{Mg}\left(\mathrm{H}_{2} \mathrm{PO}_{4}\right)_{2}\right)$ itself, and two other forms of dimagnesium phosphate $\left(\mathrm{Mg} \mathrm{HPO}_{4}\right)$ and magnesium phosphate tribasic $\left(\mathrm{Mg}_{3}\left(\mathrm{PO}_{4}\right)_{2}\right)$. The main magnesium phosphate organic form is struvite $\left(\mathrm{NH}_{4} \mathrm{MgPO}_{4} \cdot 6 \mathrm{H}_{2} \mathrm{O}\right)$, discovered in 1845 by the chemist $\mathrm{G}$. Ulex in medieval sewers of the Saint Nicolas church of Hamburg. Struvite is formed for some organic materials, as old dry dungs constituted of cow dung and horse manure or putrefied dejections.

The mineral form (other term: struveite) of struvite (https://www.mindat.org/min-3811.html) is currently studied (Talboys et al., 2016) in the aim to determine whether it could be a component of a sustainable phosphate fertiliser management strategy for arable crops. Struvite is one of the crystalline mineral (named as guanite) found in guano. In humans, struvite participates to the formation of calculus by precipitating an alkaline urine (https://colique-nephretique.fr/calcul-renal-calcul-de-struvite); the formation of struvite calculus is favoured in some bacterial infections (notably by Proteus, Pseudomonas, Klebsiella, Staphylococcus, and Mycoplasma) that hydrolyse area in ammonia and raise the urine $\mathrm{pH}$ to neutral or alkaline values. In the veterinary domain, struvite calculus are intensively studied for the horse http://www.ncbi.nlm.nih.gov/pubmed/725146), the dog http://www.shilohshepherds.info/geneticTaskForce/Uroliths.htm) and the cat (http://www.cliniqueveterinairedegranby.com/les-struvites-chez-le-chat).

The crystal system of struvite is orthorhombic . The crystals, of relatively great sizes in some cases, are colourless, white (when dehydrated), yellow or brownish, or light grey; the various crystal forms are: equant, wedge-shaped, coffin-shaped (when viewed along), short prismatic or thick tabular. Table 5 gives sizes and forms of the four struvite crystals (see the lower photograph of Figure 28) observed on the surface of the stem debris.

Their spectras (see Figure 29 and Figure 30) show two peaks of the same heights for magnesium and phosphorous (it is the equimolarity that indicates magnesium phosphate as the corresponding product). A purified struvite of reference have a very similar spectrum (Suguna et al., 2012). The quasi-absence of nitrogen in our struvite spectras (as well as its presence at a low level in the struvite sample of reference) can be explained by technical problems: briefly, the EDX analyses we practised cannot resolve levels-even elevated-of nitrogen (the detection system used gives a bad response, in general, for light elementsthose of atomic numbers $<10$ )-because there is a protection film of polymers around the crystal analyser). Another interesting possibility to explain the 
Table 5. Forms and sizes of the struvite crystals located on structure C (crystal numbers as for those on Figure 28).

\begin{tabular}{ccc}
\hline Crystal numbers & Forms & Dimensions (in $\mu \mathrm{m})$ \\
\hline $\mathbf{7}$ & short prismatic & 10 on 3 \\
$\mathbf{8}$ & thick tabular & 16 on 3 \\
9 & short prismatic & 8 on 2 \\
10 & wedge-shaped & 10 on 7 \\
\hline
\end{tabular}

absence of nitrogen in the struvite spectras is that our samples could be in fact crystals of newberyite $\left(\mathrm{MgHPO}_{4} \cdot 3 \mathrm{H}_{2} \mathrm{O}\right)$, a tri-hydrated hydrogenophospahte of magnesium that is frequently associated to struvite. This crystalline component (also of orthorhombic form) seems rare in human kidney calculus; but it was found in caves, formed directly from bat guano (http://www.webmineral.com/data/Newberyite.shtml\#Woehf9QS_Gg). Despite the fact that technical problems are responsible for nitrogen detection at low levels, very probably the "struvite crystals" we observe are in fact those of newberyite particles.

The only fertilizer known for the Middle Age period was the dung. But this manure was rare at that period, because cows were not so numerous and malnourished; moreover the cattle was scattered in moors (the meadow did not exist at that time).

Pigeon dropping was the best fertilizer of the Middle Age period, hence reserved to needy soils. The main function of Middle Age pigeonniers

(http://pigeonniers-de-france.chez-alice.fr/) was the production of the "columbine" (pigeon feces), which was hightly sought after as a fertilizer for demanding crops in vineyards, vegetable gardens and orchards.

But there was not much of it, since it had be collected from under the pigeon coop. The constitution of stone coops were costly, which meant that they were seigneurial (or monasterial) constructions, their "fertilizers" went to the master's garden and orchard.

The potassium chloride-associated to magnesium-particle (found on the stem surface) is a mineral salt. This product is odourless and has a white or colourless vitreous crystal (of crystallographic cubic structure) appearance. Under its solid form, this neutral salt occurs naturally as the mineral named sylvite and in combination with sodium chloride as sylvinite. This solid dissolves rapidly in water, and its solutions have a salt-like taste ("sel amer").

Supplementary Figure 8 summarizes the study of a powder of a today commercial lighted salt product. Of the two sorts of its particles, those (the most numerous) that are rounded in forms are of potassium chloride; those that are with angular outlines are of sodium chloride $(\mathrm{NaCl})$.

In deserted maritime regions, or in sunny salt marshes, it is possible to extract potassium chloride from seawater. Potassium chloride obtained in this way is 
more or less (depending on the local composition of the sea water) mixed with magnesium chloride $\left(\mathrm{MgCl}_{2}\right)$, as for the particle analysed that we found on the stem surface. During the extraction process from the sea-water $\mathrm{KCl}$ and $\mathrm{MgCl}_{2}$ appears under the forms of brine and deliquescents salts, that precipitate after the halite $(\mathrm{NaCl})$.

Potassium chlorine is now used in medicine, lethal injections and scientific applications. The majority of the potassium chloride actually produced is used for making fertilizer, since the growth of many plants is limited by their potassium intake. In fertilizer chemistry

(http://www.fertilizer-machine.net/solution_and_market/types-of-fertilizer.html) the generic term of potash includes, wineshim potassium chlorite (sylvite), the chloride double of potassium and magnesium (named carnallite, for its hydrated form), the sulphate double of potassium and magnesium, the potassium sulphate $\mathrm{K}_{2} \mathrm{SO}_{4}$ already cited (obtained by the action of sulphuric acid on $\mathrm{KCl}$ ), the potassium nitrate $\left(\mathrm{KNO}_{3}\right)$ and the hydroxide of potassium $(\mathrm{KOH})$.

There are documented evidence (Venturini, 2006) of salt production in the Middle Age in the South of France. All the coastal line since the Roussillon region to that of Var mouth have favourable conditions (high salinity of the Mediterranean sea water, intense evaporation favoured by both sun and wind, presence in these areas of little-deap ponds near the sea) to salt working. The central region of this coast (corresponding to the Rhone delta) contains, mainly in Camargue, the most active centers of marine salt production ("salines"), particularly around the little town of Aigues-Mortes. Salt production and exploitation were here under the control of abbeys, and we have numerous written accountable documents attesting that (dating at least since the Xth Century).

Brine can be obtained, notably from sea-water. How and why this corresponding new technology was introduced remains a mystery, through it appears the technique possibly spread from southwest France (Lemonnier, 1980). We know that natural brines always contain other substances dissolved along with salt, notably potassium chloride (the most other common of these substances are magnesium chloride, magnesium sulphate, calcium sulphate, magnesium bromide and calcium carbonate). These substances of brines may be as commercially valuable at the salt itself.

Immersing fresh vegetables and other foods in a liquid solution of salt brine was a common practice in Medieval Europe. For example, the simplest pickling was done with water, salt and herb or two; a variety of spices and herbs as well as the use of vinegar, verjuice or (after the XII th Century) lemon led to range of pickling flavours

(https://www.thoughtco.com/medieval-food-preservation-1788842). Pickling might require boiling the food in the salt mixture, but it could also be done by simply leaving the food items in an open pot, tub or vat of salt brine with the desired flavourings for hours and sometimes days.

We have no firm evidence that brine was used as fertilizer in the Middle Age. Today potassium chloride $(\mathrm{KCl})$ is the more commonly used potassium $(\mathrm{K})$ fer- 
tilizer (http://www.cropnutrition.com/potassium-chloride), because it includes more $\mathrm{K}$ than other sources ( 50 to 52 percent $\mathrm{K}, 60$ to 63 per cent $\mathrm{K}_{2} \mathrm{O}$ (potash) and 45 to 47 per cent $\mathrm{Cl}^{-}$). There are regions where plants respond favourably to application of $\mathrm{Cl}^{-}$, and potassium chloride is usually the preferred material to meet this need. There are no significant impacts on water or air associated with normal application rates of potassium chloride (elevated salt concentrations surrounding the dissolving fertilizer may be the most important factor to consider).

Antiseptic properties of salt were known since the Antiquity. The importance of salt within earlier economies (like that of the Middle Age period) can hardly be overstated; it was in fact essential for the maintenance of life, and also for commerce (HistoricEngland.org.uk/advice). In addition to preserving food (most notably fish, but also meat and some vegetables), salt plays an essential role in bread-making and in the manufacture of butter and cheese.

Concerning the studied present case, very probably the fennel was processed by salt. We know (Kaur \& Arora, 2009) that Foeniculum vulgare controls numerous infectious disorders of viral, bacterial, fungal, mycobacterium and protozoal origin. Figure 22 shows that at least two ascomycetes species contaminate the fennel plant studied.

Table 6 summarizes that we know concerning the three "fertilizers" (potassium sulphate, newberyite and potassium chloride) that were going on and we found on fennel debris; this term of fertilizer (in fact "pre-fertilizer") used here means that they looked like most modern manufacture fertilizers. The potassium chloride that was used certainly was a by-product of seawater brine. But it is only relatively recently that was found that newberyite is the main constitute of guano (and probably that of pigeon dropping). Concerning now the potassium sulphate used, its utilization at that times necessitates solid knowledge in alchemy.

As already signalled both columbine and seawater brine productions weresince the beginning of the Middle Age-under the control of lords or abbeys respectively.

After the Benedictines, several monastic orders-notably the Cistercians (an order founded in 1100 in Citeaux) and the Chartreux (founded in the XIIth Century by Bruno de Cologne, canon of Reims) continued to do the Saint-Benoït rule concerning monastic gardens and orchards (Fuhrmann, 1990). At that time, monasteries took great care of aromatic plants involved in medieval pharmacy (like mint, rosemary, sage, anise and fennel).

We know (Franzoni, 2016) that, soon after their discovery by Charles in 1279, the Marie-Madeleine relics were untrusted to Benedictines. Since the XIV th Century Dominicans replaced Benedictines, and they are here until now.

The main work on agriculture at that times was Ruralium commodorum opus, written between 1304 and 1306 by Petro di Crescenzi (1233-1320, Bologna), an Italian magistrate and agronomist of the University of Bologna (Italy). His book, that resulted from long personal practice (he cultivated his own estate, located at St Nicolas, a little village located near his birthplace), was mainly 
Table 6. Compositions and possible origins of three fertlizers found on the fennel debris.

\begin{tabular}{cccc}
\hline Products & Chemical formulaes & Dominant elements & Origins \\
\hline Potassium sulfate & $\mathrm{K}_{2} \mathrm{SO}_{4}$ & $\mathrm{~S}$ & $\begin{array}{c}\text { a product of medieval } \\
\text { alchemistry }\end{array}$ \\
Newberyite & $\mathrm{MgHPO}_{4} \cdot 3 \mathrm{H}_{2} \mathrm{O}$ & $\mathrm{P}$ & from pigeon droppings \\
$\begin{array}{c}\text { Potassium chloride (in } \\
\text { fact, a mixture with } \\
\text { magnesium chloride) }\end{array}$ & $\mathrm{KCl}$ & $\mathrm{K}$ & from seawater brines \\
\hline
\end{tabular}

centred on Mediterranean agriculture. This treatise was authoritative during all the three following centuries.

However, contents of the di Crescenzi treatise were based mainly on Greek (Plato, Aristotle, Theophrastus...) and early Roman (Varro, Pliny, Columella...) writings. He added some personal observations and teachings of the Dominican monastery of Bologna. As a consequence, soil fertility and soil amendments practices remained much the same as in the days of the Greeks and Romans, relying principally upon animal manures (notably pigeon manure) and human urine and excreta (lisier), vegetable refuses (manure), wastes from oil press, dregs from wine production, sea products (notably brine), seaweed fish in costal areas, bones and inorganic substances such as ashes, marl and lime kiln.

Historically the term "fertilizer" was modified starting the early 1900's as "chemical manure", "artificial manure", "chemical fertilizers" to "mineral fertilizers" and "commercial fertilizers" (this last term defines the products that are sold through commercial channels with warranted concentration of plant nutrients and physical properties). Commercial fertilizers are mineral fertilizers, mineral-organic fertilizers, organic fertilizers and also special fertilizers applied to foliar fertilization or horticulture.

The usual sources of fertilizer primary nutrients are, for potassium compounds, potassium chloride and potassium sulphate (and also potassium nitrate and potassium phosphate).

The modern era of fertilizers began with Justus von Liebig theory published in 1840 in "Organic Chemistry and its Application to Agriculture and Physiology". The modern definition of fertilizers (Gorecki, 2010) is as follows: fertilizers are materials which supply to plant nutrients and improve soil fertility. Most fertilizers are straight, mixed, or compound products applied as solids (mainly as granules) or liquids (in the form of clear or suspension solutions). These products contain primary (which are required by plants in large amounts) nutrients such as $\mathrm{N}$ (nitrogen), $\mathrm{P}$ (phosphorous) and $\mathrm{K}$ (potassium), secondary nutrients (which are need in smaller but still appreciable quantities) such as Ca (calcium), $\mathrm{Mg}$ (magnesium) and S (sulphur) and micronutrients. The main fertilizer products (other than nitrogen fertilizers) include phosphate fertilizers (such as single and triple superphosphates) and potassium fertilizers (potassium chloride and sulphate). All phosphate fertilizers are derived from phosphate rocks (phosphorites and apatites) and potassium fertilizers from deposits of potassium chloride 
or from marine brines.

Table 7 summarizes the numbers of particles of each class of pre-fertilizers (in large acceptance) we have found on fennel samples studied.

We have verified that the five locations of the elemental map of the stem (see Figure 27, seventh row, second position) of elevated densities in silicium correspond well to clay mineral particles of montmorillonite or illite (most of them are mixed with calcite particles).

We have also verified that all the numerous locations at the left part of the stem (see Figure 27, seventh row, first position) of elevated densities in calcium correspond well to particles of lime (calcium carbonate particles with an elevated peak of calcium). Numerous of them have forms of cubic crystals.

The four particles (numbers 1, 3, 5 and 6) of fennel debris seen on the lower photograph of Figure 28 are more surprising: they are dessicated parts of fine powder of fennel plant, in accordance with compositions (upper spectrum of Figure 29).

We interpret those as some traces of a naive attempt from farmers to stimulate the corresponding plant growth (by projection of such a fine powder on the plant surface, they think that its favour and accelerate the development of the fennel under cultivation).

The newberyite particles found are detected only in stem elemental zone where phosphorous and magnesium are simultaneously present (see Figure 27, eighth row).

Detection on the elemental map of particles of potassium sulfate $\left(\mathrm{K}_{2} \mathrm{SO}_{4}\right)$ and potassium chloride $(\mathrm{KCl})$, other than those already described, is impossible because that the potassium element is uniformly spread out on the stem (see Figure 27, fourth row).

But it is amazing that we do not find salt $(\mathrm{ClNa})$ particles on the stem surface. To find some of them, we explored stem regions where there are some concentrations of chlorine (see Figure 27, fifth row) or of sodium (see Figure 27, sixth row) on the corresponding elemental maps. Supplementary Figure 9 shows an enlarged view of such stem region where there is an apparent concentration of chlorine; the corresponding spectrum indicates some little peaks of sodium and

Table 7. Numbers of pre-fertilizer particles found on the surfaces of fennel samples.

\begin{tabular}{ccc}
\hline Class numbers & Pre-fertilizers & Numbers of particles found \\
\hline 1 & clay & 2 \\
2 & lime & 1 \\
3 & fennel debris & 4 \\
4 & potassium sulphate & 2 \\
5 & newberyite & 4 \\
6 & potassium chloride & 1 \\
7 & salt (ClNa) & 0 \\
\hline
\end{tabular}


chlorine, but all the particles observed in this area are of calcium carbonate (Supplementary Figure 10).

Supplementary Figure 11 shows an enlarged view of another stem region where there is an apparent concentration of sodium. The corresponding spectras of two sub-areas of this region indicate both also some little peaks of sodium and of chlorine; but all the particles (even those of cubic forms) observed in these two sub-areas are in fact calcite particles (Supplementary Figure 12).

The necessarily deduction of this research concerning salt particles is that, in the areas explored, $\mathrm{ClNa}$ is present in the dissolved form only. In these areas the stem is locally soaked by sea-water.

So, there is some evidence that the fennel plant associated with Marie-Madeleine hairs were specially cultivated (clay, lime, pre-fertilizers...) and processed (salts). In these conditions the plant-which was of the wild type variety-had some vigour; it can easily be taller than one metre, as the cultivated wild variety today.

Initial cultivators of this fennel plant were certainly the Cassianites (who were active between 415 and 1079), a religious Order founded by St Jean Cassien. Cassien was native of Provence (he was born in Cytharista, today Cyreste near La Ciotat) circa 365. He returned to Marseilles in 410, where he urged to spread the monastic ideal of the "Pères du Désert" (beside he lived during a long period) and created at this date the Saint-Victor abbey; it is here that he founded the monastic Cassianite Order, a group of contemplative monks who were settled at many places around Marseilles. He came in 415 to La Sainte-Baume where he installed several of his monks (initially in a simple praying place and then in a monastery), establishing permanent Catholic cult devoted to Marie-Madeleine (they know that she had spent here the last part of her life). At the same year Cassien created a similar "prieuré" in Castrum Rhodanas (today Saint-Maximin), where several burial places-notably that of Marie-Madeleinewere already particularly venerated.

\section{Conclusion}

Some fennel rests (numerous pollens, one stem and three leaf fragments) are kept at the vicinity or on the Marie-Madeleine's hairs studied. They correspond to fennel debris of one fennel plant extruding from the Marie-Madeleine mouth that was signalled at the time (on December 1279) of the Marie-Madeleine exhumation by the Prince Charles, Count of Provence. So, the circumstances of the discovery of the Marie-Madeleine body (described previously only historically) are now scientifically established. Some of these fennel fragments-particularly that of the stem-were covered by minerals (clay and lime), pre-fertilizer products (magnesium phosphate and potassium sulphate) and marine salt (potassium chloride) particles. This indicates that the fennel plant was cultivated and processed (it was not an ordinary wild variety). Cassianites were very probably the cultivators of this plant. In these conditions of cultivation, the fennel plant 
attained one metre or more of height; it constituted so for Charles an easily point of reference to locate Marie-Madeleine's burial place.

\section{Acknowledgements}

We thank the priest of the Saint-Maximin-la-Sainte-Baume, who furnished to us the Marie-Madeleine's hairs, and Jean-David Malnati for his continuous financial support.

\section{References}

Badgujar, S. B., Patel, U. V., \& Bandivdekar, A. H. (2014). Foeniculum vulgare Mill: A Review of Its Botany, Phytochemistry, Pharmacology, Contemporary Application and Toxicology. Biomed Research International. https://doi.org/10.1155/2014/842674

Badoc, A., Lamarti, A., Bourgeois, G., Carde, J. P., \& Deffieux, G. (1995). Hybridation Intraspécifique chez le Fenouil, Foeniculum vulgare Mill. Bulletin de la Société de Pharmacie de Bordeaux, 134, 107-126.

D’Avila, V. A., Aguiar-Menezes, E. L., Gonçalves-Esteves, V., Mendonça, C. B. F., Pereira, R. N., \& Santos, T. M. (2016). Morphological Characterization of Pollens from three Apiaceae Species and their Investigation by Twelve-Spotted Lady Beetle (Coleoptera: Coccinellidae). Brazilian Journal of Biology, 76, 796-803. https://doi.org/10.1590/1519-6984.07615

Ellis, R. P. (1979). A Procedure of Standardizing Comparative Leaf Anatomy in the Poacea. The Epidermis as Seen in Surface View. Bothalia, 12, 641-671. https://doi.org/10.4102/abc.v12i4.1441

Franzoni, A. (2016). Sainte Marie-Madeleine et les Saints de Provence dans la Tradition Provençale (Vol. 3 and 4). Plan d'Aups Sainte-Baume: ASTPS.

Fuhrmann, J. (1990). Les Différentes Sources, Caractéristiques et Fonctions des Jardins Monastiques au Moyen-Âge. In Vergers et Jardins dans l'Univers Médiéval (pp. 109-124). Presses Universitaires de Provence. https://doi.org/10.4000/books.pup.2975

Gorecki, H. (2010). Ammonia and Fertilizers. In Encyclopedia of Life Support Systems (EOLSS); United Kingdom Chemical Engineering and Chemical Process Technology, Vol. V.

Gronnier, E. (2015). Les Inventions de Reliques dans l'Empire Romain d'Orient (IVe-VIe s.). Thurnout: Brepols. https://doi.org/10.1484/M.HAG-EB.5.112073

Hesse, M., Halbritter, H., Zetter, R., Weber, M., Buchner, R., Frosch-Radivo, A., \& Ulrich, S. (2009). Pollen Terminology: An Illustrated Handbook. Wien, New York: Spinger.

Jones, G. D., \& Jones, S. D. (2001). The Use of Pollen and Its Implication for Entomology. Neotropical Entomology, 26, 341-350.

Kaur, G. J., \& Arora, D. S. (2009). Antibacterial and Phytochemical Screening of Anethum graveolens, Foeniculum vulgare and Trachyspermum ammi. BMC Complementary and Alternative Medicine, 9, Article 30. https://doi.org/10.1186/1472-6882-9-30

Lemonnier, P. (1980). Les Salines de l'Ouest: Logique Technique et Logique Sociale. Presses Universitaires de Lille.

Lucotte, G. (2016). The Mitochondrial DNA Mitotype of Sainte Marie-Madeleine. International Journal of Sciences, 5, 10-19. https://doi.org/10.18483/ijSci.1167

Lucotte, G., \& Thomasset, T. (2017). Study of the Red Colour of Ste Marie-Madeleine (3?-63?) Hair by Scanning Electron Microscopic Characterization of its Melanosomes. Journal of Dermatology and Pigmentation Research, 1, 108. 
Massey, M. M., Davis, J. G., Ippolito, R., \& Sheffield, R. (2009). Effectiveness of Recovered Magnesium Phosphates as Fertilizers in Neutral and Slightly Alcaline Soils. Agronomy Journal, 101, 323-329. https://doi.org/10.2134/agronj2008.0144

Muckensturm, B., Foechterlen, D., Reduron, J. P., Danton, P., \& Hildenbrand, M. (1997). Phytochemical and Chemotaxonomic Studies of Foeniculum vulgare. Biochemical Systematics and Ecology, 25, 353-358. https://doi.org/10.1016/S0305-1978(96)00106-8

Polese, J. M. (2006). La Culture des Plantes Aromatiques. Chamalières: Artemis.

Rodeva, R., \& Galber, J. (2011) Umbel Browning and Stem Necrosis: A New Disease of Fennel in Bulgaria. Journal of Phytopathology, 159, 184-187. https://doi.org/10.1111/j.1439-0434.2010.01728.x

Speranza, A., \& Galzoni, G.L. (1996). Atlas de la Structure des Plantes. Paris: Belin.

Suguna, K., Thenmozhi, M., \& Sekar, C. (2012). Growth, Spectral and Mechanical Properties of Struvite Crystal Grown in Presence of Sodium Fluoride. Bulletin of Material Sciences, 35, 701-706. https://doi.org/10.1007/s12034-012-0322-6

Talboys, P. J., Heppel, J., Roose, T., Healey, J. R., Jones, D. L., \& Withers, P. J. A. (2016). Struvite: A Slow-Release Fertilizer for Sustainable Phosphorus Management? Plant and Soil, 401, 109-123. https://doi.org/10.1007/s11104-015-2747-3

Trouillet, M. C. (2016). Les Reliques de Ste Marie-Madeleine. Aix-en-Provence: R.A. Image SARL.

Venturini, A. (2006). Le Sel de Camargue au Moyen Âge. In J. C. Hocquet, \& J. L. Sarrazin, Le Sel de la Baie: Histoire, Archéologie, Ethnologie des Sels Atlantiques (pp. 365-392). Presses Universitaires de Rennes. https://doi.org/10.4000/books.pur.7636

Yerby, F. (1969). Odour of Sanctity (New Impression Edition). William Heinemann LTD. 


\section{Supplementary}
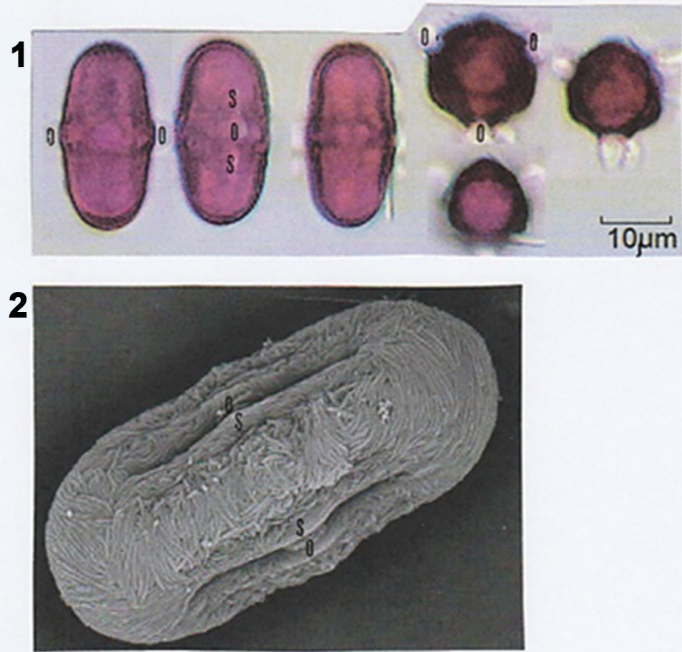

$\vdash 5$

$3^{\wedge}$

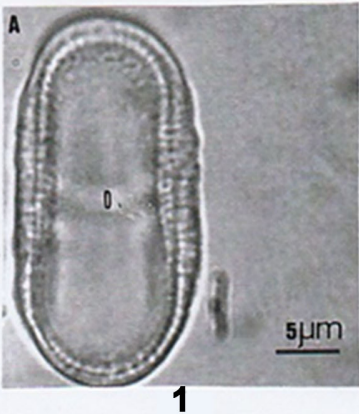

1

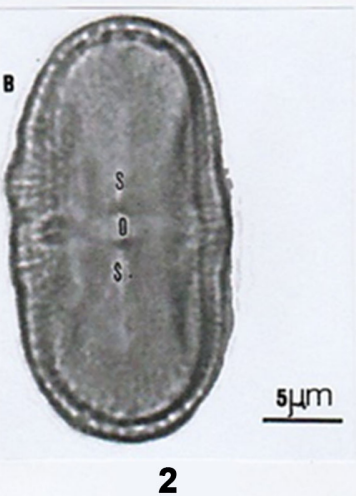

2

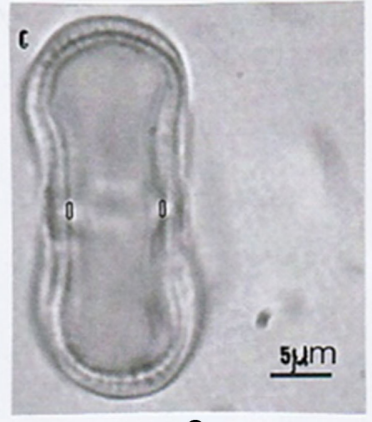

3

Supplementary Figure 1. Typical pollens of reference. First row: optical microscopy photographs (equatorial and polar views) of pollen grains of Foeniculum vulgare (from Aus Pollen-Wiki). S: sulcus; O: pore. Second row: SEM photograph (equatorial view) of a pollen grain of Foeniculum vulgare

(from http://remf.Dartmouth.edu/pollen2/pollenimages). Third row: optical microscopy photographs (equatorial views) of pollen grains of Foeniculum vulgare (1A: fennel), of Anethum graveolens (1B:dill) and of Coriandrum sativum (1C: coriander); from D'Avila et al., 2016. 

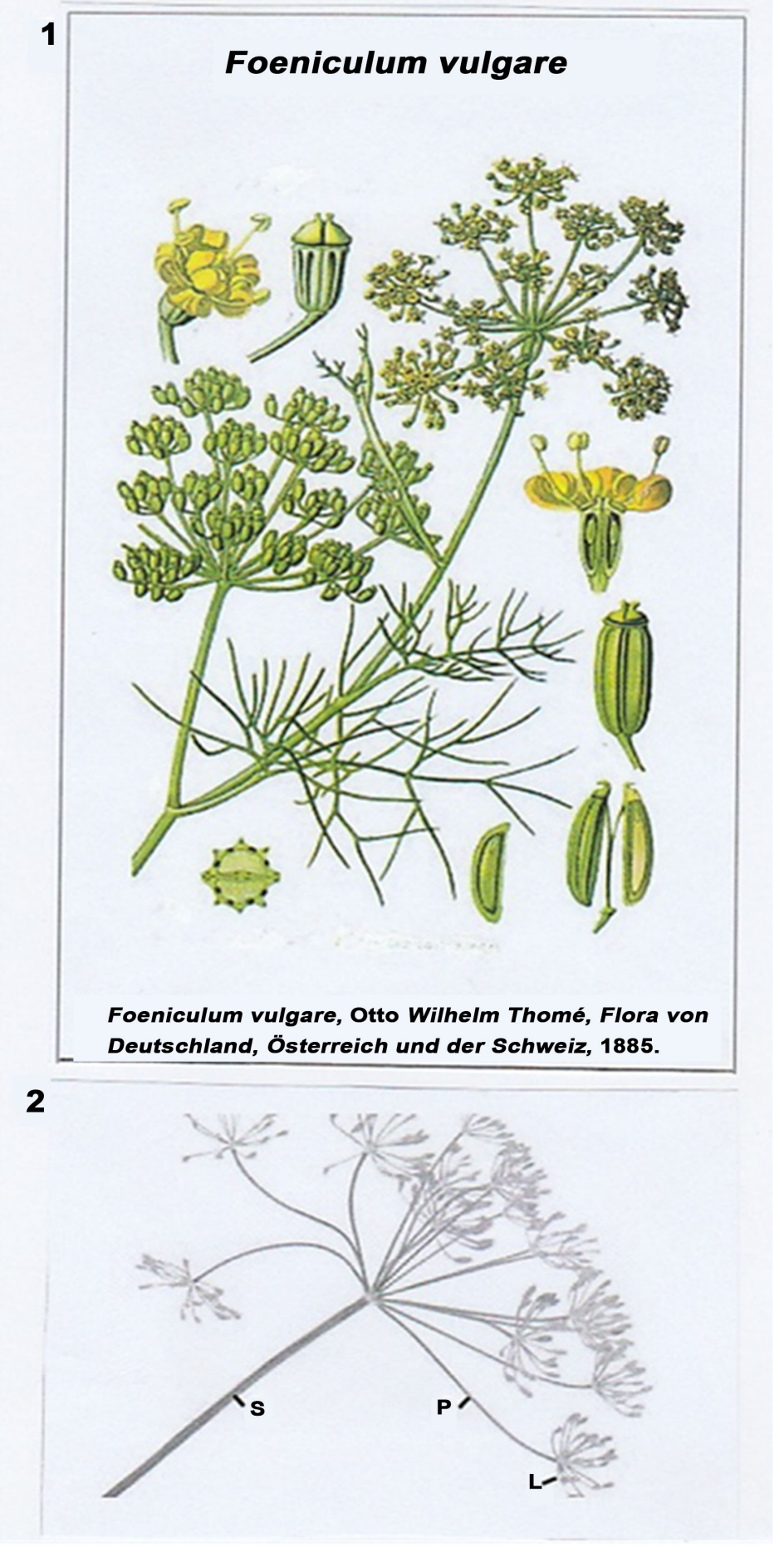

Supplementary Figure 2. Fennel (Foeniculum vulgare) images. 1: the different organs of the plant. 2: details of an umbel (S: stem; P: pedicel; L: leaf). 


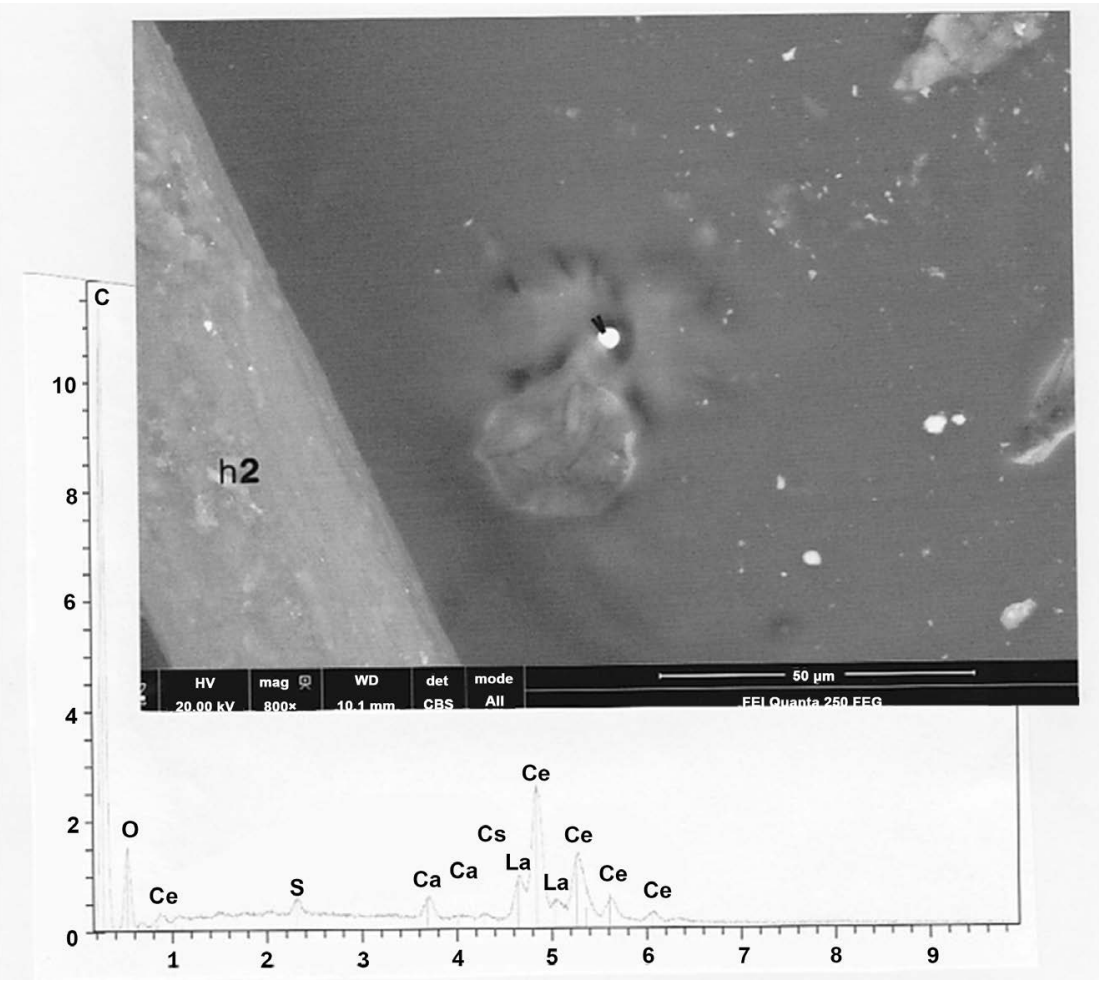

Supplementary Figure 3. An example of a micro-marble of rare earths, located at the vicinity of hair number 2 (h2). Above: SEM photograph (in CBS, 800×) of this micro-marble (indicated by an arrow point. Below. spectrum of the micro-marble. C: carbon; O: oxygen; Ce (five peaks): cerium; Ca (two peaks): calcium; Cs: cesium; La (two visible peaks): lanthane.

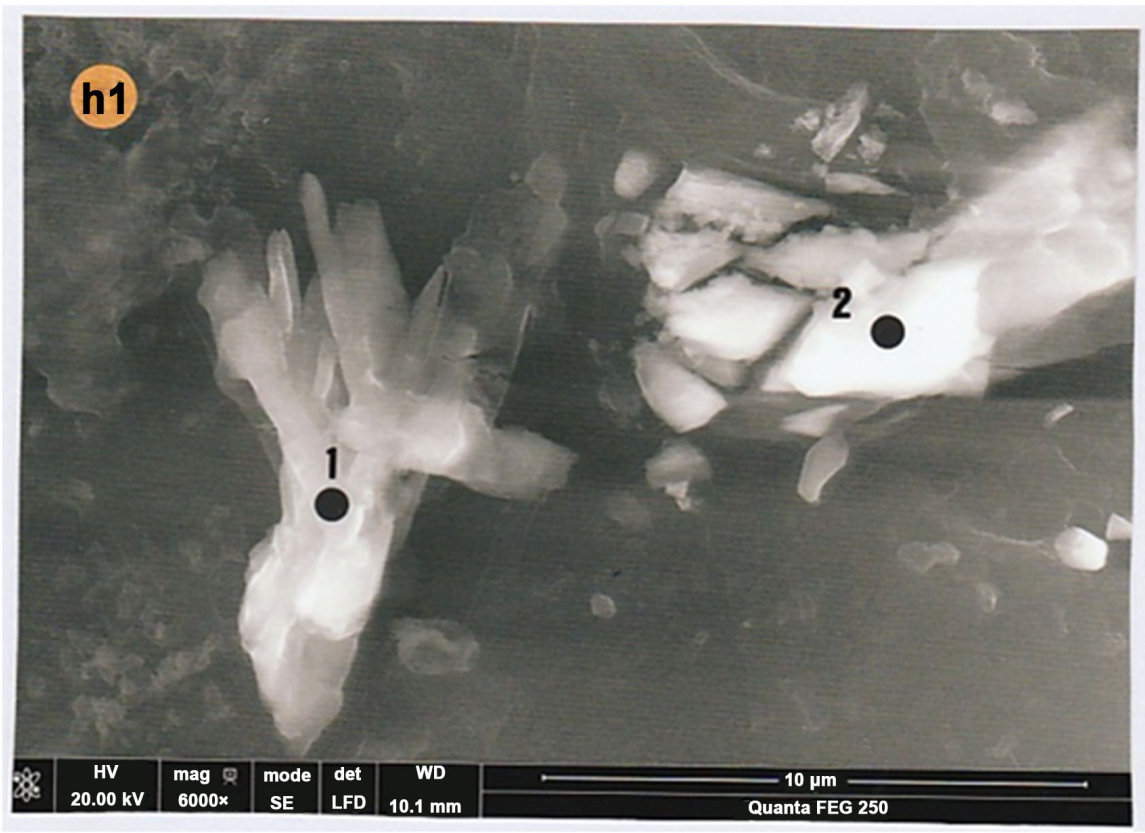

Supplementary Figure 4. SEM photograph (in LFD, 6000x) of micro-needles (1) and micro-plaques (2) of sulfate double of calcium and potassium, deposited on some part of hair number 1 (h1). Black spots indicate the locations where EDX analyses are realized. 


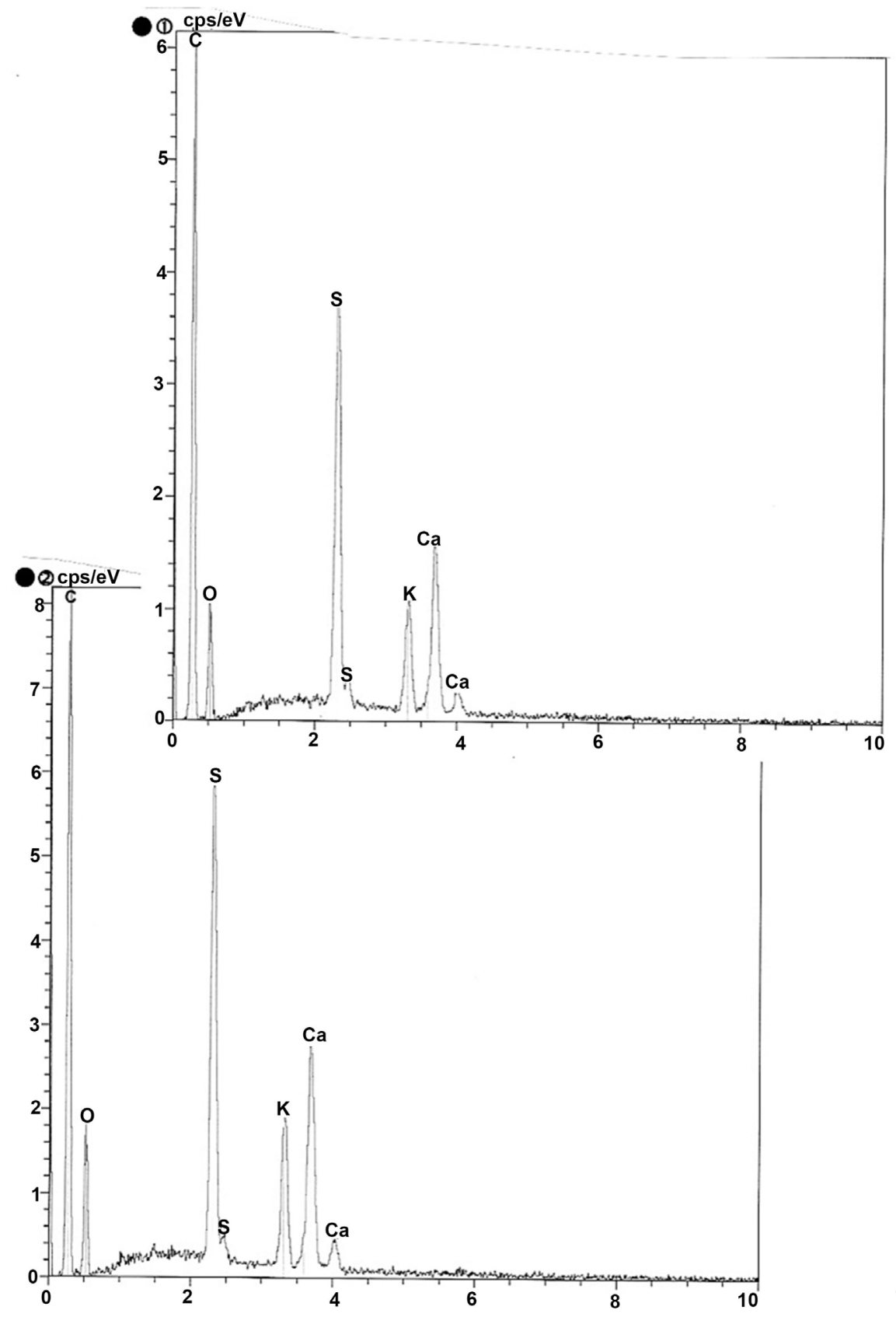

Supplementary Figure 5. Spectras of micro-needles (above) and of micro-plaques (below). C: carbon; O: oxygen; S: (two peaks): sulphur; K: potassium; Ca (two peaks): calcium. 


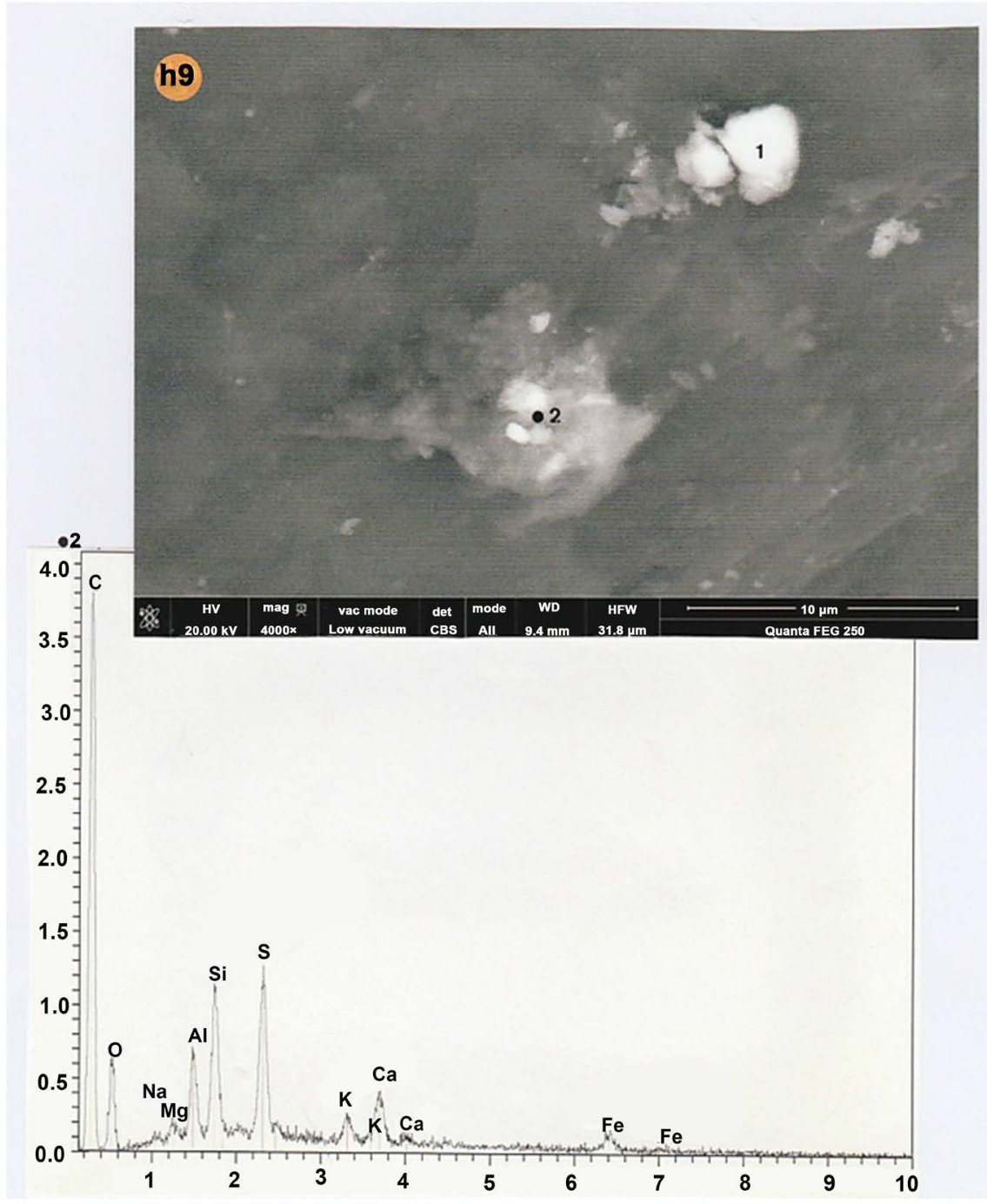

Supplementary Figure 6. An example of deposits of montmorillonite/illite particles on some part of hair number 9 (h9). Above: SEM photograph (in CBS, 1000×) of particles of calcium carbonate (1) and of montmorillonite/illite (2). The black spot indicates the location where EDX analysis is realized. Below: spectrum of 2. C: carbon; O: oxygen; Na: sodium; Mg: magnesium; Al: aluminium; Si: silicium; S: sulphur; K: (two visible peaks): potassium; Ca (two peaks): calcium; Fe (two visible peaks): iron. 


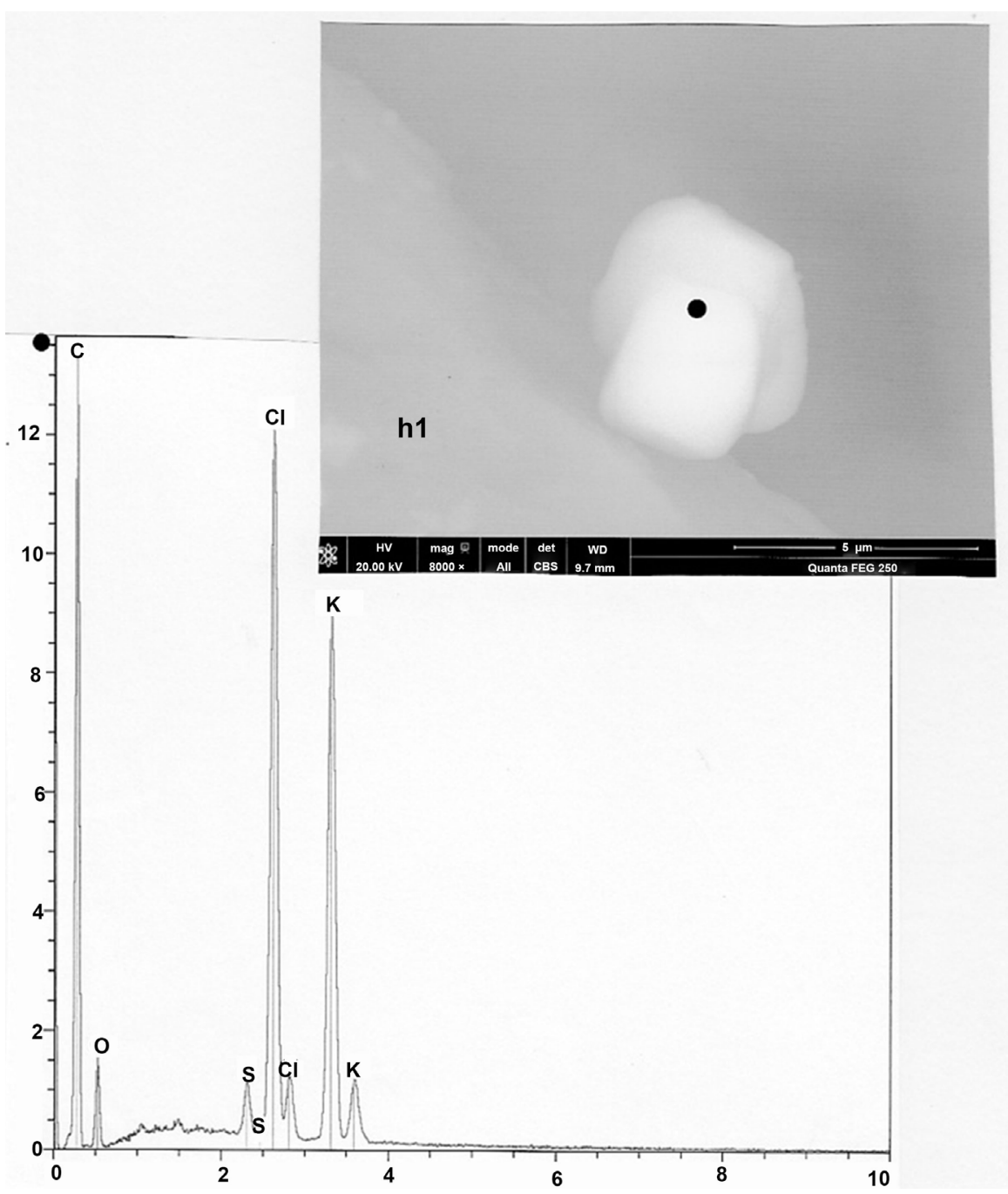

Supplementary Figure 7. An example of crystals of potassium chloride on some part of hair number 1 (h1). Above : SEM photograph (in CBS, 8000×) of these crystals (the black spot indicates the location where EDX analysis is realized. Below. spectrum at the black spot. 


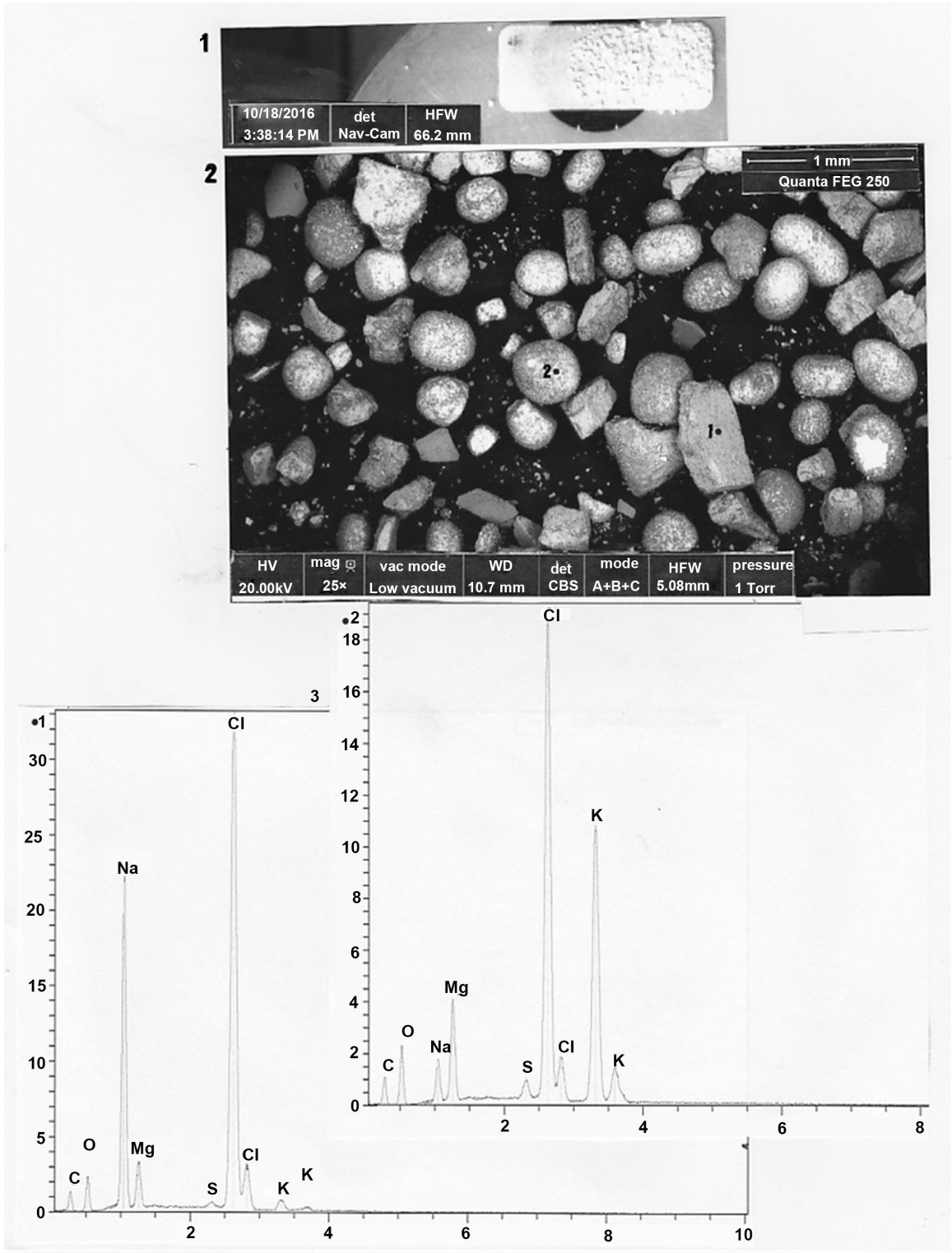

Supplementary Figure 8. Study of commercial lighted salt. 1: Optical microscopic view $(3 \times)$ of a powder of the product. 2. SEM photograph (in CBS, $25 \times$ ) showing the two different forms of particles from this sample. Some of them (like 2), that are the most numerous, are rounded in form; other (like 1) are with angular outlines. 3: spectras of 1 (below) and 2 (above). 


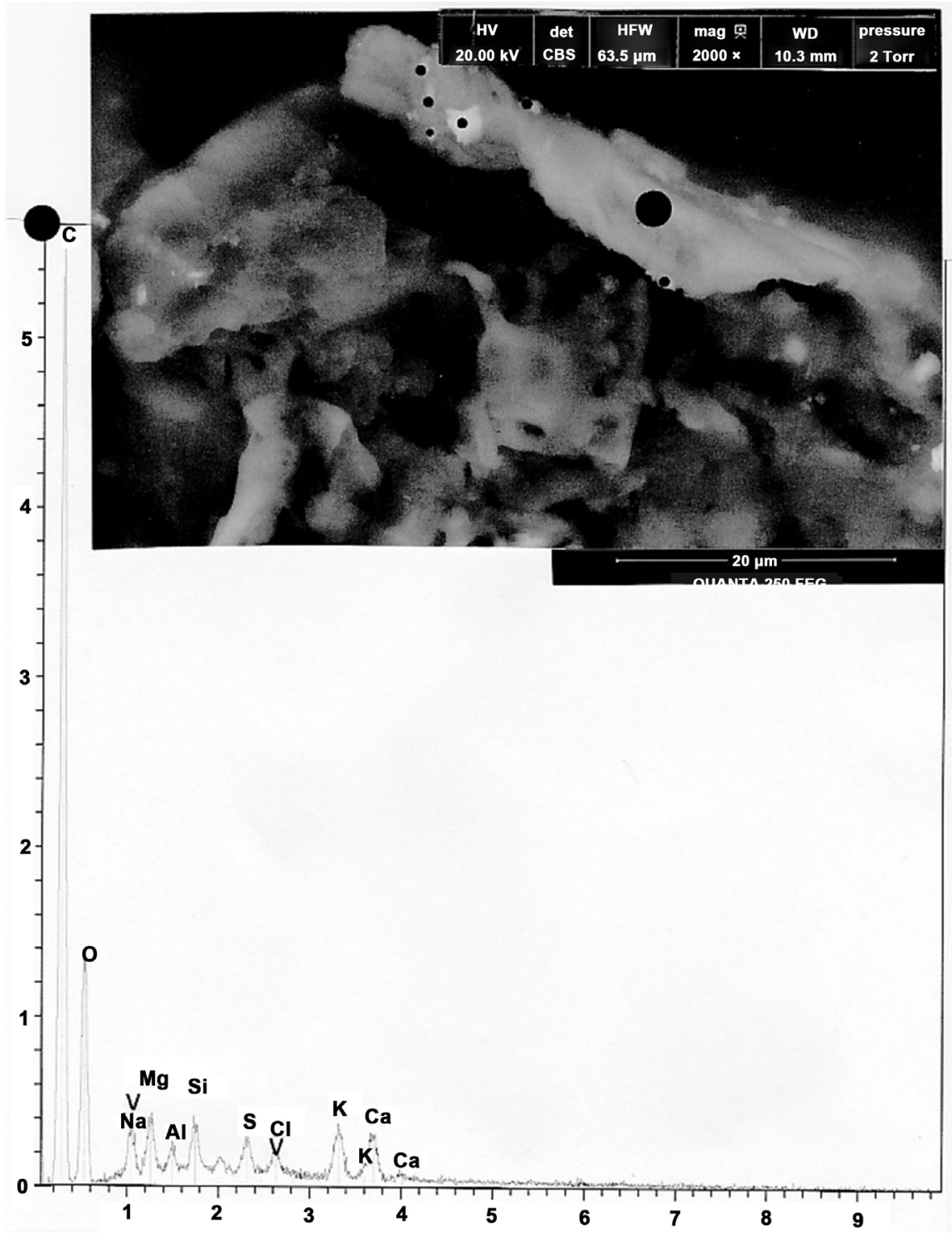

Supplementary Figure 9. Study of one of the superior border of the stem, to detect salt particles composed of chlorine. Above: SEM photograph (in CBS, 2000×) showing this border. The great black spot indicates the location where EDX analyses are realized. Below: spectrum at the great black spot (arrows indicate peaks of chlorine and of sodium elements). 


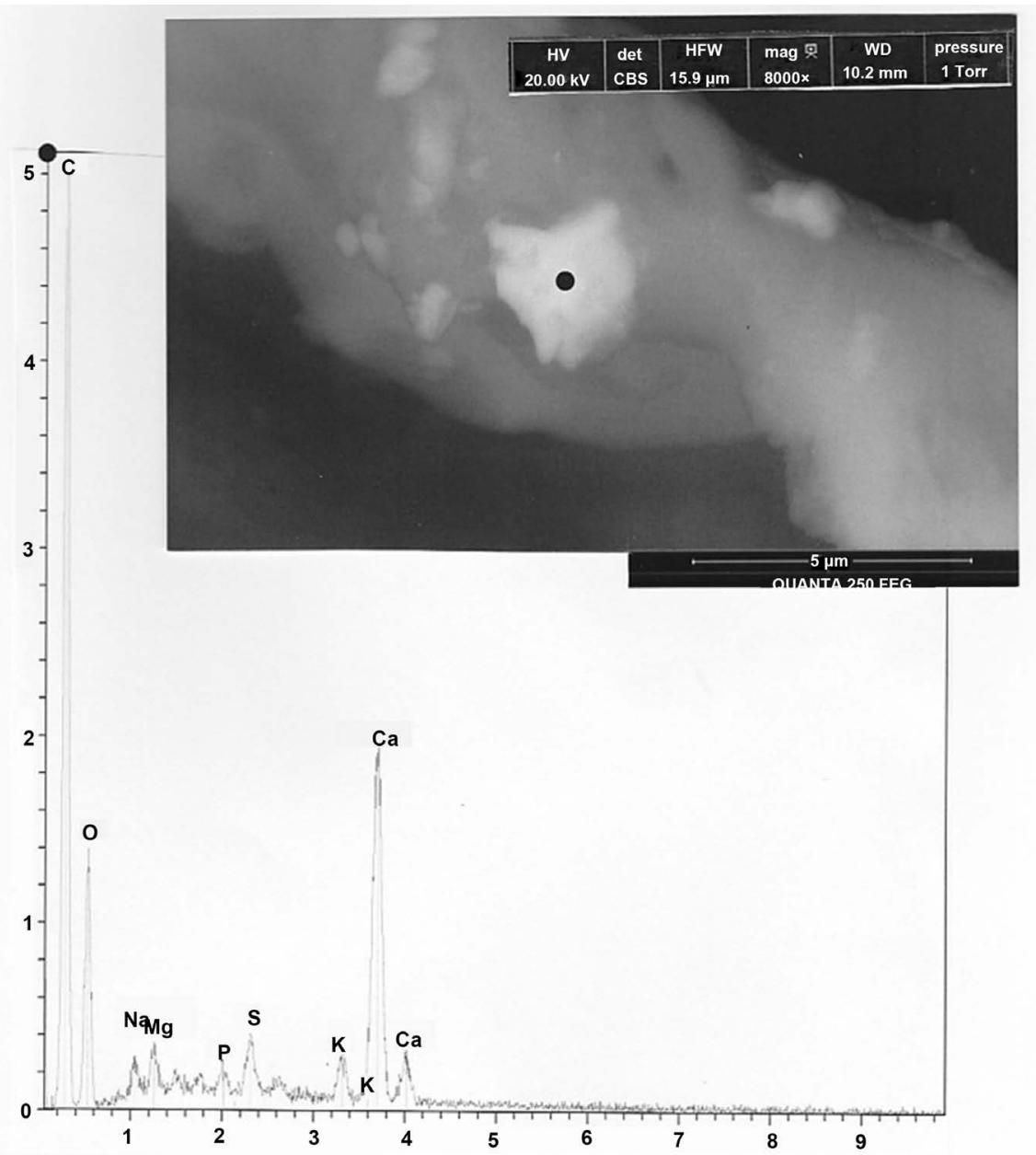

Supplementary Figure 10. Above: SEM photograph (in CBS, 8000×) showing an enlarged view of the previous one. Below. spectrum of the greatest particle. 


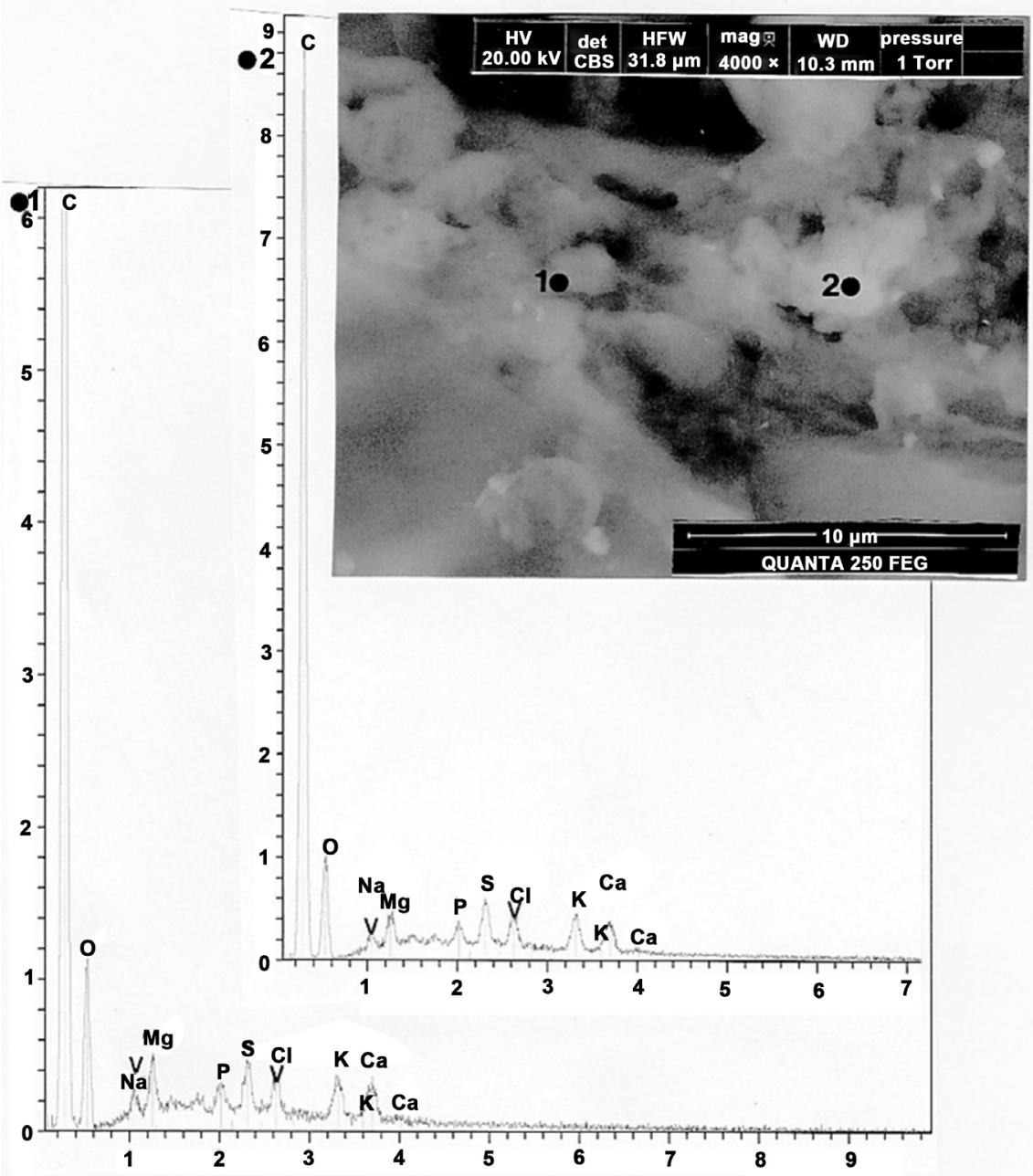

Supplementary Figure 11. Study of the stem part rich in sodium, to detect salt particles composed of sodium. Above: SEM photograph (in CBS, 4000×) showing two sub-parts (1 and 2) of this part (dots indicate locations of these sub-parts where EDX analyses are realized). Below: spectras at dots 1 and 2 (arrows indicate peaks of chlorine and of sodium elements). 


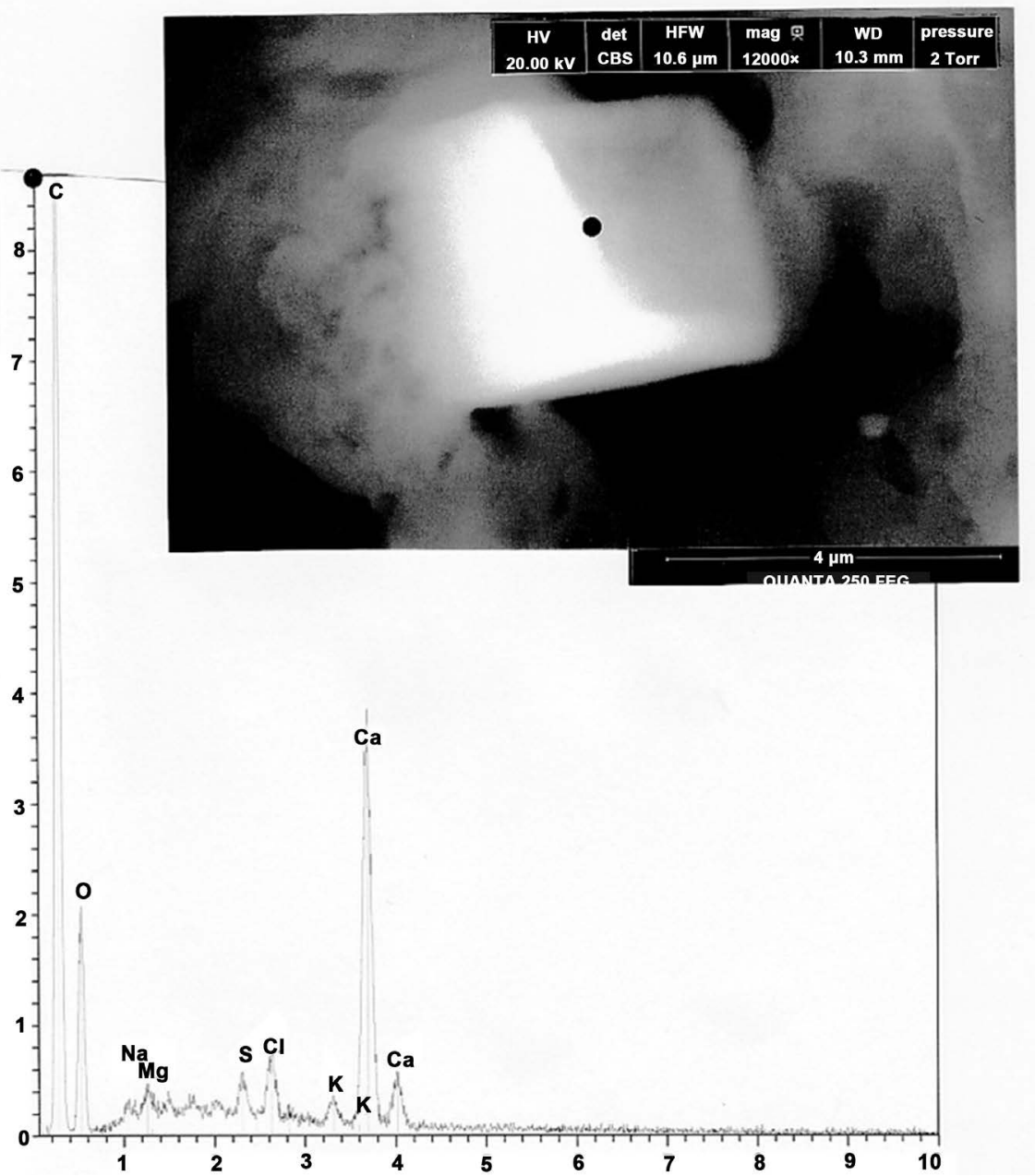

Supplementary Figure 12. An example of an analysis of a cubic particle (crystal) found in the stem area of high concentration of sodium. Above: SEM photograph (in CBS, $12000 \times)$ of this crystal. Below: its corresponding spectrum. 